\title{
ISE System Development Methodology Manual (U)
}

\author{
Approved by
}

W. C. Foster, Manager, Level 3

Information Systems Engineering

Publication Date: February 17, 1992

Authorized Derivative Classifier
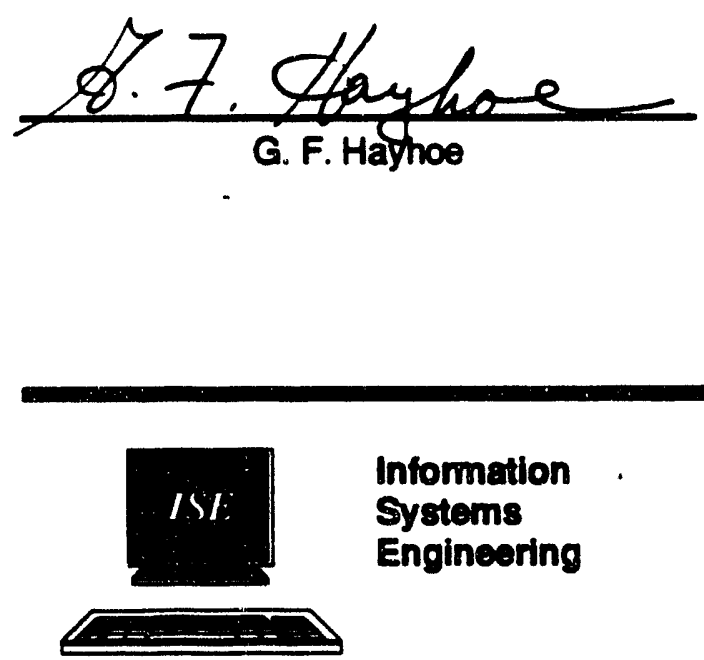

Westinghouse Savar.nah River Company

Savannah River Stte

Alken, SC 29808

Prepared for the U. S. Department of Energy Under Contract No. DE-AC09-8, SR18035 


\section{Notice to Recipient}

You are officially charged with this document until it is reassigned.

Updates to this manual will be issued from time to time via a document receipt. You are responsible for maintaining the most current version of this manual.

If you no longer need this document, if you wish to assign it to another person, or if you change your address, notify Publications Control, Building 703-43A.

Savannah River Site

Alken, SC 29808 


\section{Table of Contents}

Table of Contents $\ldots \ldots \ldots \ldots \ldots \ldots \ldots \ldots \ldots \ldots \ldots$

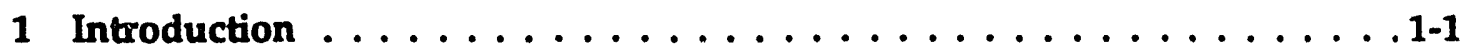

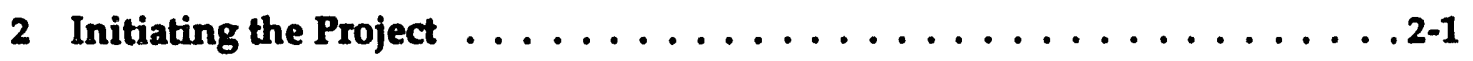

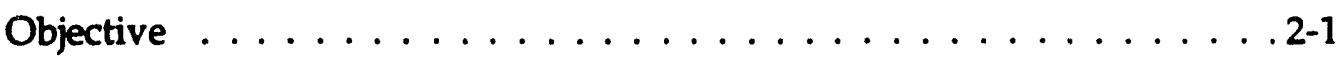

Description . . . . . . . . . . . . . . . 2-1

Tasks and Activities $\ldots \ldots \ldots \ldots \ldots \ldots \ldots \ldots \ldots .2-2$

Deliverables . . . . . . . . . . . . . . . . . . . 2-9

Attachment 1: ISE Work Request Form . . . . . . . . . . . . . 2-11

Attachment 2: Project Participation Matrix . . . . . . . . . 2-12

Attachment 3: Project Quality Plan Checklist . . . . . . . . . . 2-13

Attachment 4: Software Acquisition and Development Checklist $\ldots . .2-23$

Attachment 5: ISE Technical Review Form . . . . . . . . . . . . 2-24

3 Defining Project Requirements . . . . . . . . . . . 3-1

Objective $\ldots \ldots \ldots \ldots \ldots \ldots \ldots \ldots \ldots \ldots \ldots \ldots \ldots \ldots \ldots \ldots$

Description . . . . . . . . . . . . . . . . 3-1

Tasks and Activities . . . . . . . . . . . . . . . .

Deliverables . . . . . . . . . . . . . . . . . . . . . 3-12

4 Studying Project Feasibility . . . . . . . . . . . . . 4-1

Objective $\ldots \ldots \ldots \ldots \ldots \ldots \ldots \ldots \ldots \ldots \ldots \ldots \ldots \ldots \ldots$ 
Description ....................... . . . .

Tasks and Activities . . . . . . . . . . . . . . . 4-2

Deliverables . . . . . . . . . . . . . . . . . . . 4-10

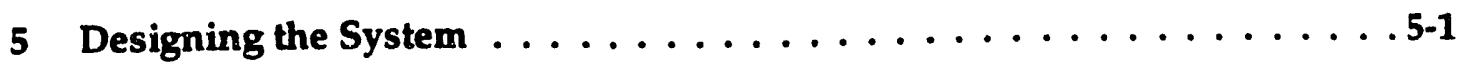

Objective .........................

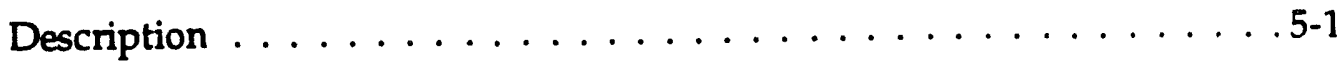

Tasks and Activities . . . . . . . . . . . . . . . . 5-2

Deliverables. . . . . . . . . . . . . . . . . . . 5-12

6 Constructing the System and Gaining Customer Acceptance . . . . . . 6-1

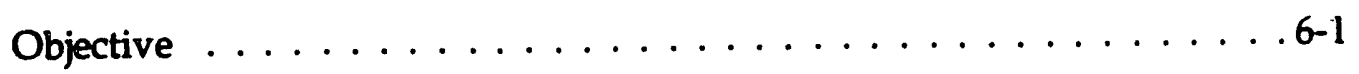

Description ........................... 6-1

Tasks and Activities ...................... . . . . .

Deliverables. . . . . . . . . . . . . . . . . . . 6-11

7 Implementing the System . . . . . . . . . . . . . . . 7-1

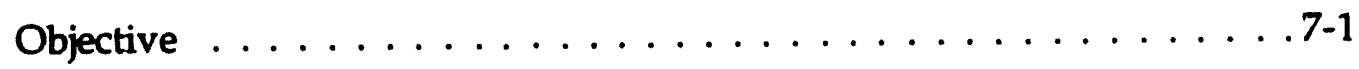

Description ..........................

Tasks and Activities . . . . . . . . . . . . . . . 7-2

Deliverables. . . . . . . . . . . . . . . . . . . .

8 Evaluating and Reviewing the System $\ldots \ldots \ldots \ldots \ldots \ldots$

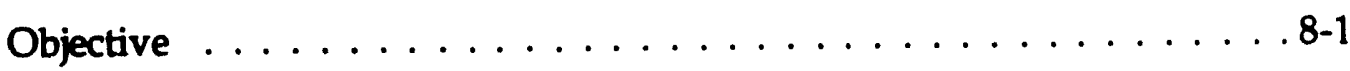

Description ............................

Tasks and Activities . . . . . . . . . . . . . . 8-2

Deliverables. . . . . . . . . . . . . . . . . . 8-4

Attachment 1: Post-implementation Review Questions . . . . . . . . . . 8-5 
9 Maintaining the System ..................... . . . . .

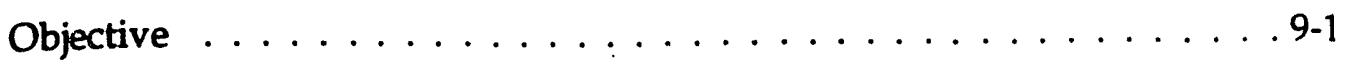

Description ..........................

Tasks and Activities . . . . . . . . . . . . . . . 9-2

Emergency Maintenance Process . . . . . . . . . . . . . 9-2

Scheduled Maintenance Process . . . . . . . . . . . . . . . . 9-6

Attachment 1: Scheduled Maintenance-Corrective

Project Quality Plan Checklist . . . . . . . . . . . . . . . . . . 9-7

Attachment 2: Scheduled Maintenance-Enhancement

Project Quality Plan Checklist . . . . . . . . . . . . . . . . 9-11

Attachment 3: Scheduled Maintenance-Ad hoc

Project Quality Plan Checklist . . . . . . . . . . . . . . . . . . 9-15

Attachment 4: Scheduled Maintenance-Adaptive

Project Quality Plan Checklist . . . . . . . . . . . . . . . . . 9-18

10 Reviewing and Evaluating the SDM . . . . . . . . . . . . 10-1

Nomination Process . . . . . . . . . . . . . . . . 10-1

Review Process . . . . . . . . . . . . . . . . . . 10-1

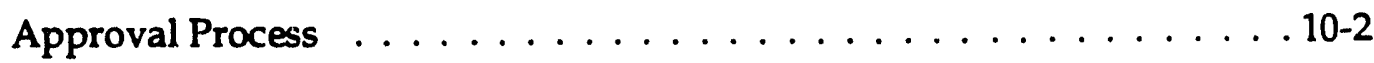

Attachment 1: ISE Procedure/Manual Revision Request Form . . . . . . 10-3

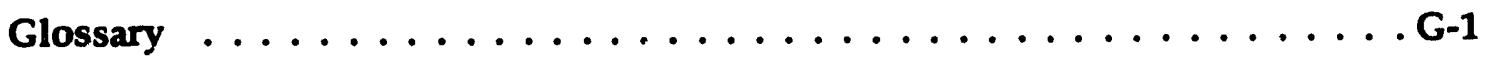

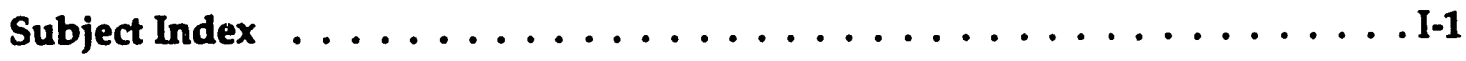




\section{Note on Revisions}

Substantial changes to Revision $\mathrm{OA}$ of this document are indicated by revision bars in the left margins in sections $1,2,3,5$, $6,7,8$, and 10 , and in the Glossary.

Revision bars have not been used in sections 4 and 9 .

Section 4 has been completely rewritten for Revision 0 .

Section 9 and the Subject Index are new in Revision 0. 
Introduction 


\section{Introduction}

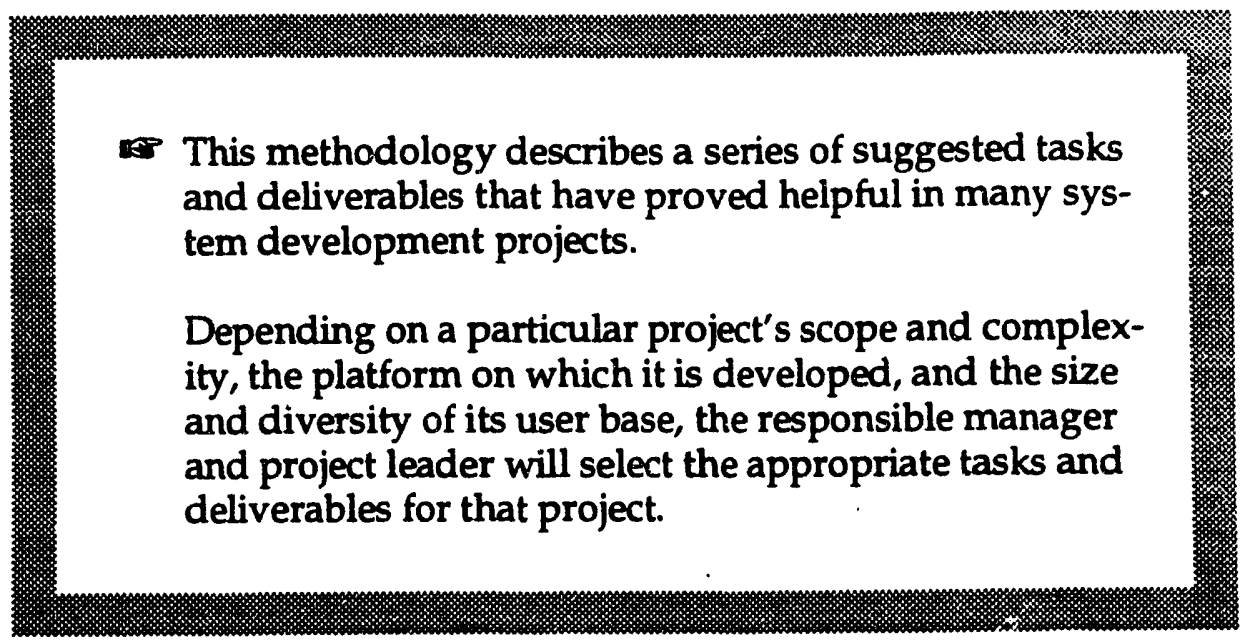

The ISE System Deoelopment Methodology Manual (SDM) is a framework of life cycle management guidelines that provide ISE personnel with direction, organization, consistency, and improved communication when developing anc' maintaining systems. These guidelines were designed to allow ISE to build and deliver Total Quality products, and to meet the goals and requirements of the U.S. Department of Energy (DOE), Westinghouse Savannah River Company, and Westinghouse Electric Corporation.

Although the development process is described in linear terms in this methodology, it may in fact be a recursive process, in which some phases overlap and are sometimes repeated.

The SDM is intended to improve the quality of ISE's products by documenting the steps used to create or maintain computer systems. Not every step of this methodology applies to every project, but the SDM profiles the tasks and activities which should be considered for major new development projects, routine maintenance projects, and large revisions or enhancements to existing systems. Subsets and supersets of this methodology are determined by the project leader and group manager and recorded on the Project Quality Plan (PQP).

This SDM takes a life-cycle approach. It reduces the job of developing and maintaining systems to a series of logical steps, with each step representing a phase of the life cycle. This life cycle is generally process-driven; that is, the processes rather than the data are the primary focus of the analysis effort. However, the data-driven approach is receiving increasing emphasis within the section with the advent of Information Engineering. 
Sections 2 through 8 each detail one of the life-cycle phases. An outline of the corresponding phase is printed on the section divider for easy reference. Each outline lists the objective, tasks and activities, and deliverables for that phase. More experienced personnel may need to refer only to the outlines, while others may need to study the sections more closely. Each section explains the items in the corresponding outline in detail, in addition to specifying the roles and responsibilities, and the review and check points for advancing to the next phase. Each phase builds on the products of the previous phase and allows for containment of risks by incremental commitment and planning for the next phase.

Section 9 of the SDM describes the procedures for maintaining systems. System maintenance is categorized as either emergency or scheduled maintenance, and there are four types of scheduled maintenance: corrective, adaptive, ad hoc, and enhancement. Project Quality Plans for each type of scheduled maintenance are provided in section 9.

The process of system development and maintenance involves personnel from ISE, customer organizations, End User Services (EUS), and (for systems that run on the Central Computer Facility) Computer and Telecommunications Management (CTM). This methodology was written to be useful to these different groups in several ways.

- New ISE personnel can gain an understanding of the section's operating procedures and standards.

- Experienced ISE personnel can refer to the SDM to resolve questions of methodology, supplement their knowledge of less familiar life-cycle phases, and train inexperienced personnel.

- Members of customer organizations can gain a better understanding of ISE procedures and customer responsibilities in the system development and maintenance process.

- EUS and CTM personnel can gain an understanding of the development and maintenance process within ISE and develop methods to assist ISE in maximizing system quality and customer satisfaction.

The success of a computer application project depends heavily on the commitment and involvement of people from each of these groups throughout the entire life cycle. ISE's participation in a computer application project is contingent on this commitment of required resources by all involved parties throughout the project. 


\title{
Initiating the Project
}

\section{Objective}

To make an initial assessment of the project; define its objectives, benefits, and scope; and determine whether further work is appropriate.

\section{Tasks and Activities}

\author{
submit ISE Work Request \\ a conduct initial analysis \\ 口 conduct steering committee review \\ 口 identify resources \\ D prepare Project Quality Plan \\ set up ISE Service Order \\ set up project folder \\ a review high impact software \\ 口 determine sitewide authorization requirements \\ 口 prepare project scope document \\ a prepare preliminary project schedule \\ a conduct internal review \\ a conduct customer review \\ u update software inventory
}

\section{Deliverables}

\author{
口 ISE Work Request form \\ a initial analysis memo \\ - Project Participation Matrix \\ - Project Quality Plan \\ a ISE Service Order \\ - project folder \\ a project folder index \\ D project scope document \\ a preliminary project schedule \\ - ISE Technical Review form (for project scope document) \\ customer sign-off memo(s) (for project scope document)
}




\section{Initiating the Project}

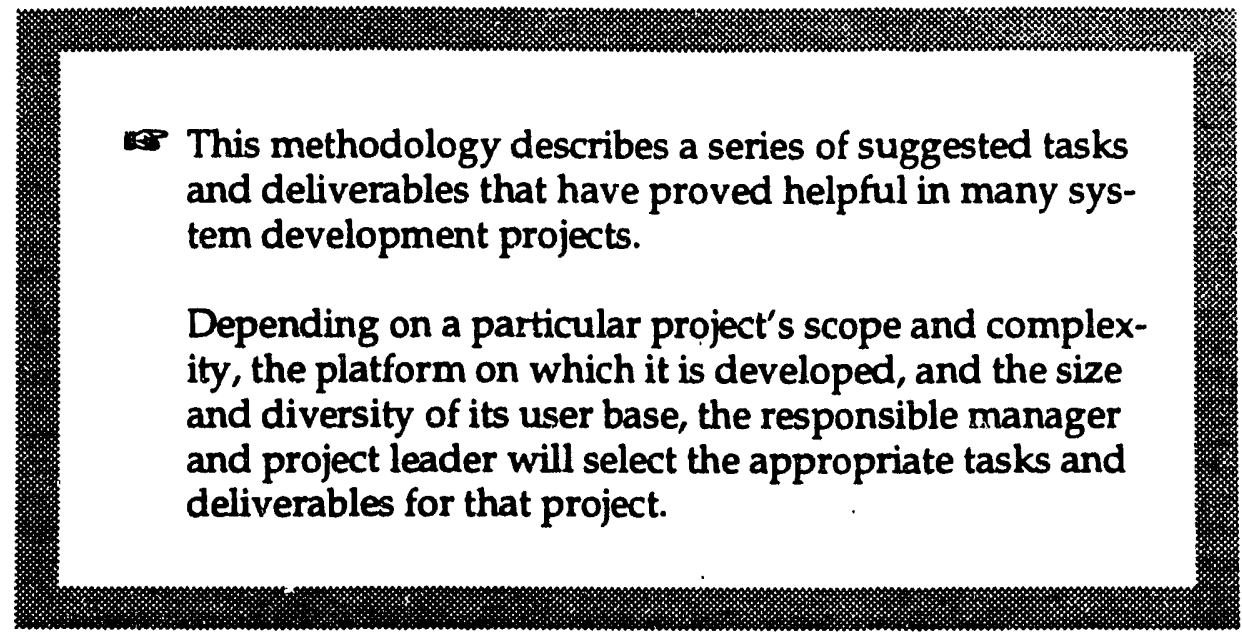

\section{Objective}

To make an initial assessment of the project; define its objectives, benefits, and scope; and determine whether further work is appropriate.

\section{Description}

Project Initiation is the preliminary assessment of the problem or opportunity and an evaluation of the benefits to be gained by pursuing the project. This phase is used to eliminate inappropriate requests and unnecessary work. The phase begins with the management activities necessary to set the development or maintenance process in motion and ends with a clear definition of what will be addressed, what will not be addressed, and what benefits will :esult from continuing the project. It should also be used to determine whether the commitment and resources necessary to proceed with the project are present and to educate customers about the system development process and their responsibilities for the project. 


\section{Tasks and Activities}

\section{Submit ISE Work Request}

Before any work can begin, either an ISE employee or a customer organization must complete an ISE Work Request form (see Attachment 1). The Work Request should include a description of the work requested and a summary of reasons for the request.

All requests for ISE work must be documented using the ISE Work Request form, including system development requests, problem reports, enhancement requests, ad hoc software requests, etc. Work Requests should also be used to document unscheduled emergency work.

A unique work request number should be assigned to each Work Request. The ISE clerks will assign the next available work request number.

One copy of each Work Request must be maintained in the group's Work Request folder to allow tracking of work requests for that group. Another copy of the Work Request must be kept in the project folder for the corresponding project.

Work Request folders should be maintained only in approved locations. Each ISE group manager should designate the location of his or her group's Work Request folder.

The status of the Work Request should be tracked as the request moves through its lifecycle. Valid status conditions are: Received, Estimated, Approved, Cancelled, Hold, Active, and Completed. Work Request folders should be organized so as to facilitate status reporting (for example, separate files for each status).

Work performed should be restricted to work identified on Work Requests. The Work Request is the authorizing document for performing work.

Work history (date completed, actual hours worked, programs changed, etc.) should be captured for each Work Request and filed with the completed Work Request.

The Work Request folder is the basis for accounting for all work requested, producing reports for ISE management (backlog statistics, productivity analyses, problem area analyses, etc.), and reporting Work Request status to the customer.

\section{Conduct initial analysis}

The purpose for conducting an initial analysis is two-fold. First, the analysis, along with the Work Request, provides a method for documenting customer requests and preliminary solutions. This information provides statistical documentation for future development and enhancements and it meets audit trail requirements. Second, the analysis assists the steering committee in validating user requests.

This process involves a brief review of the customer request to determine whether there is sufficient information to continue the project initiation phase. If there is not enough in- 
formation, the request may be returned to the potential customer for more details. Lack of personnel or scheduling conflicts may require that requests be refused or deferred until a date that is suitable for ISE and the customer.

For simple support requests for existing systems, the initial analysis may provide sufficient information to define the project scope. The time and resources required to carry out the analysis will vary among applications. In some cases, group managers or project leaders will be able to complete this step without the need for additional resources. At times, however, the scope of the application cannot be defined without more extensive analysis and assistance from the customer organization. This information is used by managernent and the steering committee to determine whether further work on the request is to be completed.

The initial analysis should include such items as:

- preliminary estimates of time and cost

- impact statements for all related systems and programs

The analyst documents the results in a memo to the steering committee.

\section{Conduct steering committee reoiew}

The primary objective of the steering committee is to ensure an efficient, orderly, and controlled process in which requests are submitted, reviewed, prioritized, and scheduled. If the committee determines that further work is inappropriate or unnecessary, the reason is documented and attached to the ISE Work Request. A copy of the Request is kept in the group's Work Request folder, and a copy is returned to the customer.

\section{Identify resources}

When a project is approved by the steering committee, the assigned project leader and responsible group manager then determine the level of coordination and resources required to accomplish the project using the Project Participation Matrix (see Attachment 2).

The composition of the project team may vary during the project life cycle, depending on the resources and experience levels required in each phase. However, stability and consistency within the project team are essential to keep the project on schedule. Ensuring that all personnel involved in the project are committed to it and are stakeholders in the project's outcome is also essential.

The project leader should always be assigned during the Project Initiation Phase. Other analysts may also be assigned at this time, depending on the size and nature of the project. The project leader is responsible for developing the project scope, directing the efforts of the project team, scheduling project activities and resources, and providing staffing recommendations. Management will assign personnel based on these recommendations of needed skills and numbers. Many tasks described throughout the SDM are defined as responsibilities of the project leader. He or she is free to perform the task or 
delegate it to another on the team, but the project leader is responsible for seeing that it is performed in a quality, timely manner.

Whether the project encompasses one organization or several, one person who will be sensitive to the needs of all organizations involved should be designated as a customer liaison. This person must represent and speak for all customer organizations and resolve conflicts which may arise.

If the system will likely be developed on the Central Computer Facility, a CTM liaison should also be assigned at this time. The CTM liaison works as a member of the team throughout the project. He or she is responsible for seeing that CTM support for the system is available when needed and for coordinating resource needs to allow CTM to plan internal resources. The CTM liaison will have a larger role in the project once the requirements have been defined, but assignment at this time facilitates CTM participation and planning.

The project leader should also anticipate the need for specialists to provide help, expertise, and guidance. These specialists may represent the customer, CTM, End User Services, the Computer Protection Program Manager, ISE Data Administration, ISE Technical Writing Team, or the ISE Quality Coordinator. On the other hand, these specialists may be experts in a particular technique or tool. If special support is needed, the project leader should make arrangements as early as possible to ensure its availability.

\section{Prepare Project Quality Plan}

The Project Quality Plan (PQP) Checklist (see Attachment 3) is the cornerstone of the SDM and is required for all ISE projects. The PQP gives the methodology flexibility to be applied to both development and maintenance and to both large and small projects. It allows the project leader and responsible group manager to select the tasks and deliverables necessary to ensure a Total Quality system.

The items selected will vary according to project size and the potential risk associated with the project. A large key project will require more tasks and deliverables than a smaller project where an error would result in little monetary loss, safety or security risk, or embarrassment for the Savannah River Site.

The project leader should consider grouping a number of small maintenance requests into a larger project. This method allows the team to manage the requests as one project and to issue the changes together as a new release of the system, just as many software companies release upgrades of their products. This approach has the advantage of consolidating much of the overhead associated with reviews, testing, documentation, and production turnover which would otherwise need to be duplicated for each revision.

After the PQP is completed, the project leader and group manager should obtain customer agreement for this outline of the project. Once the PQP is approved, the selected activities and deliverables become requirements for the project. The official copy of the PQP is kept in the project folder. 
The original PQP and all revisions to it must be retained in the project folder, even though the plan may undergo substantial revisions over the life of the project. If revisions are made to the plan, these changes must be approved by the group manager and $c:=$.jmer and filed with the original PQP.

\section{Set up ISE Service Order}

The decision to set up a new Service Order or to bill to an existing Service Order is made by the customer, the project leader, and ISE management. This decision depends on the size, duration, and complexity of the project. Large projects should be subdivided, with each part of the project covered by a separate Service Order. The Feasibility Study Phase often provides a natural division point. At the conclusion of that phase, the team is in a good position to make accurate estimates concerning the remainder of the effort. (See the ISE clerks for details regarding ISE Service Order creation.)

\section{Set up project folder}

A project folder must be established and stored in a central location determined by the group manager and easily accessible to all. This folder is the official repository of information about the project. The project leader and others on the team may maintain their own working folders, but these are not the official project folder. Each project deliverable is added to the project folder as it is completed; minutes of internal and external reviews of each project phase are also placed in the folder. The project leader is responsible for establishing and maintaining the project folder and for creating and updating an index of all folder contents. The ISE Quality Coordinator will conduct regular audits of project folders to ensure that folders are indexed and properly maintained.

Discretion should be used in deciding whether to establish a project folder for a small maintenance project. If a new project folder is not established, the project leader should use an existing project folder for the system. However, a project folder is always established for a new system, a major enhancement, or a large maintenance project.

When the project is completed, the project folder is processed through the ISE Records Coordinator in accordance with the IRM Records Management procedure (IRM Procedure 1.04). A copy of the project folder is kept in a central location for future maintenance requests.

\section{Review high impact software guidelines}

Review with the customer liaison the definitions of high impact software in QAP 2-1 of the SRS Quality Assurance Manual. The customer organization is responsible for determining whether the proposed system will qualify as high impact software. Whether the proposed system is identified as high impact or not, the customer liaison is responsible for securing this determination in the form of a memo signed by the customer manager and addressed to the ISE Level 3 manager. A copy of this memo is placed in the project folder. A system that qualifies as high impact software must follow the guidelines in the ISE System Development Methodology Manual and in QAP 20-1 of the SRS Quality Assurance Manual. 


\section{Determine sitewide authorization requirements}

Software development, enhancements, or acquisitions that exceed a predetermined cost threshhold, have DOE-wide impact, or otherwise meet the requirements specified on the Software Acquisition and Development Checklist (see Attachment 4) require DOE approval. (The Software Acquisition and Development Checklist form can be obtained from the ISE clerical staff.) The scope document for any software that requires DOE approval must include information concerning cost/resource estimates, and documentation of a search for existing software both onsite and in the DOE community. The project cannot progress beyond the Initiation Phase until DOE approval of the scope document is received.

\section{Prepare project scope document}

The project scope document defines the boundaries for the proposed project. It identifies the business area in which the system will operate and gives an overview of this area. The document should also examine how this business area fits into the overall business. Looking at the big picture helps to put things into perspective. System-level data flows are very useful in this task because they show movement of data between organizations or functional areas.

The customer liaison and others within the customer organization are the chief sources of information; however, ISE personnel assigned to the project may need to familiarize themselves with the background of the project by reviewing information relevant to the project, such as system manuals and user's guides for existing systems, and internal organizational documents.

The project team should be careful to determine whether the right problem is being addressed. Sometimes a short-sighted approach proposed to ISE addresses the symptoms rather than the root causes. ISE is responsible for providing the analytical skills necessary to identify the real issues.

The project scope document develops a preliminary consensus with the customer about the objectives and functionality of the desired system. The following is a suggested outline for the scope document.

\section{- Transmittal documents}

The transmittal documents, under the signature of the ISE manager, request formal approval of the project scope document and are addressed to the customer organization manager.

- Sign-off pages

The sign-off sheets document the formal approval requested in the transmittal documents. 
- Introduction

The introduction is usually one page and briefly describes the purpose of the project scope document.

- System name

The system (or project) name reflects what can realistically be expected from the system. The system name is important to the rest of the scoping and analysis effort because it is the initial statement of the purpose and functionality of the proposed system.

\section{- Statement of function}

The function statement is a concise description of what the proposed system will do.

\section{- Objectives}

Objectives reflect the ultimate goals of a particular business area. The proposed system will assist the business in meeting the objectives listed in this section.

\section{- Benefits}

Benefits are advantages obtained by pursuing the objectives. The benefits justify the time and effort spent on the system.

\section{- Organization}

The organization(s) involved in the project and their relationships are described. All levels from management to clerical are included.

\section{- Input and outputs}

Inputs and outputs are the major pieces of information that flow into and out of the system. Inputs are external information required for the system to perform its function-the information accepted into the system. Outputs are the information generated by the system for use outside of the system-the information produced by the system.

These are described in broad, general terms. Actual data items will be identified later.

- Issues

Issues are factors that may restrict or impede development of the system. Putting them in writing facilitates their removal or resolution by management early in the project. 


\section{Prepare preliminary project schedule}

A preliminary schedule covering the Initiation through the Feasibility Study phases of the project is prepared. This schedule is subject to revision as the complete customer requirements are defined. Fairly accurate estimates of these activities should be possible at this time, however. Following the Feasibility Study Phase, a revised schedule is developed covering the remainder of the project. To develop the preliminary project schedule:

- list tasks and activities, noting those which are dependent on another

- estimate effort required to complete each activity

- determine skills required for each activity

- identify personnel available to perform each activity

- develop a project calendar schedule which combines these items

The preliminary project schedule includes each task and activity identified on the PQP for the initial phases of the project in the order in which they are scheduled to be performed. An effort estimate indicates the effort required to complete each. $A$ skills estimate should consider the complexity of each task and the skill level required to complete it. The personnel availability estimate should indicate available personnel, showing total hours available. This estimate should take into consideration time constraints such as holidays, vacations, other work assignments, and overhead activities such as safety and task team responsibilities. These estimates are merged to create the project schedule. This schedule reflects estimated completion dates for each task and activity.

\section{Conduct internal review}

An internal review of the project scope document is required. The project leader and group manager should consider requesting participation by the following functional areas as appropriate for the project:

- customer liaison and other representative customers

- senior analyst(s) on the project

- CTM Database Administration group (for systems that will run on the Central Computer Facility)

\section{- ISE Data Administration}

The group manager or another project leader in the same group will chair the review. Depending on the size and complexity of the project, other personnel may also be asked to serve on the review team. This review tearn will review the project scope document with the project team to ensure clarity and completeness. The review team will also point out potential problems or oversights, and offer various suggestions to improve the project scope. The team may make the following types of comments: 
- mandatory changes-The review team will ask that the problems be corrected and the project team return for a follow-up review.

- recommendations-The review team will make recommendations for improving the system, but the final decision is left up to the project leader.

- suggestions-The review team will offer suggestions for the project team members to consider in future assigruments.

The review team must approve the project scope document and record the results of the review on an ISE Technical Review form (see Attachment 5).

\section{Conduct customer review}

A review of the project scope document with the customer is also necessary since the project team and the customer must agree on what the proposed system will accomplish. Formal approval across organizational lines must be obtained before the Requirements Definition Phase begins. Each recipient signs an individual sign-off sheet and returns it to the indicated address. If revisions to the scope document are necessary, the document must be resubmitted to the requester and other customers for review and approval.

Refer to the ISE Guide to Business and Technical Communication for samples of a transmittal document and a sign-off page for customer approval.

\section{Update software inventory}

The IRM Procedures Manual (B-10) requires each IRM section to maintain a software inventory. Contact the ISE clerical staff to add the development project to the ISE Software Inventory with the status Development.

\section{Deliverables}

- ISE Work Request form

- initial analysis memo

- Project Participation Matrix

- Project Quality Plan

- ISE Service Order

- project folder

- project folder index

- project scope document 
- preliminary project schedule

- ISE Technical Review form (for project scope document)

- cusiomer sign-off memo(s) (for project scope document) 


\section{Attachment 1: ISE Work Request Form}

Anv. 3. 32002

\section{INFORMATION SYSTEMS ENGINEERING WORK REQUEST}

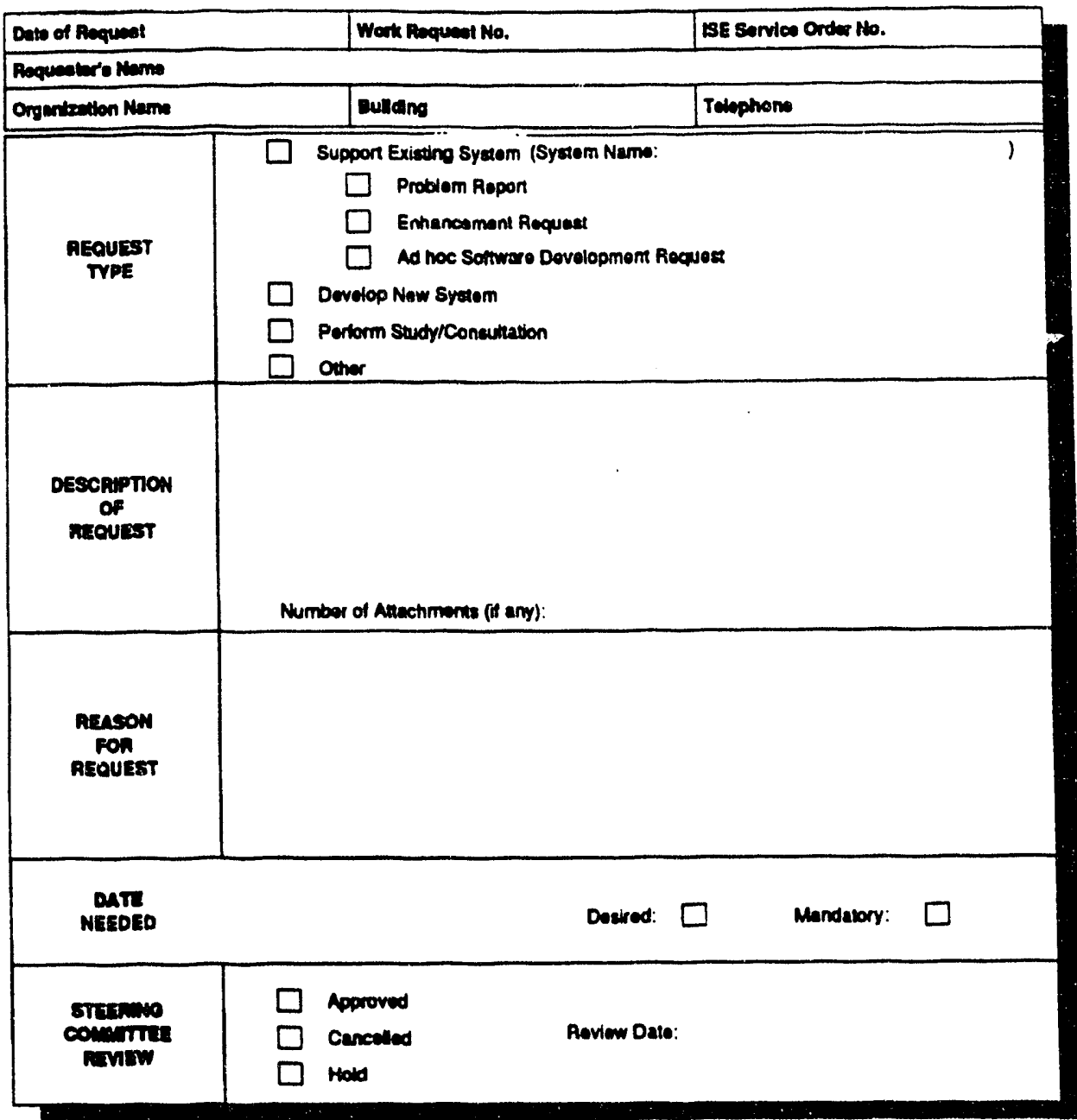

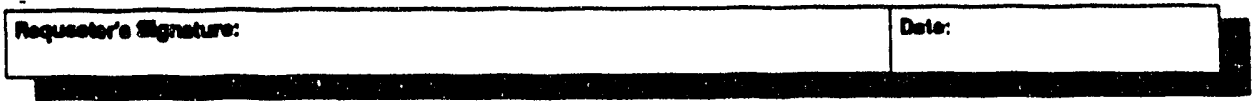




\section{Attachment 2: Project Participation Matrix}

Mark the boxes to indicate the participants and their responsibility by phase.

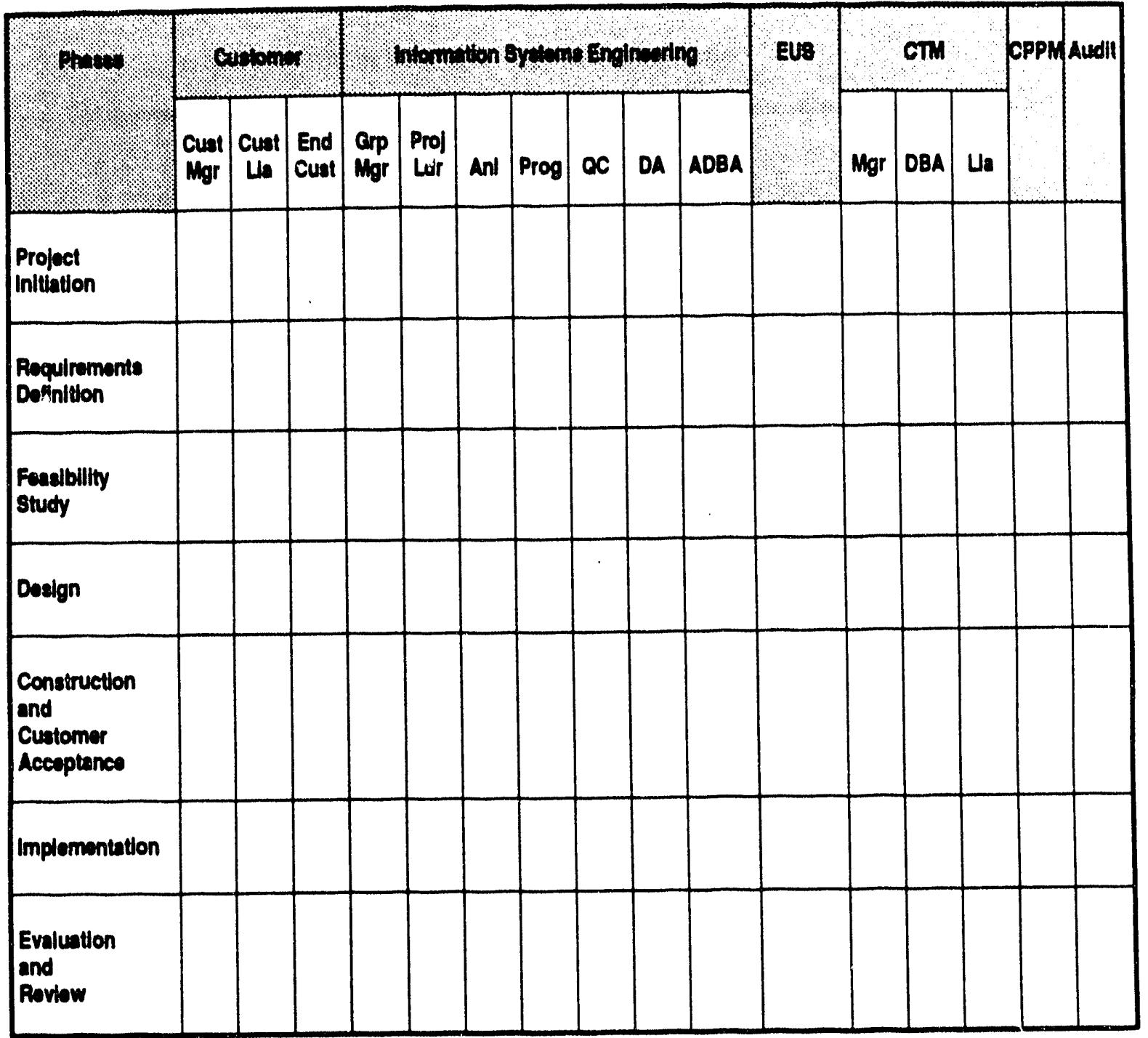

\section{Table Key:}

$P=$ Perform

$A=$ Approve

$C=$ Consult

NA $=$ Not applicable 


\section{Attachment 3: Project Quality Plan Checklist}

\section{Project Quality Plan Checklist}

ISE Work Request \#

Project

Page 1 of 10

This checklist is used to designate the required tasks, activities, and deliverables for the above request.

\section{Project Initiation Phase}

Tasks and Activities

- submit ISE Work Request

a conduct initial analysis

ㅁ conduct steering committee review

identify resources

口 prepare Project Quality Plan

set up ISE Service Order

ㅁ set up project folder

review high impact software guidelines

a determine sitewide authorization requirements

ㅁ prepare project scope document

口 prepare preliminary project schedule

a conduct internal review

ㅁ conduct customer review

update software inventory

\section{Deliverables}

ISE Work Request form

口 initial analysis memo

口 Project Participation Matrix 


\section{Project Quality Plan Checklist}

ISE Work Request \#

Project

Page 2 of 10

口 Project Quality Plan

口 ISE Service Order

a project folder

a project folder index

口 project scope document

口 preliminary project schedule

a ISE Technical Review form (for project scope document)

customer sign-off memo(s) (for project scope document)

\section{Requirements Definition Phase}

\section{Tasks and Actioities}

a review project scope document

identify major business activities within the business area

a review features of similar systems or packaged software

a select technique(s) to gather requirements information

a analyze and document current processes

analyze and document desired processes

analyze and document data

analyze and document conversion requirements

- document existing policies

a analyze and document existing problems

a analyze and document current and projected volumes and frequencies

a document performance requirements 


\section{Project Quality Plan Checklist}

ISE Work Request *

Project

Page 3 of 10

a analyze and document custodianship and security requirements

a analyze and document desired interfaces

a analyze and document backup and recovery requirements

a develop disaster plan

a prioritize requirements and state justifications

a assess impact on all organizations

a count function points

prepare requirements definition document

a conduct internal review

b conduct customer review

u update Project Quality Plan

u update project schedule

u update project folder

\section{Deliverables}

口 requirements definition document

ISE Technical Review form (for requirements definition document)

a customer sign-off memo(s) (for requirements definition document)

․ Computer Program Protection Manager sign-off memo (for requirements

definition document)

u updated Project Quality Plan

u updated project schedule

u updated project folder 


\section{Project Quality Plan Checklist}

ISE Work Request \#

Project

Page 4 of 10

\section{Feasibility Study Phase}

Tasks and Activities

a categorize requirements based on effort and cost considerations

口 review and reprioritize requirements with customer organization(s)

consider external issues that will influence the development project

a conduct a literature search

examine possibility of upgrading an existing system

investigate potential external software purchases

explore alternative system development solutions

consider the security requriements of each alternative

analyze benefits and costs

prepare feasibility study document

conduct internal review

conduct customer review

update Project Quality Plan

update project schedule

update project folder

\section{Delioerables}

a feasibility study document

ISE Technical Review form (for feasibility study document)

customer sign-off memo(s) (for feasibility study document) 


\section{Projecł Quality Plan Checklist}

ISE Work Request *

Project

Page 5 of 10

a updated Project Quality Plan

q updated project schedule

a updated project folder

\section{Design Phase}

Tasks and Activities

口 perform external design

a select hardware/software and facility requirements

口 define online applications

a define batch applications

口 define special processing logic

口 document external design

C conduct internal review of external design

a conduct customer review of the external design

perform internal design

C. develof file structures

a define tables

a define backup and recovery and security mechanisms

a define conversion mechanisms

口 define specific interface requirements

- design audit trails

a create program specifications 


\section{Project Quality Plan Checklist}

ISE Work Request *

Project

Page 6 of 10

a develop customer training strategy

口 develop test plan

․ count function points

口 document internal design

a conduct internal review of internal design

口 complete design document

a conduct customer review of the design document

update Project Quality Plan

update project schedule

口 update project folder

\section{Deliverables}

a ISE Technical Review form (for external Design Phase deliverables)

口 customer sign-off memo(s) (for external Design Phase deliverables)

a design document

ㄴ ISE Technical Review form (for internal Design Phase deliverables)

口 Computer Program Protection Manager sign-off memo (for design document)

a customer sign-off memo(s) (for design document)

u updated Project Quality Plan

a - updated project schedule

u updated project folder 


\section{Project Quality Plan Checklist}

ISE Work Request \#

Project

Page 7 of 10

\section{Construction and Customer Acceptance Phase}

Tasks and Activities

- generate physical files and database structure

a develop in-house software

口 install and test procured software and hardware

a prepare conversion software

walk-through programs with peers

a review programs with project leader

a create test data

口 perform program testing

address discrepancies and concerns

prepare user's guide

a prepare system manual

a train customers

a conduct internal review

a conduct customer review

u update project schedule

u update Project Quality Plan

- update project folder

\section{Deliverables}

installed and tested software and hardware

a system test plan 


\section{Project Quality Plan Checklist}

ISE Work Request *

Project

Page 8 of 10

口 system test results

a user's guide

口. system manual

口 ISE Technical Review form(s) (for Construction Phase deliverables)

a customer sign-off memo(s) (for Construction Phase deliverables)

a updated project schedule

口 updated Project Quality Plan

u updated project folder

\section{Implementation Phase}

Tasks and Actioities

口 develop implementation plan

a review implementation plan

a confirm customer organizational changes

a confirm completion of documentation

a confirm installation of hardware

a transfer training

c contact Help Desk

a create production files

口 implement conversion plan

口 install system

口 retire old system 


\section{Project Quality Plan Checklist}

ISE Work Request *

Project

Page 9 of 10

口 count function points

a create support plan and support ISE Service Order

a conduct internal review

a conduct customer review

u update software inventory

口 write project closure letter

u update project schedule

口 update Project Quality Plan

u update project folder

Deliverables

implementation plan

口 production system

a support plan

a support ISE Service Order

a ISE Technical Review form (for Implementation Phase deliverables)

a project closure letter

customer sign-off memo (for project closure letter)

u updated project schedule

口 - updated Project Quality Plan

u updated project folder 


\section{Project Quality Plan Checklist}

ISE Work Request *

Project

Page 10 of 10

\section{Evaluation and Review Phase}

Tasks and Activities

conduct project evaluation

口 review SDM applicability

a review schedule adherence

a schedule post-implementation system review

a conduct post-implementation system review

口 interview customers

口 review requirements

a review documentation

a review operating efficiency

a review maintenance history

口 identify problems or opportunities

a conduct customer review

a complete project folder

\section{Deliverables}

口 project evaluation report

a post-implementation system review report

- completed project folder 


\section{Attachment 4: Software Acquisition and Development Checklist}

\section{SOFTWARE ACOUISITION AND DEVELOPMENT CHECKLIST}

This checklist is to be completed for every project and flled with the project folder

SYSTEM NAME

WORK REQUEST

1. Does software acquisition or development project have development, acquisition and implementation costs totaling $\$ 1,000,000$ or more?

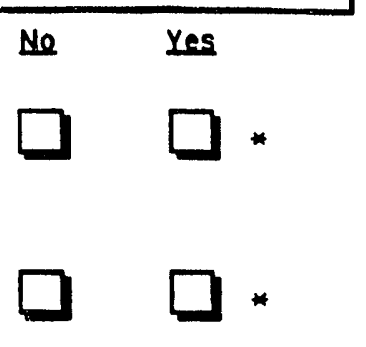

2. Does software acquisition or development have DOE-wide impact? (WIII it affect the way they will have to do business?)

3. Does software acquisition project have customization, acquisition and implementation costs totaling $\$ 500,000$ and less than $\$ 1,000,000$ ?

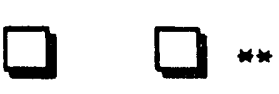

4. Does software development project have development and implementation costs totaling $\$ 300,000$ and less than $\$ 1,000,000$ ?

- Ves answer to question 1 or $=2$ requires the project to be submitted to DOE-SR for DOE-HO apdroval 90 days prior to planned start of solleltation (RFP) or development (Requirements Definition phase) process.

* Yes answer to question -3 or $* 4$ requires the project to be submitted to DOE-5R for DOE-SR approval 45 days prlor to planned start of solicltatlon (RFP) or devetopment (Requirements Definition phasel process.

To obtain approval, prepare a scope document in accordance with ISE. SOM Be prepared to discuss the scope document if required. Include information concerning cost/resource estimates (from an Analys is of Benefits and Costs) and documentation of a search for existing software - both onsite and In the DOE community, as well as estimated times and funding type (cost or capltol). Contact ISE Methods Groud to coordinate DOE approvals.

\begin{tabular}{l|l|l|}
\hline & APPROVED & REJEETED \\
NAME & (Print) & (Signature) \\
TITLE & DATE & (Print) \\
\hline Comments: & \\
\hline
\end{tabular}




\section{Attachment 5: ISE Technical Review Form}

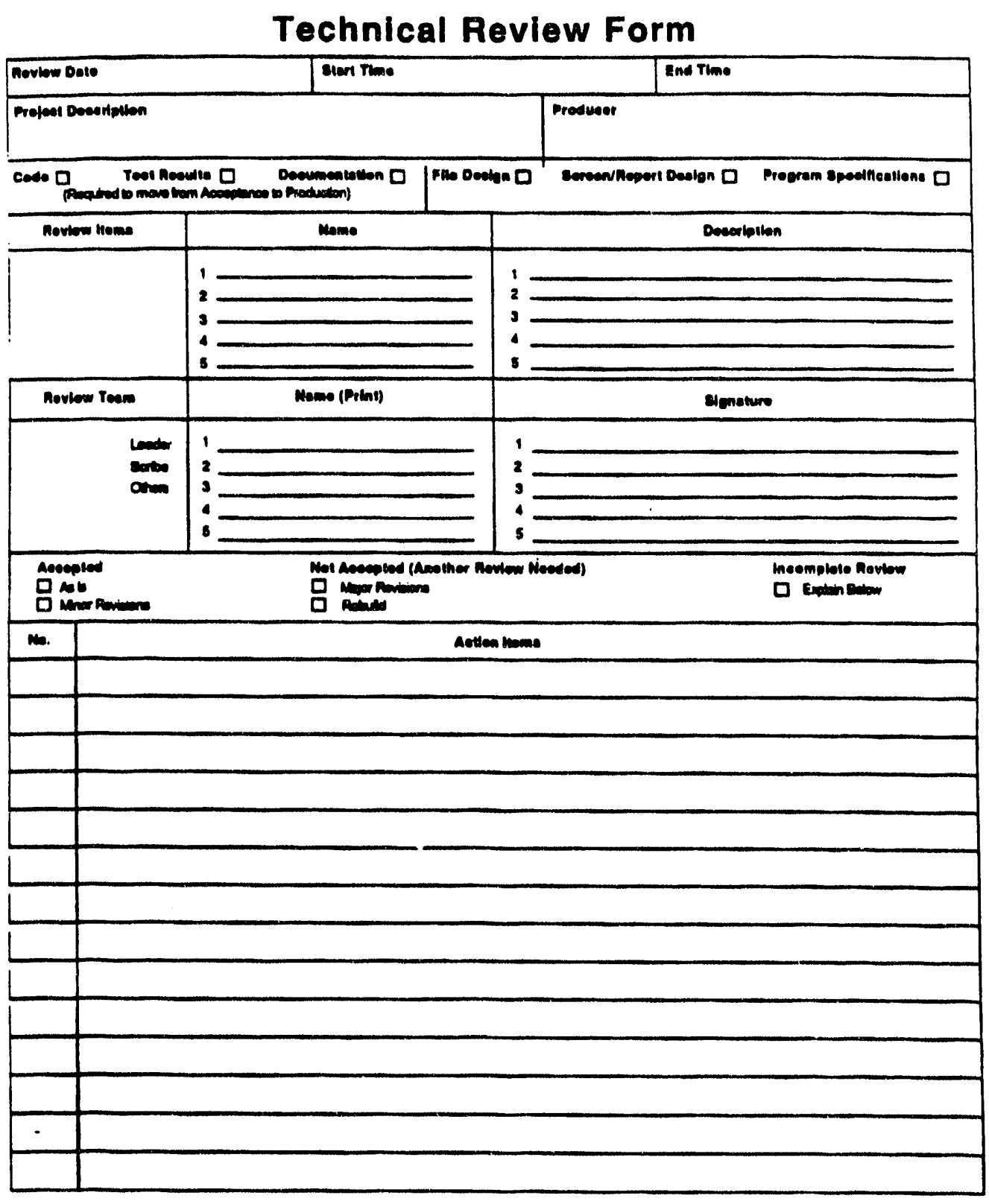

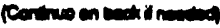




\section{Defining Project Requirements}

\section{Objective}

To define and document requirements for the proposed system.

\section{Tasks and Activities}

review project scope document

a identify major business activities within the business area

a review features of similar systems or packaged software

D select technique(s) to gather requirements information

a analyze and document current processes

analyze and document desired processes

Q analyze and document data

analyze and document conversion requirements

document existing policies

a analyze and document existing problems

a analyze and document current and projected volumes and frequencies

document performance requirements

analyze and document custodianship and security requirements

a analyze and document desired interfaces

analyze and document backup and recovery requirements

a develop disaster plan

Q prioritize requirements and state justifications

assess impact on all organizations

a count function points

prepare requirements definition document

- conduct internal review

conduct customer review

update Project Quality Plan

a update project schedule

update project folder 


\section{Deliverables}

a requirements definition document

a ISE Technical Review form (for requirements definition document)

a customer sign-off memo(s) (for requirements definition document)

- Computer Program Protection Manager sign-off memo (for requirements definition document)

a updated Project Quality Man

a updated project schedule

a updated project folder 


\section{Defining Project Requirements}

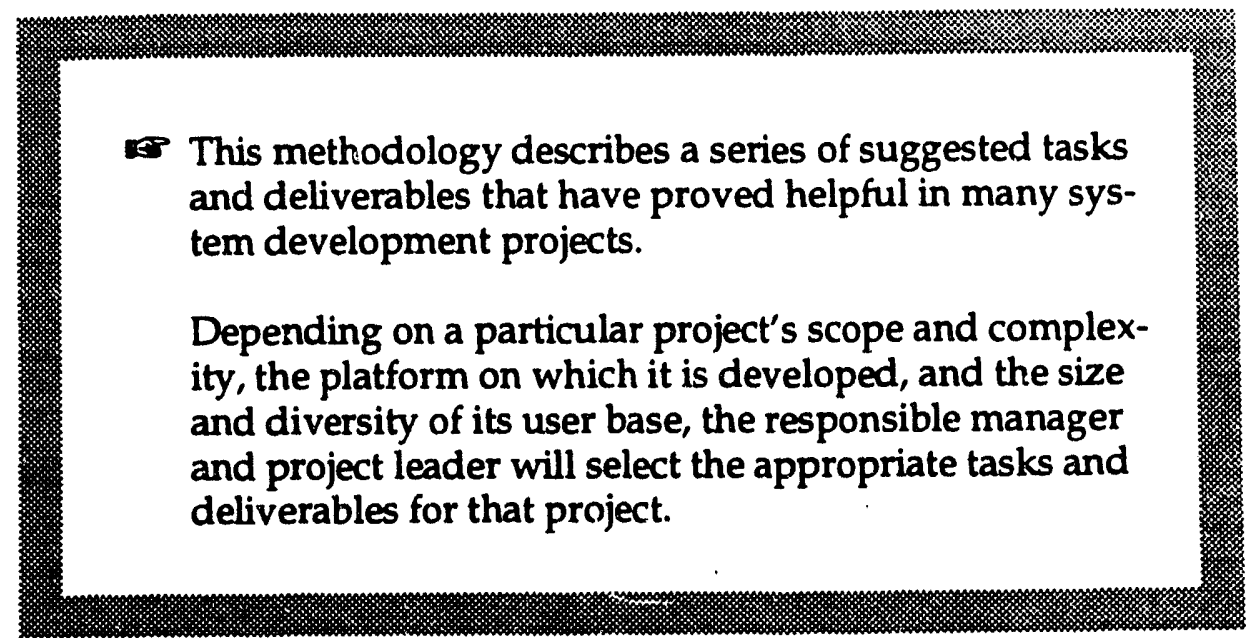

\section{Objective}

To define and document project requirements for the business area identified in the Project Initiation Phase. These requirements are functional in nature and should be independent of specific technology to avoid precluding potential design solutions. The important point is that the requirements must be stated in sufficient detail to define a solution which adequately addresses the customer's needs. Depending on the size and complexity of the business area being studied, the desired system may actually be multiple subsystems.

The requirements defined in this phase are the basis for the Feasibility Study and, subsequently, the design of the system.

\section{Description}

The Project Quality Plan, prepared during the Project Initiation Phase and revised throughout the project life cycle, specifies the tasks and activities which have been selected for the Requirements Definition Phase of the project.

The Requirements Definition Phase is the most critical in the development process. It develops a clear, documented understanding of the functions the business area performs and the data required to support those functions. The requirements definition document 
defines the functional requirements of the business area being studied as well as facility needs, interfaces, security issues, and impact on the customer's organization. The requirements are the foundation for the subsequent design. If requirements are omitted or incomplete, the design and ultimately the system will not be complete and will fail to meet the customer's intended need.

The project team should make full use of information gathered about the current system in defining requirements. Both the strengths and weaknesses of the current system should be considered. The objective of this evaluation is to ensure that the requirements incorporate the applicable strengths of the current system and exclude the weaknesses.

Reviews must be held throughout the requirements definition process. The frequency and formality of these reviews will depend on the size and complexity of the proposed system.

\section{Tasks and Activities}

\section{Review project scope document}

The requirements definition document builds upon the project scope document produced in the previous phase. The objectives, boundaries, and issues should be reviewed by the project team in order to gain a clear understanding of the problem at hand.

\section{Identify major business activities within the business area}

From the analysis in the previous phase, the project is further broken down into the major activities associated with this business area. This task is performed primarily by the project leader and customer liaison, with input from other customers when necessary. For example, for the business area of Order Processing, the major activities are order entry, packing, and delivery.

\section{Review features of similar systems or packaged software}

It is very helpful to review documentation of software packages and systems developed by other companies to support the business area being studied. Such a review can save considerable time in developing a list of requirements and can alert the customer and analyst to features which they haven't yet considered but which are necessary. The list of features in promotional material for software packages can serve as a ready-made requirements list and be used as a baseline for customer interviews. One of the best sources for this information is trade magazines. Many such magazines are available in the ISE library and from the customer organization.

\section{Select technique(s) to gather requirements information}

The most common technique used to determine, the requirements of the new system is interviewing. Key personnel knowledgeable about the existing system should be identified and interviewed. The information generated in the interviews should be used to docu- 
ment the current system and the requirements for a proposed system using diagrams, outlines, and text to describe the system requirements and data flows.

Another technique gaining in popularity is extensive group sessions with customers, the analyst(s) involved in the project, and a session leader. This approach is known as Joint Application Design (JAD).

Yet another effective way of extracting customer requirements is through the use of prototyping. A prototype is a preliminary or trial version of system components. It can include reports, screens, some basic field and table edits, database processing functions such as storing and retrieving records, minimal error handling, and some algorithms. A prototype gives customers a better idea of what their system will look like based on the information received thus far, and it helps them further define their requirements. If the decision is made to use this technique to define the system requirements, it should be done only after the business activities have been analyzed and the data needed to support these activities defined. It is therefore necessary to use this technique in conjunction with another, such as interviewing or holding JAD sessions. Prototyping is a very effective technique in defining requirements, but starting a prototype effort too early may accelerate the team into the Design Phase before requirements are fully determined.

Other techniques used to define requirements include temporarily assigning one or more project team members to work in the customer areas, having customers complete questionnaires regarding their areas of responsibility, and analyzing written organizational procedures.

Based on preliminary understanding of the business area and the customer involved, the project leader chooses the best approach to gather the needed information. The approach may be a single technique or a combination of those discussed.

\section{Analyze and document current processes}

The objective of this task is to understand each activity in the business area and use this information as a basis for defining the requirements of a proposed system. The current system may be automated, manual, or a combination of the two. The analyst should constantly ask who and why them?; what and why that?; when and why then?; where and why there?; how and why that way? This process involves reviewing all forms used in performing the activity and understanding the processing that supports them. The result should not only clarify the activity itself but show how it fits into the overall business area.

People who actually operate the current system must be included in this phase of the analysis since managers may not be fully aware of the entire activity or of common deviationis from prescribed methods.

If the project is a maintenance or enhancement effort and documentation is not available, it may not be feasible to analyze and document the entire system. It is important, however, to analyze and document at least the activities involved in the maintenance/enhancement effort. For development efforts, all automated and manual activities of the existing system must be fully understood and documented. 


\section{Analyze and document desired processes}

Only after a clear understanding of the present business is reached can the analyst and customer concentrate on what the new system should do. The important thing for the analyst to keep in mind at this point is that he or she is determining what is required and why it is required. Decisions about how the requirements will be met (for example, whether processes will be automated or manual, online or batch, etc.) will be made during the project's Design Phase.

When the desired business activities and work flows are analyzed, it is important to understand not only what is performed but also why it is done. This understanding will aid in prioritizing requirements later.

Data flow diagrams are generally regarded as the most flexible and self-explanatory technique available for understanding and documenting processes and the data which flows between them. These diagrams show the sources and destinations of data, the activities that transform the data, and the places where the data is stored. Data flow diagrams graphically describe what the new system will and will not do and help determine whether all the customer's needs are being addressed.

Benefits of data flow diagramming include:

- better communication between the analyst and the customer, which ensures that the new system will support the business requiruments

- documentation for the requirements definition document as well as for the system manual, which ensures that requirements are complete and that the new system will be easier to maintain

- better translation of business requirements to automated system design, which facilitates the design effort

\section{Analyze and document data}

Identifying the data needed to support the activities being studied is vital. If this is a maintenance or enhancement effort for an existing system and documented data analysis is not available, it may not be feasible to completely analyze the data of the entire area being studied. Nonetheless, at least all the data involved in the current effort and its relationship to the system as a whole must be understood. For a development project, a comprehensive data analysis is mandatory.

This activity refines the major categories of data inputs and outputs identified in the Project Initiation Phase. The analyst should identify and document the data required for processing within the system by identifying the content of necessary input and output data, including interfaces. A description of each data element should include:

- data element name

- description/purpose 


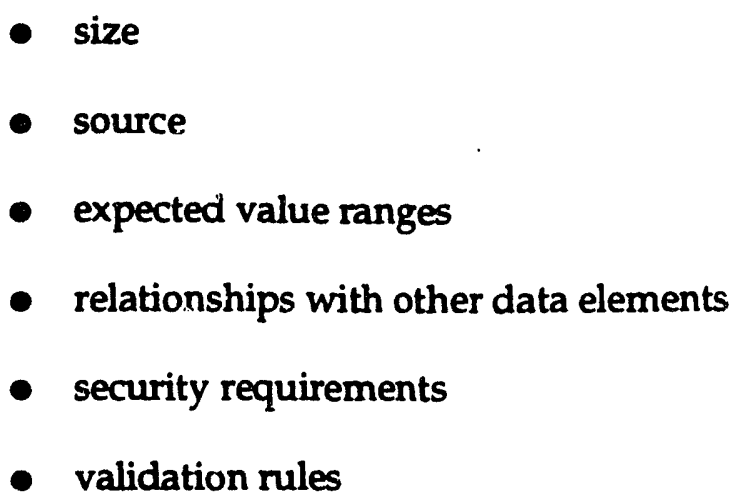

Data models are very useful in understanding data entities and the relationships among them. These models represent the fundamental properties of the data independent of their physical environment.

ISE IU.a Administration can provide assistance in developing data flow diagrams and data models.

\section{Anaiyze and document conversion requirements}

Once the analyst and customer have analyzed the data, they should next determine its source. Much of the data needed is typically available in the current system, but some may have to be obtained from outside systems or be newly geserated. The analyst should not worry about how; that question will be handled later. The important thing now is identifying what is needed and what its source is. Whether the data can be converted from its present form or whether some cleaning up is necessary must also be determined.

\section{Document existing policies}

All relevant policies must be understood and documented. The analyst generally works with a non-policy-making customer in analyzing the business activities, so the policies of the customei's upper management which are inherent in the current system may not be obvious to him or her. For an order entry activity, for example, it may be management's policy that turnaround time on all orders is two weeks. The analyst must be aware of this and all other relevant policies in order to ensure that the new system will support them.

\section{Analyze and document existing problems}

All problems with the existing system should be analyzed and documented. Oftentimes the customer assumes that once the analyst understands the current system, he or she is also aware of all of its problems. This area should be considered a separate task to ensure that the new systexit addresses all of the existing system's shortcomings. Problems encountered with the incoming information, processing, and outgoing information must all be identified. Problen: areas include quality, timeliness, accuracy, efficiency, excessive cost, and unexploited business opportunities. Potential solutions should also be discussed and documenied. Here again, operational personnel should be involved since they are usually intimately familiar with the present system's shortcomings. 


\section{Analyze and document current and projected volumes and frequencies}

Working from the data flow diagrams or other documents used to define the work flows from the current and proposed systems, the customer and analyst must determine the volume of work, the frequency of transactions, and the average data population in each activity. The system may adversely affect the current operating environment or may require additional or upgraded equipment. These factors are obviously important to the feasibility and design considerations in the next phases.

\section{Document performance requirements}

A variety of characteristics should be considered when discussing desired performance requirements. Some of the following items have critical impact in certain systems:

- response times-time of day, peak load, etc.

- task completion times-sequential relationships with other systems' processing and times when the outputs are required in order to meet delivery schedules

- delivery time for reports - the earliest time the reports can be available and the latest time after which the reports will be ineffective or useless; delivery run schedules; customer pickup capability; dedicated printers; etc.

\section{Analyze and document custodianship and security requirements}

These requirements define the custodian of the data-the person(s) responsible for determining who may access the data, what users may do with it, and how access will be controlled. When determining security requirements for various functions, the analyst and customer should remember that complexity and sophistication of security vary with the sensitivity of the information and the type of processing involved. They should consider whether the entire function or only a part of it requires security procedures. The customer should be aware of and evaluate the trade-off between security and cost and convenience. The sophistication of security devices should be consistent with the sensitivity of information processed in the system.

\section{Analyze and document desired interfaces}

This step includes both a summary of all interfaces to systems outside the project scope and an explanation of each interface. The summary should identify the interface system and briefly describe its purpose. In analyzing individual interfaces, the analyst must justify each data element to be included in the interface. This step requires a determination of the source and destination of each element, and it necessitates looking beyond existing interfaces and existing methods of accomplishing tasks. Present interfaces inay exis، only because of the way business is currently done, not because of a functional need for the information. The analyst and customer should recognize such situations and attempt to determine the actual needs. 


\section{Analyze and document backup and recovery requirements}

The analyst and customer must identify processes within the business area that are sufficiently important to require backup and determine timing requirements for system recovery. The requirements at this point are at the conceptual level only; the technical aspects of backup and recovery should not be addressed until the Design Phase. When developing backup requirements, the analyst and customer should consider the cost of implementing backup requirements versus the benefits subsequently obtained. They should also consider the risks involved in not implementing backup and recovery procedures.

\section{Develop disaster plan}

In the event of a hardware failure, the customer must have an alternative means of performing essential business activities. This requirement should not be taken lightly. The analyst and customer must develop a disaster plan which addresses how vital functions can be performed without use of the computer system.

\section{Prioritize requirements and state justifications}

The customer usually specifies more requirements than can be reasonably implemented due to time constraints and contradictory requirements. For example, one requirement for an online system might be ease of operation with minimal training, while another might specify tight controls on all data input. Obviously, the tighter the controls, the harder the system will be to operate, and the more training it will require. Justification of the desired requirements must be documented so that customer management can prioritize the needs for the entire system. Asking why throughout the requirements definition helps the analyst in this process.

The customer manager must resolve conflicting requirements. This person may be chosen by various organization managers for projects which span several organizations.

Prioritizing may mean that some requirements will be implemented later (as enhancements to the new system) or dropped from consideration altogether. To help establish priorities, the customer should be asked throughout this phase to divide requirements into categories:

- high priority-essential to the operation of the business function

- medium priority-contributing to efficiency of operations

- Low priority-useful and desirable, but less urgent than the other two categories

\section{Assess impact on all organizations}

At this point, the analyst should examine the impact the proposed system will have on the customer organization as well as other organizations. The analyst should review the proposed system requirements from an operational point of view, including ensuring 
that system requirements are consistent with customer objectives and that the proposed system could be operated in the customer environment. Whether staff levels or ability needs to be adjusted and whether training is needed to implement the new system must also be determined. This review is typically performed by customer management.

A preliminary assessment of the proposed systern's impact on the existing computing environment is also necessary. In subsequent phases, more information will be available to help assess this impact in greater detail, but knowing of potential problems with computing resources as soon as possible is important.

\section{Count function points}

Function point analysis is the industry standard method of quantifying the functionality provided by software, based primarily on logical design. A program is rated as having a certain number of function points based on the specific, countable functionality it provides to the user. Only user-requested, visible components are counted. Using this analysis, the project manager can accurately estimate the project's size, cost, and development time.

The project should be evaluated at three milestones in the development process. The project should first be measured as soon as the requirements have been identified and defined. This early measurement will help to prioritize user requirements. The project is measured again during the Design Phase to analyze growth as well as to revise cost estimates. Finally the application is measured at production turnover time to measure productivity and to identify changes to the original requirements. This count is also used as the baseline for future enhancements or modifications.

The ISE Methods Development group can provide assistance in counting function points.

\section{Prepare requirements definition document}

The requirements definition document provides a clear, concise, and systematic report of the requirements for the customer's business area. It is compiled using the results of the previous activities of this phase. This document is the basis for the feasibility study and the guide for the design; it is therefore vital to the success and customer acceptance of the final product.

The following outline is a suggested format but is not the only way to structure the document.

\section{- Transmittal documents}

The transmittal documents, under the signature of the ISE manager, request formal approval of the requirements definition and are addressed to the customer organization manager and the Computer Protection Program Manager or his or her designate. A copy of the requirements definition and other transmittal documents are sent to 
the manager of Internal Audit section, Internal Oversight Department, for information purposes.

- Sign-off pages

The sign-off sheets document the formal approval requested in the transmittal documents.

\section{- Introduction}

The introduction is usually one page and briefly describes the purpose and scope of the requirements definition.

- Management summary

This section summarizes the report, conveying to management its main emphasis. It familiarizes the reader with the general work environment into which the proposed system will be placed, with particular emphasis given to areas most affected by the new system. The summary outlines the business area and associated activities addressed in the study, and briefly describes the differences between the current and proposed systems. This section also summarizes the justification for recommended changes.

- Method of study

This section briefly describes how the information contained in the document was obtained. It includes the names of those who conducted the study and a description of how the study was conducted. It may also include the names of customer contacts and acknowledgments.

- Current system review

This section summarizes findings from the analysis of the current system and the problems associated with it. It includes an overview of the current system and the reasons for redesign. Also documented here are the functions which will remain unchanged and a description of major innovations required for the proposed system. If immediate improvements are needed, recommendations for them are also summarized here.

\section{- System objectives}

This section details management policies and individual user requirements that must be supported by the new system. It includes objectives both directly related to and generally in support of these requirements. 


\section{- Proposed system requirements}

This section presents findings from the analysis of the desired system. It includes an overview which describes the proposal in general terms, tells what business activities will be addressed, and briefly describes the people and systems affected by the proposal. It includes system requirements which describe the data and process requirements associated with each business activity using both text and diagrams. Also included are system design considerations:

performance-related details, the person(s) who will accept responsibility for the system, its security requirements, detailed interface requirements, backup and recovery requirements, and disaster plan requirements.

The following outline is suggested for this section:

- overview

- general description

- scope

- impact on:

- organization

- other systems

- system requirements

- data requirements

- process requirements

- input

- output

- processing

- system design considerations

- performance requirements

- ownership and security requirements

- interface requirements

- backup and recovery requirements 
- disaster plan requirements

- Proposed system conversion requiruments

This section includes a description of all activities necessary to convert to the proposed system from the existing system.

\section{Conduct internal review}

An internal review of the requirements definition document is required. The project leader and group manager should consider requesting participation by the following functional areas as appropriate for the project:

- customer liaison and other representative customers

- senior analyst(s) on the project

- CTM Database Administration group (for systems that will run on the Central Computer Facility)

- ISE Data Administration

- Computer Protection Program Manager

The group manager or another project leader in the same group will chair the review. Depending on the size and complexity of the project, other personnel may also be asked to serve on the review team. This review team will review the requirements definition with the project team to ensure clarity and completeness. The review team will also point out potential problems or oversights, and offer various suggestions to improve the requirements definition. The team may make the following types of comments:

- mandatory changes-The review team will ask that the problems be corrected and the project team return for a follow-up review.

- recommendations-The review team will make recommendations for improving the system, but the final decision is left up to the project leader.

- suggestions-The review team will offer suggestions for the project team members to consider in future assignments.

The review teain must approve the requirements definition document and record the results of the review on an ISE Technical Review form.

The output from the data analysis task must be reviewed by the Data Administration team. This review ensures data consistency and integrity across projects and controls redundant data. 


\section{Conduct customer review}

A review of the requirements definition document with the customer is also necessary. Formal approval across organizational lines must be obtained before the Feasibility Study Phase begins. Each recipient signs an individual sign-off sheet and returns it to the indicated address. If revisions to the requirements definition document are necessary, the document must be resubmitted to the requester and other customers for review and approval.

In addition to being approved by the customer, the requirements definition document must also be approved by the Computer Protection Program Manager (CPPM) or his or her designate. Refer to the ISE Guide to Business and Technical Communication for samples of a transmittal document and a sign-off page for customer approval.

\section{Update Project Quality Plan}

With the information gathered in this phase, the project leader should update the Project Quality Plan.

\section{Update project schedule}

After the requirements have been defined, the project leader will have a better understanding of the project's complexity. The project leader updates the project schedule to reflect any additional work foreseen as a result of the requirements definition process. Information on completed tasks should also be included on the updated project schedule.

\section{Update project folder}

A copy of each deliverable must be filed in the project folder, and the title and location of each deliverable must be documented in the index.

\section{Deliverables}

- requirements definition document

- ISE Technical Review form (for requirements definition document)

- customer sign-off memo(s) (for requirements definition document)

- Computer Program Protection Manager sign-off memo (for requirements definition document)

- updated Project Quality Plan

- updated project schedule .

- updated project folder 


\section{Studying Project Feasibility}

\section{Objective}

To analyze the costs/benefits of the requirements; evaluate economic, operational, and technical feasibility of alternatives; and recommend a solution.

\section{Tasks and Activities}

categorize requirements based on effort and cost considerations

review and reprioritize requirements with customer organization(s)

a consider external issues that will influence the development project

- conduct a literature search

- examine possibility of upgrading an existing system

- investigate potential external software purchases

a explore alternative system development solutions

a consider the security requirements of each alternative

a analyze benefits and costs

prepare feasibility study document.

口 conduct internal review

a conduct customer review

update Project Quality Man

u update project schedule

u update project folder

\section{Deliverables}

a feasibility study document

a ISE Technical Review form (for feasibility study document)

a customer sign-off memo(s) (for feasibility study document)

u updated Project Quality Plan

a updated project schedule

a updated project folder 


\section{Studying Project Feasibility}

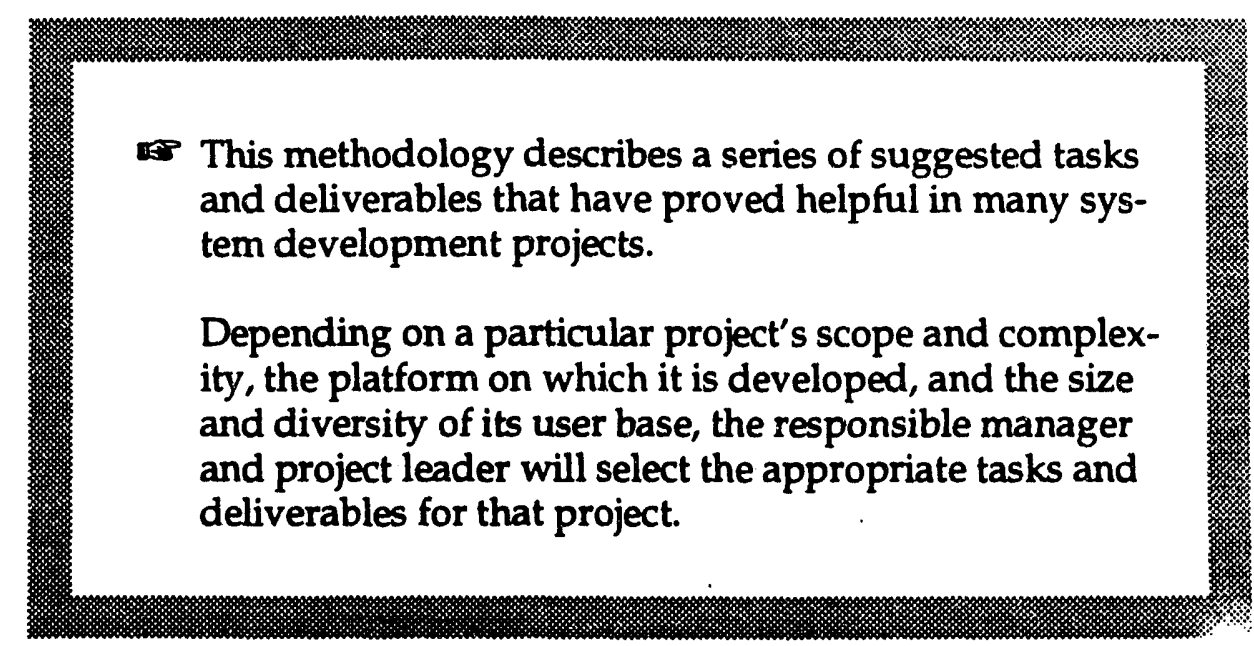

\section{Objective}

To determine the most feasible solution by analyzing the benefits and costs (in dollars, time, and resources) of the requirements and considering alternatives for dealing with the problem or opportunity. This solution is identified by evaluating the economic, operational, and technical feasibility of the available alternatives.

When determining the feasibility of any project, ISE always retains the option to reject work as well as to accept it, based on priorities, staffing levels, work loads, and other factors.

\section{Description}

The Project Quality Plan (PQP), prepared during the Project Initiation Phase and revised throughout the project life cycle, specifies required tasks and activities for the Feasibility Study Phase.

Based on the information gathered in the previous phase, the project leader and customer liaison re-evaluate the requirements in terms of effort and cost considerations (dollars, time, and resources), as well as expected benefits. Some requirements defined in the previous phase may not be addressed immediately due to their impact on existing systems, the lack of expertise or specialized equipment, or time and money constraints. 
Once the scope of the current effort has been assessed, the project team investigates the alternatives for dealing with the problem or opportunity. All possible options are analyzed and documented. Then the alternatives are reviewed, and the best solution (in terms of time, money, and resources) determined.

Customers should be involved in the Feasibility Study Phase as ruuch as possible. Their participation during this phase can result in greater commitment to the solution that is ultimately selected.

The system manager of the computing platform(s) being considered is also very important during this phase. This person may be able to assist when categorizing requirements, especially when considering and quantifying resource requirements. He or she will certainly be helpful when considering alternatives. The system manager is intimately familiar with the operating environment and can assist in evaluating how each alternative will affect current operations.

\section{Tasks and Activities}

\section{Categorize requirements based on effort and cost considerations}

The requirements defined in the previous phase have already been prioritized by the customer based on expected benefits. The analyst, along with the system manager, should now categorize each requirement based on estimated effort and cost (dollars, time, and resources). Requirements should be divided into three effort/cost categories: small, medium, and large. Requirements considered small in terms of effort and cost would be relatively easy to implement and would require minimal additional resources. Large category requirements, on the other hand, would require a sizable commitment of resources-possibly expertise not presently available within ISE, a great deal of time, or specialized equipment. Where possible, the analyst should quantify resource estimates in terms of time and money (for example, for personnel or equipment needed). Consideration should also be given to the use of available local expertise versus the cost of training or hiring personnel with the necessary skills.

The analyst and the customer liaison should not neglect to estimate the effort required from the customer organization to implement the requirements.

\section{Review and reprioritize requirements with customer organization(s)}

Once the requirements have been categorized based on effort and cost, the analyst should discuss the results with the customer. Until this point, cost considerations have not been considered to prevent the customer from holding back on suggestions because they might be too costly to implement. The customer should now analyze costs and benefits of the requirements, and determine which requirements must be addressed in this development/maintenance effort, which requirements can be deferred and implemented as a later phase of the project, and which requirements can be dropped altogether. Some requirements identified in the previous phase may also need to be deferred until other systems can be modified to allow necessary interfaces or until additional re- 
sources become available. Several design/construction projects may be identified from a single requirements study.

\section{Consider external issues that will influence the development project}

A variety of issues and events in the business environment will impact the development of any system. The development team should consider how all of the following will affect the proposed system:

- other systems (either existing or under development) which utilize technology which might be adapted for this system (for example, networks, client-server applications, etc.)

- other systems being developed which will interface with this system

- business procedures required for the proposed system as well as procedures external to it

- pending business decisions which will impact the type and amount of data the system must handle

- the possible conflict between customer schedule ronstraints and such issues as employee location, number of users, maturity of hardware and software, hardware availability, etc.

- the technical fit of the proposed system with the IRM long-range plan's description of existing and future WSRC systems and technology

- ISE's capability to maintain a system proposed for purchase or development

\section{Conduct a literature search}

To identify alternatives, the project team should consult relevant books, periodicals, DOE and Westinghouse corporate reports, and internal SRS publications. The Technical Library in 773-A can assist in conducting an automated search of many of these sources using databases to which they have access. These sources may contain valuable information about other businesses which have attempted to solve similar problems, implemented similar solutions, or evaluated products being considered by the project team.

One source which should not be overlooked is reports of Technology Research and Evaluation (TRE) teams both at WSRC and other Westinghouse sites. Another possible source of information is vendor responses to a Request for Information issued by the WSRC Procurement and Materials Management Department (consult with Procurement about the possibility of issuing a Request for Information). 


\section{Examine possibility of upgrading an existing system}

Now that the requirements have been further refined, possible solutions can be explored. One development alternative is the upgrading of an existing system. Modifications to accommodate at least the mandatory requirements must be considered and evaluated.

\section{Investigate potential external software purchases}

The project leader should identify software products available from other Department of Energy sites and from commercial software vendors and evaluate any which appear to meet the project's requirements (functions and inputs and outputs that were determined in the Requirements Definition Phase). The proposed software package does not have to be entirely an external package. The alternative could be a combination of external packages and internal development. If external products appear suitable from the vendor documentation, obtain the packages for physical evaluation if possible. (Consult with Procurement for specifics on obtaining products for evaluation.) The identification of potential externally available solutions is followed by a critical analysis of each package's characteristics. This analysis should include:

- identification of business functions, including the operational, management, and regulatory information provided by the package and a comparison with the requirements; this analysis should include all information repurting features, as well as the controls and security provided by the package

- analysis of the package's design concepts, file structures, ease of use, and compatibility with existing standards

- analysis of the package's maintainability, design architecture, program structure, flexibility, level of generality, and expandability

- analysis of the package's operating characteristics, such as throughput performance and potential volume constraints, as well as its impact on the computer environment in which it will operate

The basic acquisition and maintenance costs, as well as any required enhancements and modifications, should be clearly defined for all potential software purchases.

\section{Explore alternative system development solutions}

A variety of alternatives exists here as well. Mainframe, midrange computer, minicomputer, $P C$, and possible multiple platform approaches should be considered. If the system involves extensive data sharing and real-time views of the data, a mainframe, midrange, or minicomputer application should be considered. If the system is primarily intended for a single user with no data sharing necessary, it is a good candidate for a PC application. If the system is primarily a reporting system using established database files, the analyst should consider a combination PC/host application. The analyst should 
investigate all options for solving the problem and not be limited to the first idea that comes to mind.

\section{Consider the security requirements of each alternative}

For each alternative, the project team must analyze the physical and data security constraints. The customer's Authorized Derivative Classifier (ADC), ISE Department Computer Security Officer (DCSO), and Safeguards and Security personnel should be actively involved in addressing these issues.

The team should be certain that knowledgeable customer personnel, including the customer manager and the customer organization's ADC have addressed the requirements of SRS Quality Assurance procedure 20-1 by determining whether the proposed system qualifies as high-impact software. The results of the customer's evaluation should be documented, and a copy should be included in the project folder.

\section{Analyze benefits and costs}

After the preliminary alternatives have been identified, an assessment of the feasibility, benefits, and risks of each alternative must be undertaken by the project team.

The evaluation of the proposed system's impact on existing WSRC policies, practices, and procedures is performed in accordance with DOE Orders $1330.1 \mathrm{C}$ and 1360.8 , and MRP 3.41. The comparison of costs and savings in the analysis of benefits and costs highlights whether a new application can be expected to produce sufficient savings to justify its development based on dollar benefits alone.

During this assessment, the following questions can be asked.

\section{Technical}

- Does all or part of the necessary hardware and software already exist? If not, can it be developed in time to implement the system?

- What are the risks of using new, untried hardware or software?

- Will this approach satisfy all of the mandatory requirements?

- Are there additional requirements that will also be satisfied?

- Is this approach consistent with the SRS Computing Architecture, and with the division's and IRM's long-range plans?

- Is this approach a good fit with the overall systems plan for the site, the division, and this business area?

- If only a portion of the requirements will be addressed in this system, what will be the effect on future system development? 
- What are the risks and consequences of each alternative if the system fails to meet customer needs?

- Do the project schedule deadlines take adequate acrount of the technical constraints imposed by this alternative?

- Is this alternative technically feasible? (The answe $r$ to this question, based on previous answers, is a go/no go decision about the alternative's technical soundness.)

\section{Economic}

- What economic benefits may be gained by using this approach? (Include both one-time and recurring costs.)

- What will the new system or enhancement cost, in dollars, time, and resources, in both the short and the long term? (Include both one-time and recurring costs.)

- What will the new systern or enhancement save, in both the short and the long term? (Include both one-time and recurring costs.)

- Do the savings justify the costs? (Include both one-time and recurring costs.)

- Is this alternative economically feasible? (The answer to this question, based on previous answers, is a go/no go decision about the alternative's economic soundness.)

\section{Operational}

- Is the proposed system compatible with the SRS Computing Architecture, and with the division's and IRM's long-range plans?

- Is the proposed system compatible with the current operating environmerit?

- Are both customer management and operational personnel committed to support the system?

- Does ISE have the staff necessary to develop, test, and implement the system?

- Do both the customer and the system manager have the staff necessary to develop, test, and imple inent the system?

- If new staff members are needed, can they be hired?

- What retraining of current staff will be necessary? 
- What are the consequences of not meeting staffing or training goals?

- Is this alternative operationally feasible? (The answer to this question, based on previous answers, is a go/no go decision about the alternative's operational soundness.)

The analyst, the system manager, and the customer liaison should evaluate each alternative based on the above considerations. If additional expertise is needed, the appropriate personnel should be sought to perform a comprehensive analysis.

Nonquantifiable and intangible benefits should also be identified in the analysis to provide management with a complete evaluation. These benefits may include:

- improved product quality

- increased service level

- improved management information

- expanded product capabilities

- increased safety and security

- fulfilled regulatory requirement

\section{Prepare feasibility study document}

When the project team has completed the Feasibility Study Phase and has selected the best solution in terms of time, money, and resources, it prepares the feasibility study document. This document should reflect the process described above by providing an orderly presentation of the collected data and demonstrating the trade-offs considered in the selection process. It should provide a clear, concise report of the requirements to be addressed in this effort and those that will be deferred for later consideration. It must be clear and complete in order to prevent misinterpretation by the customer and possible subsequent dissatisfaction with the new system.

The following outline is a suggested way of structuring the document.

\section{- Transmittal documents}

The transmittal documents, under the signature of the ISE manager, request formal approval of the feasibility study and are addressed to the customer organization maniger.

- Sign-off pages

The sign-off sheets document the formal approval requested in the transmittal documents. 


\section{- Introduction}

The introduction is usually one page and briefly describes the purpose and scope of the feasibility study.

\section{- Review of requirements}

This section is a brief overview of the requirements identified in the Requirements Definition Phase and any changes to rey. irements which have resulted from the feasibility study. Requirernents which have been added or deleted, adjustments to priorities, identification of requirements which can and cannot be automated, and any other issue related to requirements are included. If only a portion of the requirements identified in the requirements definition document will be addressed in this effort, details of how the remaining requirements will be handled should also be included here.

\section{- Description of altematives}

This section describes the alternatives, detailing the technical and operational feasibility, cost, benefits, and risks of each. It states all advantages and disadvantages for each approach. If additional requirements other than those identified as mandatory in the first section will be satisfied, they are also documented here.

- Conclusion

This section summarizes the comparative analysis of the alternatives and specifies a recommended solution to the problem or opportunity.

\section{Conduct internal reoiew}

An internal review of the feasibility study document is required. The project leader and group manager should consider requesting participation by the following functional areas:

- customer liaison

- other representative customers

- senior analyst(s) on the project

- subject area data experts

- system manager (CTM Database Administration group for systems that will run on platforms maintained by CTM)

- ISE Data Administration 


\section{- representative from Safeguards and Security}

The group manager or another project leader in the same group will chair the review. Depending on the size and complexity of the project, other personnel may also be asked to serve on the review team. This review team will review the feasibility study with the project team to ensure clarity and completeness. The review team will also point out potential problems or oversights, and offer various suggestions to improve the feasibility study. The team may make the following types of comments:

- mandatory changes-The review team will ask that the problems be corrected and the project team return for a follow-up review.

- recommendations-The review team will make recommendations for improving the system, but the final decision is left up to the project leader.

- suggestions-The review team will offer suggestions for the project team members to consider in future assignments.

The review team must approve the feasibility study document and record the results of the review on an ISE Technical Review form.

\section{Conduct customer review}

A review of the feasibility study document with the customer is also necessary. Formal approval across organizational lines must be obtained. Each recipient signs an individual sign-off sheet and returns it to the indicated address. If revisions to the feasibility study document are necessary, the document must be resubmitted to the requester and other customers for review and approval.

Ordinarily, the customer review consists of a formal presentation of the findings of the feasibility study by one or more members of the project team. At the conclusion of the presentation and any discussion arising from it, the project team should request formal approval of the feasibility study by customer management documented on a customer sign-off page. (Refer to the ISE Guide to Business and Technical Communication for samples of a transmittal document and a sign-off page for customer approval.)

Both ISE and its customer should understand that either organization has the option of choosing not to undertake a project on the basis of the feasibility study's results.

\section{Update Project Quality Plan}

Based on the information gained in the Requirements Definition and Feasibility Study Phase, the Project Quality Plan (PQP) may need to be revised. The project leader may have discovered that the system is more complex than originally expected and that additional tasks, activities, or deliverables must be included to ensure development of a quality system. The project leader must update the Project Quality Plan to reflect any additional work and revised estimates. The project leader must consider all aspects of 
the project and allow reasonable time for completing the effort. Information on actual work to date must also be included on the revised Project Quality Plan.

\section{Update project schedule}

Once the requirements have been defined and a path forward determined, a clear understanding of the time needed to complete the project should be gained. The project leader updates the project schedule to reflect any additional work and revised estimates. It is realistic for the customer to hold the project team responsible for adhering to this revised project schedule, barring any unforeseen problems. Thus, the project leader must consider all aspects of the project and allow reasonable time for completing the effort. Information on work completed to date must also be included on the revised schedule.

\section{Update project folder}

A copy of each deliverable must be filed in the project folder, and the title and location of each deliverable must be documented in the index.

\section{Deliverables}

- feasibility study document

- ISE Technical Review form (for feasibility study document)

- customer sign-off memo(s) (for feasibility study document)

- updated Project Quality Plan

- updated project schedule

- updated project folder 


\section{Designing the System}

\section{Objective}

To design a computer system and prepare a design document with sufficient detail to facilitate coding, testing, and conversion of the system.

\section{Tasks and Activities}

a perform external design

a select hardware/software and facility requirements

a define online applications

a define batch applications

define special processing logic

D document external design

conduct internal review of external design

a conduct customer review of the external design

a perform internal design

a develop file structures

a define tables

- define backup and recovery and security mechanisms

Q define conversion mechanisms

a define specific interface requirements

a design audit trails

a create program specifications

a develop customer training strategy

a develop test plan

a count function points

a document internal design

a conduct internal review of internal design

a complete design document

a conduct customer review of the design document

a update Project Quality Plan

a update project schedule

update project folder 


\section{Deliverables}

0 ISE Technical Review form (for iexternal Design Phase deliverables)

口 customer sign-off memo(s) (for external Design Phase deliverables)

a design document

口 ISE Technical Review form (for internal Design Phase deliverables)

a Computer Program Protection Manager sign-off memo (for design document)

c customer sign-off memo(s) (foir design document)

u updated Project Quality Plan

a updated project schedule

a updated projact folder 


\section{Designing the System}

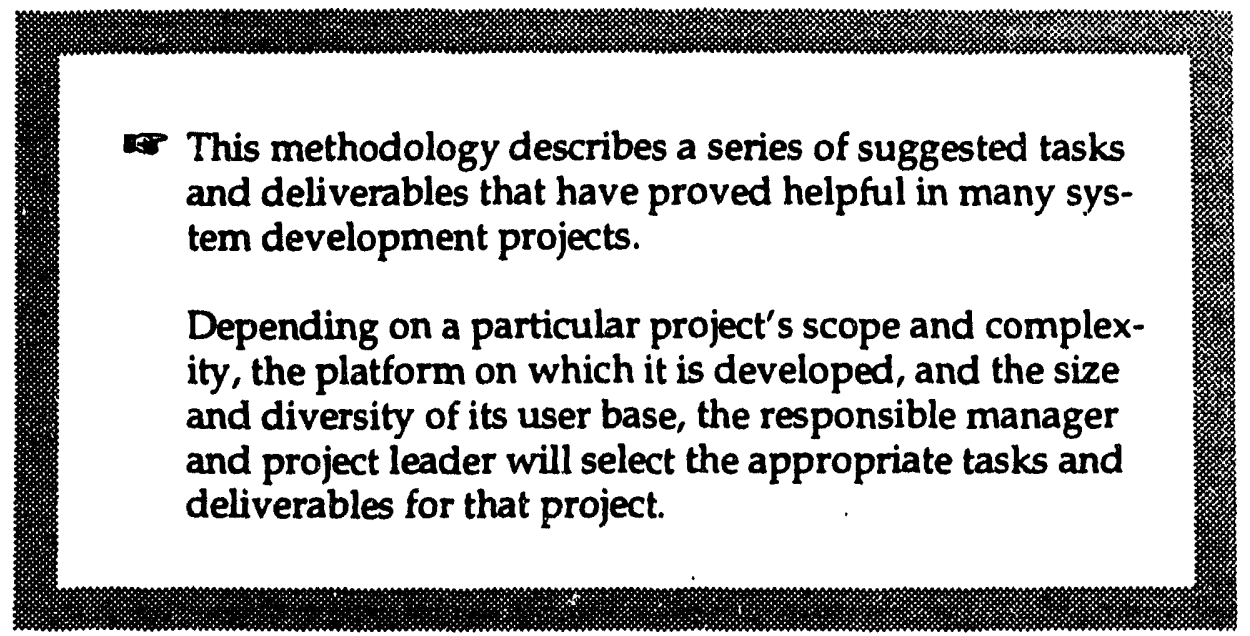

\section{Objective}

To design a computer system which satisfies the requirements identified in the Requirements Definition Phase and the alternative selected in the Feasibility Study Phase; to prepare a design document with sufficient detail to facilitate coding, testing, and conversion.

\section{Description}

The Project Quality Plan, prepared during the Project Initiation Phase and revised throughout the project life cycle, specifies required tasks and activities for the Design Phase.

The Design Phase consists of two major parts: the external step and the internal step. Interaction with the customer is essential throughout the Design Phase and is a key to the success of the external step. The customer must understand and agree with the analyst's conception of the system. 
During the external step, the logical system flow, input/output, screens/reports, processing rules, and operational characteristics are established based on the customer's requirements but without regard for which programs will perform which functions.

Once the external design is complete, the project team moves to the internal design. Here the customer-oriented external design is translated into a set of computer program specifications, file layouts, audit trails, interfaces, and test plans designed as input for the tasks of the Construction and Customer Acceptance Phase.

During the entire Design Phase, change control is essential. If the customer wishes to change the requirements, the decision whether or not to honor the change must be made by the project leader and the group manager. Consideration must be given to the change's impact on cost and schedule; the greater the impact, the greater the cost to honor the change. The customer should be made aware of the impact and the cost. Some changes may be deferred until after production turnover. For those changes, care must be taken to evaluate each change thoroughly and move as far back through the life cycle as appropriate to adequately address the change. If requirements change, the requirements definition document must be revised. The Project Quality Plan must also be reviewed and revised accordingly.

Any customer requests for changes received after the customer has approved the system design should be treated as enhancements and postponed until after the project is completed.

\section{Tasks and Activities}

\section{Perform external design}

\section{Select hardware/software and facility requirements}

During this phase, the analyst must work out the details of the decision made during the Feasibility Study Phase concerning hardware options and combinations. For example, which mainframe will the system reside on-classified, unclassified, or VM? If a PC/host combination is selected, what parts of the system will reside on the PC and what parts will reside on the host?

In most cases, the system being designed will fit the existing environment. However, on occasion, the preferred design of the system may require new hardware or system software, such as special printing capabilities, or it may significantly increase the load on existing computer facilities, terminal network, or support staff. Such a situation may require a great deal of discussion and planning with CTM or End User Services.

A purchased system may also require specific computers, peripherals, or system software to support its operation. Making provisions for those requirements is part of the Design Phase for a purchased system.

Special facility requirements, such as network capacity, increased air conditioning capacity, or changes in the customer's physical facilities, should also be addressed. 
Software needs should be addressed as well. Several programming languages and software engineering technologies are available for use in ISE. The analyst should explore all options to ensure that the best tools are selected for the project. When selecting tools, the analyst needs to remember that ISE must continue to support the application after it is implemented. The ISE Standard Tool Set should be consulted when making these decisions.

Prototypes, models, CASE tools, or other techniques which assist the analyst can be used to complement program and database specification concepts. In some cases, these may be expanded to become the production system. Resources, required training, time constraints, and the size of the project need to be considered in determining whether the use of these techniques will be beneficial.

\section{Define online applications}

All screen layouts will be defined through a graphical representation of the screen. Even if the system has been purchased, some customization or additional options may be required for the Savannah River environment. All locally developed screens and functions, as well as their interfaces with the purchased system, must be defined. This definition includes a schematic of a screen hierarchy and description of all options on the screen. For example, "by pressing PF6 on the Main Menu, the user initiates the online search, and Screen REHOOOOA is displayed." Any special logic activated by a screen option must be described. Screens should be designed according to ISE guidelines.

Prototyping can be a very helpful tool in determining what the screens should look like and how they will interact. A prototype is especially helpful in communicating with the customer about the system. If prototyping was performed in the Requirements Definition Phase, the design effort can build upon that prototype.

Online printing should be described, with specific information on volume, location, and required special forms. The design of the online printed forms and reports should be completed, and examples should be provided.

Estimates of volume and number of users of this application are required. If online functions do not require real-time support, consideration should be given to handling them in batch mode. Hours of operation for the online applications must also be specified.

If new forms are required, arrangements should be made to have them printed by test time. Primary responsibility for the forms will be assumed by the customer liaison, with the help of the ISE project team. Discussions with the Forms Control group of Technical Information Services should be initiated as early as possible. Technical Information Services can provide guidance concerning the lead time required to design, print, and deliver the forms. Stores can stock these special forms.

\section{Define batch applications}

For systems that utilize batch processing, a narrative description and job step flowcharts for all batch jobs must be provided. A purchased system may require locally developed batch functions. These should be defined just as for any other system. The narrative 
should include run frequency (daily, weekly, monthly, yearly, or on-call), required completion time for batch networks, and delivery time for reports. Input deadlines should be set with consideration of time required for data entry. Discussions between the analyst, the CTM liaison (when appropriate), and the customer will be necessary to resolve scheduling questions.

For all print jobs, a report format, along with the volume, report frequency, number of copies, special forms requirements, delivery time, and recipients, must be provided. Appropriate notification regarding the completion status must be included for batch jobs with no specific output.

Batch jobs should be scheduled to minimize interruption of and file contention with online processing. Jobs must execute from object code and not perform time-consuming compiles and links each time they are executed. All mainframe production jobs must be executed from JCL and maintained by CTM. This practice ensures that production JCL will be kept up-to-date when system software changes occur on the mainframe.

\section{Define special processing logic}

The analyst must explain in detail special processing logic or complex algorithms for batch or online programs. For example, stock reorder logic in an inventory system, decay functions in a nuclear material accountability system, or invoice-matching logic for . an accounts payable system should be documented in detail for approval by the customer during review.

\section{Document external design}

Information defining the system's external design should be documented at this time for review by the ISE review team and by the customer. This documentation will ultimately be incorporated into the design document for the system.

\section{Conduct internal review of external design}

An internal review of the external Design Phase deliverables is required. The project leader and group manager should consider requesting participation by the following functional areas as appropriate for the project:

- customer liaison and other representative customers

- senior analyst(s) on the project

- CTM Database Administration group (for systems that will run on the Central Computer Facility)

- ISE Data Administration

The group manager or another project leader in the same group will chair the review. Depending on the size and complexity of the project, other personnel may also be asked 
to serve on the review team. This review team will review the deliverables with the project team to ensure clarity and completeness. The review team will also point out potential problems or oversights, and offer various suggestions to improve the deliverables. The team may make the following types of comments:

- mandatory changes-The review team will ask that the problems be corrected and the project team return for a follow-up review.

- recommendations-The review team will make recommendations for improving the system, but the final decision is left up to the project leader.

- suggestions-The review team will offer suggestions for the project team members to consider in future assignments.

The review team must approve the deliverables and record the results of the review on an ISE Technical Review form.

\section{Conduct customer review of external design}

A review of the external Design Phase deliverables with the customer is necessary. Formal approval across organizational lines must be obtained before the internal design begins. Fach recipient signs an individual sign-off sheet and returns it to the indicated address. If revisions to the external design deliverables are necessary, the deliverables must be resubmitted to the requester and other customers for review and approval.

Refer to the ISE Guide to Business and Technical Communication for samples of a transmittal document and a sign-off page for customer approval.

\section{Perform internal design}

\section{Develop file structures}

The design of all physical files must be based on the logical file structures created during the Requirements Definition Phase. All data elements must be named in conformance with ISE naming standards, and a definition for each must be provided in common business terms. For assistance with file design, see the ISE Data Administration Team, the ISE Applications Database Administrator (ADBA), and when applicable, the CTM Database Administration group. All database file designs must be approved by these groups prior to proceeding with the design process.

\section{Define tables}

Many systems utilize external table-driven logic. Rather than maintain embedded tables or hard coded values within the program itself, the programmer places the values in external tables. These values can then be adjusted by the customer independent of the programmer. Such tables must be defined. 


\section{Define backup and recovery and security mechanisms}

Backup and recovery for abnormal termination of online applications and batch jobs must be provided. The judicious use of data backup can minimize downtime and facilitate recovery. The approach may include archiving tape files or copying online files prior to key processing steps. The design must specify the facility the customer will use when the computer system is not available for an extended period of time (such as following a major disaster). The design must also specify procedures or programs for reinitializing the computer system once it is available again.

Security for all system functions must also be considered. Generally, only specific people will be allowed to update or even view certain data. Security considerations may cause the unbundling of an online function to allow certain data to be protected at a higher level. CTM procedures are sufficient in most cases for batch jobs. When appropriate, special security requirements should be discussed with the CTM liaison during the Design Phase.

\section{Define conversion mechanisms}

The analyst must design the required conversion mechanisms to establish the initial data or revise existing files to support the new or revised system. Purchased systems often require considerable effort for converting local files to the format supported by the new system. If computer programs are required for conversion, they should be designed at this time.

At a minimum, the following questions should be addressed.

- What must be done to establish the production files?

- What must the customers do to their existing manual files to prepare them for use with the new system?

- When will the conversion take place?

- Where is the data currently located?

- Has the data been validated?

- Is the data consistent? (The analyst must examine the data personally to determine consistency.)

\section{Define specific interface requirements}

Interface requirements identify the data which must be provided to or received from other systems or applications. Interfaces can be external to a totally separate system or internal to a subsystem. In either case, synchronization of the data must be planned.

A discussion with the data custodians and support personnel for other systems involved must be held for each interface. The analyst should fully understand the data to be trans- 
ferred from one system to another, including how the data will be used by the receiving system, how the data will be sent from the providing system, and what data protection considerations are required. Knowing which data is being transferred (media and format) is not sufficient; understanding the timing involved in capturing the data is essential. Another consideration with online interfaces is the physical location of the database files. For example, if all ADABAS files are not in the same database management system nucleus, problems can occur if concurrent updates are attempted (for more information, see the ADBA or CTM liaison).

Interfaces can be in batch or online mode. When the interface is in batch mode, backup copies for the transferred data should be maintained for a period, based on when the receiving system uses the data. Online interfaces require a great deal more planning. If the system being designed has files that are updated interactively by other systems, or vice versa, a great deal of coordination is required. The new system must include facilities to keep the cooperative systems synchronized.

Synchronization is also necessary when one system's data is used to validate another's data. If a new system uses an existing file to validate data, there must be a means to handle data items which become invalid in the existing file but are still needed to validate data in the new system.

When a system is purchased, interface requirements may be the largest item in the Design Phase. Considerable effort may be required to coordinate the new system with existing Savannah River systems. The analyst should design interfaces so that the system can access data from other applications (locally developed or purchased). The analyst should also consider other Savannah River applications which could benefit from the data created by the purchased system.

\section{Design audit trails}

Data custodians may want to know who or what program changed a piece of data, when it was changed, and what the change was. An audit trail can provide these answers and assist in data recovery. Even if the customer does not request audit trail mechanisms, the analyst should discuss their benefits and overhead costs with the customer.

When applicable, the ADBA and the CTM Database Administration group can provide the analyst with information on the availability of log data. Typical audit trails mechanisms provide for the storing of before and after images whenever a file is updated. The required information, retention time, and retrieval mechanism (standard report or ad hoc query) must be considered.

\section{Create program specifications}

The analyst should break the system down into logical modules and then into individual programs. Program specifications must be written for each program. The analyst can choose from many techniques to communicate these specifications (for example, HIPO charts, pseudocode, program flowcharts, etc.). The specifications should be sufficiently detailed so that programmers can write program code directly from them in the Construction and Customer Acceptance Phase. 


\section{Develop customer training strategy}

A curriculum must be developed for the customer with consideration given to the time required for the customer to complete it. Customers must often learn a new way of doing business as well as the new computer system. The analyst must assess the customer population's degree of comfort with computers. In most cases, customer involvement with computers will drastically increase after system implementation.

A basic curriculum could begin with a general orientation to mainframe, midrange, minicomputer, or PC use, and then progress to the specific application. The Scientific Computing Resource Center and IRM End User Services are good sources for information and training. Other sources are outside contractors and courses developed and presented by the project team. The customer liaison should assume the major responsibility for training design and, on large systerns, perhaps take complete responsibility for the training. Customer management customer management must be aware that training is entirely th : customer's responsibility after implementation.

\section{Develop test plan}

The test plar describes the approach to testing. The test plan should begin with module testing and progress through integration testing to the acceptance test. This plan should cover all design aspects, including conversion and interface requirements and directions for creating test data.

Test data may be captured from source documents or copied from production files. Test data should be created to test each specific case. Merely processing a volume of data through the system is not sufficient. Production files should not be used for testing.

The test plan should also specify how and by whom the test results will be shecked. Clistr mer participation in testing is vital. The ISE Quality Coordinator can provide assistance with the test plan.

\section{Count function points}

When the general design of the system has been completed, the system's function points should be counted again. This count should be used to measure growth of the system since the Requirements Phase, as well as to assist in revising cost estimates. The ISE Methods Development group can provide assistance in counting function points.

\section{Document internal design}

Information defining the system's internal design should be documented at this time for review by the ISE review team. This documentation will ultimately be incorporated into the design document for the system. 


\section{Conduct internal review of internal design}

An internal review of the internal Design Phase deliverables is required. The review is conducted by a panel and chaired by the group manager or another project leader in the same group. The project leader and group manager should consider requesting participation by the following functional areas as appropriate for the project (it is especially important for the members of the review team to be experienced technical professionals):

- group manager

- customer or customer liaison

- senior analyst

- senior programmer

- CTM Database Administration (for systems that will run on the Central Computer Facility)

- ISE Data Administration

The purpose of this internal review is to look for flaws, weaknesses, errors, and omissions in the design architecture for the new software before the design document is completed and before any code is written. The panel should first review the deliverables from the external design, and then focus on the internal design. The panel should verify that all requirements defined in the requirements document have been met, and should identify any internal design features that will affect the external design that the customer has already approved.

Conducting a review of the internal design prior to the preparation of the design document minimizes revisions to the document and allows early identification of problems so that time can be devoted to making the appropriate changes. Consequently, a higher quality system is designed without placing an unappropriate emphasis on preparation of the final design document.

The review team may make the following type of comments:

- mandatory changes-The review team will ask that the problems be corrected and the project team return for a follow-up review.

- recommendations-The review team will make recommendations for improving the system, but the final decision is left up to the project leader.

- suggestions-The review team will offer suggestions for the project team members to consider in future assignments.

The review team must approve the deliverables and record the results of the review on an ISE Technical Review form. 


\section{Complete design document}

The design document must be issued before proceeding to the next phase. It will be the input to the Construction and Customer Acceptance Phase. The project team is responsible for creating the design document.

The following outline is provided as a guideline for the design document. Sections can be added or omitted as necessary.

\section{- Transmittal documents}

The transmittal documents, under the signature of the ISE manager, request formal approval of the design document and are addressed to the customer organization manager and the Computer Protection Program Manager or his or her designate. A copy of the design document and other transmittal documents are sent to the manager of Internal Audit section, Internal Oversight Department, for information purposes.

- Sign-off pages

The sign-off sheets document the formal approval requested in the transmittal documents.

- Introduction

This section briefly describes the purpose and scope of the design document.

\section{- Description of the operating environment}

This section describes the computer facilities to be usad for the production operation of this system. What hardware (PC, 3081, VAX, terminals, printers, etc.), and software (languages, query tools, database management system, etc.) will be used?

\section{- Data definition}

This section lists all data elements, their definitions, and their validation criteria. ISE encourages the use of any CASE tools or other programming aids that may be helpful in developing data elements.

\section{- Online functions}

This section provides narratives that describe hierarchical diagrams for each online application, the specific logic for each available option on the screen, and layouts for all maps. Program specifications for all online programs must be included. 
- Batch functions

This section provides a narrative that describes each batch program. For each job, a job flowchart, run frequency, report layouts with volume estimates, backup and rerun information, files to be used, and other pertinent information about the jobs are included. Program specifications for all batch programs must also be included.

- Backup and recovery mechanisms

This section describes the mechanisms used by the system to back up and recover files, and it describes the processes to restart the system in the case of abnormal termination. Program specifications for all backup and recovery programs must also be included.

- Audit trails

This section describes the facilities to capture data file activity. Additional reports or online applications may provide audit data. Program specifications for all audit programs must be included. A representative of the Internal Auditing Section and Internal Oversight Department must approve these auditing provisions.

- Test plan

This section details the test plan to be utilized.

- Conversion plan

This section describes in detail the process necessary to convert from an existing system to the new system. The plan should list activities, responsible personnel and organizations, time estimates, data validation processes, and system parallel processing requirements. Program specifications for all conversion programs must be included.

\section{Conduct customer review of the design document}

A review of the design document with the customer is necessary. Formal approval across organizational lines must be obtained before the Construction and Customer Acceptance Phase begins. Each recipient signs an individual sign-off sheet and returns it to the indicated address. If revisions to the design document are necessary, the document must be resubmitted to the requester and other customers for review and approval.

In addition to being approved by the customer, the design document must also be approved by the Computer Protection Program Manager (CPPM) or his or her designate. 
Refer to the ISE Guide to Business and Technical Communication for samples of a transmittal document, a sign-off page for customer approval, and a Computer Protection Program Manager sign-off page.

\section{Update Project Quality Plan}

With the information gathered in this phase, the project leader should update the Project Quality Plan.

\section{Update project schedule}

The project leader should develop a detailed schedule for the Construction and Acceptance Phase. This schedule includes a list of milestones, all tasks and activities associated with each milestone, responsible personnel associated with each task and activity, and deadline dates for each entry.

\section{Update project folder}

A copy of each deliverable must be filed in the project folder, and the title and location of each deliverable must be documented in the index.

\section{Deliverables}

- ISE Technical Review form (for external Design Phase deliverables)

- customer sign-off memo(s) (for external Design Phase deliverables)

- design document

- ISE Technical Review form (for internal Design Phase deliverables)

- Computer Program Protection Manager sign-off memo (for design document)

- customer sign-off memo(s) (for design document)

- updated Project Quality Plan

- updated project schedule

- updated project folder 


\section{Constructing the System and Gaining Customer Acceptance}

\section{Objective}

To code, test, and document the computer system programs specified in the Design Phase.

\section{Tasks and Activities}

generate physical files and database structure

D develop in-house software

a install and test procured software and hardware

a prepare conversion software

a walk-through programs with pæers

a review programs with project leader

口 create test data

a perform program testing

a address discrepancies and concerns

a prepare user's guide

D prepare system manual

- train customers

a conduct internal review

a conduct customer view

a update project schedule

u update Project Quality Plan

a update project folder

\section{Deliverables}

a installed and tested software and hardware

a system test plan

a system test results

口 user's guide

] system manual

口 ISE Technical Review form(s) (for Construction Phase deliverables) 

a customer sign-off menio(s) (for Construction Phase deliverables)
口 updated project schedule
a updated Project Quality Plan
a updated project folder




\section{Constructing the System and Gaining Customer Acceptance}

This methodology describes a series of suggested tasks and deliverables that have proved helpful in many system development projects.

Depending on a particular project's scope and complexity, the platform on which it is developed, and the size and diversity of its user base, the responsible manager and project leader will select the appropriate tasks and deliverables for that project.

\section{Objective}

To code, test, and document the computer system programs specified in the Design Phase.

\section{Description}

The Project Quality Plan, prepared during the Project Initiation Phase and revised throughout the project life cycle, specifies required tasks and activities for the Construction and Customer Acceptance Phase.

In the Construction and Customer Acceptance Phase, a working system is developed to satisfy all requirements definition and design criteria. Any procured software or hardware is installed and tested during this phase. Source programs, data, and procedures are written in accordance with the design document. In addition, the test plan is executed and test results are documented. The customers are trained on their system, all documentation is completed, and the customer organization accepts the system as complying with the requirements definition document. 
The construction of a computer system should involve the coding, testing, and documenting of programs defined in the Design Phase. Ideally, there should not be any requested changes to the requirements. If changes are requested during this phase, the change should be treated as an enhancement and deferred until after the project is completed. Any modifications that are accepted must be scrutinized to ensure that changes will not negatively affect the construction efforts of the project team. As in the Design Phase, any requested changes must move as far back through the life cycle as appropriate to adequately address the change. Any changes to the requirements or design of the system requires a review and possible update of the project schedule and Project Quality Plan.

\section{Tasks and Activities}

\section{Generate physical files and database structure}

The project team, with the assistance of the DBA and ADBA, must establish the files and database structures specified in the Design Phase. Files must be established in the test environment for unit and system testing.

\section{Develop in-house software}

Using the program specifications assernbled in the Design Phase, the programmer(s) will write snurce code which satisfies the program specifications. The project leader assigns program development to project team members and advises them of estimated start and completion dates. Programming, screen and report layout, function key assignment, and naming convention guidelines that were established for the system should be followed.

\section{Install and test procured software and hardware}

The installation and testing of all procured software, hardware, and telecommunications equipment must be completed prior to the Implementation Phase. When the installation of the equipment or software is complete, the project leader must ensure that all customer personnel who will operate the equipment have been properly trained. All input/output procedures are tested to verify operating characteristics and efficiency of the hardware and software. If required, terminal and online security software and procedures should be activated during this step.

\section{Prepare conversion software}

The software for data conversion, whether procured or developed internally, is just as important as the application software itself. The conversion software will transform existing data into a format that can be processed by the newly developed system. Like the application software, the conversion software must conform to standards and guidelines, be tested by the programmer and customer, and be subject to a peer review. Formal system documentation is required for conversion programs only if they will be available for execution (re-conversion) after the computer system is implemented. 


\section{Walk-through programs with peers}

A review by the programmer and several knowledgeable colleagues is encouraged for each program. Participants should be selected by the project leader on the basis of expertise and knowledge of the system. These participants include the following:

- chairperson (group manager or project leader)-leads the review and records the proceedings

- presenter (analyst/programmer)-explains the project and its purpose

- reviewers (programmers) -analyze the information and pose questions to the presenter

A Walk-through is conducted to provide a forum for identifying problem areas and to:

- bring collective knowledge and experience to bear on the subject task

- produce better code faster

- be an instructive tool as well as to make the software development process more efficient

The system must follow standards and guidelines, display workable syntax and logic, and must be:

- understandable

- maintainable

- modifiable

The order of evaluation is as follows:

- requirements definition

- system/subsystem specifications

- hierarchy chart (including the purpose of each module)

- program specifications

- pseudocode (or other model)

A Walk-through Review is not performed to influence the design and implementation of programs or to rewrite specifications or code. The process described above is known as egoless programming. One method is not necessarily better than another. The objective is to create better code faster. 
Results of peer reviews are recorded on the ISE Technical Review form.

\section{Review programs with project leader}

All programs are subject to project leader review at any point in construction, production, utilization, and modification. This review will be a sampling determined by the project leader and will typically emphasize critical algorithms, manipulation of sensitive data, and key points in the program logic. The project leader's review ensures the program's adherence to requirements definition and design requirements.

\section{Create test data}

The project leader, with the help of the customer liaison, should identify valid data for unit and system testing. Test data should be built as specified in the Design Phase and should include error data as well as valid data. For individual program or unit testing, a sample of data is sufficient. If several programmers are testing with the same files, a block of test records should be assigned to each programmer. This practice will allow valid tests with reasonable results. The project leader must ensure the integrity of the test data and be certain it is available for scheduled unit, integration, and system testing.

\section{Perform program testing}

Testing is a critical component of software development and maintenance. As a result, the procedures must be consistent and based on sound principles. For development projects, the test plan is intended to define the expected output and test for valid, invalid, expected, and unexpected cases; the goal of testing is to find errors, not to prove that errors do not exist. The test plan should also define the degree and depth of testing to be performed and the disposition of test materials upon successful completion of the testing. For maintenance projects, the original test plans should be modified to include current changes. Afterwards, the procedures for development projects should be followed. In either case, the test procedures and test data need to be developed by a member of the project team (a member other than the person who performed the actual coding of the system).

There are three measurements in the test stage:

- Unit test

As a program is developed or maintained, the programmer should perform the preliminary unit test. This test verifies edits, calculations, and processing within the program.

- Integration test

The integration test is an extension of the unit test. The integration test includes several related programs and functions, and it tests the interaction and dependencies of the system. The integration test will verify the relationship with other programs and processes. The customer can be involved in the unit or integration testing of each module, once the 
programmer has tested the software and is satisfied that it adequately meets the design requirements.

After the programs have been tested and debugged, and the integration test has verified their processing with other programs in the system, the acceptance test can be scheduled.

- Acceptance test

When all unit and integration testing is complete, acceptance testing by the customer may begin. Customer participation in the acceptance testing ensures that system requirements have been met.

For the acceptance test, test files must be at 80 to 100 percent of their anticipated production size. The acceptance test should be done in an environment very much like the production environment in which the system will run.

Acceptance testing is the vital control of the development effort. It is the main technique for verifying that the system performs as intended and that system requirements have been met. The acceptance test will include the project leader, customer liaison, and other participants that the project leader designates. Some of the customers who will actually operate the system should also be included in this test. The acceptance test will follow the acceptance test plan outlined during the Design Phase. Results of the acceptance test must be documented in a Test Analysis report for inclusion in the project folder. Any questions or concerns regarding the acceptance test or the system itself must be resolved before customer acceptance is secured.

Since a cont nlled test environment is crucial to monitor results and verify data, x,o other testing should access the records or files involved in the acceptance test. $A$ predetermined set of records can be identified for non-system testing. Any other testing must be done outside of the scheduled acceptance test time to prevent contention for resources or faulty performance results. The project leader should schedule the acceptance test and coordinate the efforts of all using the file(s).

Once the customers agree that the system complies with the system requirements, the customer organization, with ISE and when appropriate CTM, should continue to assess the new system's impact on the operating system. This procedure involves testing the system with multiple customers and large quantities of data. The objective is to determine the response degradation with mass processing, restart procedures, recovery facilities, and system performance. This test should represent the worst-case situation to which the production system could be subjected. 
The ADBA should be involved in the acceptance test, and monitoring tools should be used to identify problem areas and define the results of the test.

\section{Address discrepancies and concerns}

Any discrepancies and concerns identified in the testing must be addressed before customer acceptance. Any changes to the system should be discouraged. The project leader must remember that changes can be deferred until after implementation if the change will not impact the system's operation. Consideration must be given to the type of change requested, the change's anticipated impact on the system, the time required to make the change, the ramifications (ripple effect) of the change, and the customer requirements for the change to be made prior to system acceptance and implementation. Care must be taken to evaluate each change request thoroughly and move as far back through the life cycle as appropriate to adequately address the change. Each change also requires a review and possible revision of the Project Quality Plan.

\section{Prepare user's guide}

The user's guide facilitates the customer's operation of the system. It serves as both a training and a reference document. As a module is coded and tested, the corresponding section of the user's guide should be completed. This documentation is given to the project leader, who will coordinate the efforts of all team members with the ISE Technical Writing Team. Using technical writers for documentation ensures consistency in the final product despite the fact that several people with different styles have contributed to the document.

The responsibility to develop the user's guide rests with the customer liaison and the analyst. During subsequent maintenance efforts, the customer liaison and the ISE analyst assigned are responsible for updating the document.

For existing systems with no current user documentation, the project leader and the group manager responsible for that project must decide whether or not effort should be spent to create a user's guide. The factors for making this decision vary from project to project. Advantages and disadvantages should be weighed to make the best decision regarding documentation and its value versus the cost of creating it.

The following outline provides a guideline for the user's guide. Sections can be added or omitted to efficiently co vey the system's function and operation.

\section{- Introduction}

This section provides the reader with a brief description of the system, its components, references to policies and procedures involved in its operation, and responsibilities for operating the system. 


\section{- System description}

This section outlines the computer system's different functions. A graphic depiction of the system as well as a brief outline of operating procedures can be included here.

\section{- Online processing}

This section describes the functions included in the online portion of the system. Screen layouts and instructions are included, as well as any software-generated error messages, with corresponding explanations and corrective actions.

\section{- Batch processing}

This section describes the functions included in the batch portion of the system. Each batch program is described in detail with regard to input, execution, output, and recovery.

\section{- File restoration}

This section is included only if facilities are available to restore data files after implementation. Specific instructions for restoration and any considerations for timing or subsequent file processing for restoration should be included.

\section{- Utilities}

This section includes instructions for externally-accessed utilities or systems. For example, if SPF is required for batch execution, a section on using SPF is included. If another system is required for verification or investigation, that information is added. This section does not tell the customer how to operate the system but provides information on where training and user's guides for that system can be obtained.

\section{- Table entries}

Computer systems often require the maintenance of tables for validation and extraction. This section includes a description of these tables and their use in the system. If an online query is not available for all table entries, a batch facility must allow review. Table entry processing or displays not included in the online or batch processing sections of the manual must be documented.

\section{- Customer access authorization}

This section provides instructions and identifies special requirements for accessing the computer system. When appropriate, a copy of the Request for Authorization form should be included to provide a sample for future customer requests to CTM. 


\section{Prepare system manual}

The system manual is the technical document used by the ISE analyst who supports, maintains, and evaluates future modifications to the computer system. The system manual should reflect the system design from the Requirements Definition and Design Phases of the project life cycle. As a module is completed, the corresponding portion of the system manual should be completed and given to the project leader. The project leader will coordinate the publication effort with the ISE Technical Writing Team.

The responsibility for developing the system manual rests with the ISE analysts who write the application system. The ISE analysts assigned to maintain the system are responsible for updating the system manual when revisions are required.

For existing systems with no current system manual, the project leader and the ISE manager responsible for that project must decide whether or not effort should be spent to create a system manual. The factors for making this decision vary from project to project. Advantages and disadvantages should be weighed to make the best dec sion regarding system documentation and its value versus the cost of creating it.

The following outline provides a guideline for the system manual. Sections can be added or omitted to efficiently convey the technical aspects of the system.

- Introduction

This section is a narrative of the entire system and its primary purpose and function. The narrative describes how the system fits into the organization's work flow. The ISE support analyst needs a basic understanding of the system's overall function and objective relative to the customer environment and business before making modifications to the system.

- File descriptions

This section presents all the main system databases and files. It also describes each file and its relationship to the jobs that update and use it.

- Job descriptions

This section describes the batch and online system jobs. The description details the functions performed; provides an overview of the internal processing, input and output, and interd. endence of each part on other portions of the system; and specifies the frequency of opera. tion. The validation criteria used in the jobs that handle input are also listed.

\section{- Program aescriptions}

This section explains the online and batch programs by function, including the program name, a brief description of program activity, 
files used or created in each program, fields updated, other programs called or fetched, and parameters passed between programs.

- Data conversion

Since questions regarding the data used by the system at startup often arise after system implementation, this section provides a brief description of how the data originally got into the system (manual input, data file conversion, etc.). If the capability exists to reconvert data after implementation, this information is also included here.

- System Interfaces

External systems affected by the input, processing, or output of the computer system need to be documented. This information is extremely important for future enhancements and modifications.

\section{- Program specifications}

Program specifications and file structures are used as an aid to understand the program by the maintenance programmer when enhancements and modifications are requested.

\section{- Program maintenance suggestions}

A good programmer will anticipate potential modifications and enhancements to the computer system. This section provides instructions which describe these suggestions to aid in revisions and speed up the maintenance process.

\section{- File restoration}

This section identifies all the potential error messages and the steps necessary to restart and back up the system. For each input error message, the system manual needs clear, concise instructions for correcting the input error.

\section{- Change control log}

The analyst who is assigned primary support responsibility for a computer system will establish and maintain a change control log to provide a historical record and audit trail of all system modifications. At a minimum, this log includes copies of the completed ISE Work Request form for every modification to the system, along with all supporting documentation needed to clarify the modifications. The ISE Work Request form has a block for the request number. It is the support analyst's responsibility to record work request numbers to provide an auditable log of changes made to the system. 


\section{Train customers}

When a module of the system is complete.and the corresponding user's guide section is in a readable draft form, the customer liaison and other customers responsible for training system users should be trained on that part of the system. The project leader will determine when a module is ready for training and will coordinate the training effort with the customer liaison. The customer liaison and/or project leader can contact the EUS Computer Education group to arrange transferring training from the customer organization to EUS if appropriate.

\section{Conduct internal reoiew}

An internal review of the Construction Phase deliverables is required. The project leader and group manager should consider requesting participation by the following functional areas as appropriate for the project:

- customer liaison and other representative customers

- senior analyst(s) on the project

- CTM Database Administration (for systems that will run on the Central Computer Facility)

- ISE Data Administration

The group manager or another project leader in the same group will chair the review. Depending on the size and complexity of the project, other personnel may also be asked to serve on the review team. This review team will review the deliverables with the project team to ensure clarity and completeness. The review team will also point out potential problems or oversights, and offer various suggestions to improve the deliverables. The team may make the following types of comments:

- mandatory changes-The review team will ask that the problems be corrected and the project team return for a follow-up review.

- re ommendations-The review team will make recommendations for improving the system, but the final decision is left up to the project leader.

- suggestions-The review team will offer suggestions for the project team members to consider in future assignments.

The review team must approve the deliverables and record the results of the review on an ISE Technical Review form.

\section{Conduct customer review}

A review of the Construction and Acceptance Phase deliverables with the custom $r$ is also necessary. Formal approval across organizational lines must be obtained before the 
Implementation Phase begins. Each recipient signs an individual sign-off sheet and returns it to the indicated address. If revisions to the deliverables are necessary, the deliverables must be resubmitted to the requester and other customers for review and approval.

Refer to the ISE Guide to Business and Technical Communication for samples of a transmittal document and a sign-off page for customer approval.

\section{Update project schedule}

The project leader should develop a detailed schedule for the Implementation Phase. This schedule includes a list of milestones, all tasks and activities associated with each milestone, responsible personnel associated with each task and activity, and deadline dates for each entry.

\section{Update Project Quality Plan}

With the information gathered in this phase, the project leader should update the Project Quality Plan.

\section{Update project folder}

A copy of each deliverable must be filed in the project folder, and the title and location of each deliverable must be documented in the index.

\section{Deliverables}

- installed and tested software and nardware

- system test plan

- system test results

- user's guide

- system manual

- ISE Technical Review form(s) (for Construction Phase deliverables)

- customer sign-off memo(s) (for Construction Phase deliverables)

- updated project schedule

- updated Project Quality Plan

- updated project folder 


\section{Implementing the System}

\section{Objective}

To install the completed system and transfer operational responsibility for the system to the customer.

\section{Tasks and Activities}

a develop implementation plan

review isoplementation plan

a confirm customer organizational changes

口 confirm completion of documeniation

a confirm installation of hardware

口 transfer training

ه contact Help Desk

a create production files

a implement conversion plan

Q install system

口 retire old system

count function points

a create support plan and support ISE Service Order

a conduct internal review

a conduct customer review

u update software inventory

口 write project closure letter

u update project schedule

口 update Project Quality Plan

u update project folder

\section{Deliveräbles}
a implementation plan
- production system
a support plan
a support ISE Service Onder
- ISE Technical Review form (for Implementation Phase deliverables)
project closure letter 
- customer sign-off memo (for project closure letter)

a updated project schedule

a updated Project Quality Plan.

口 updated project folder 


\section{Implementing the System}

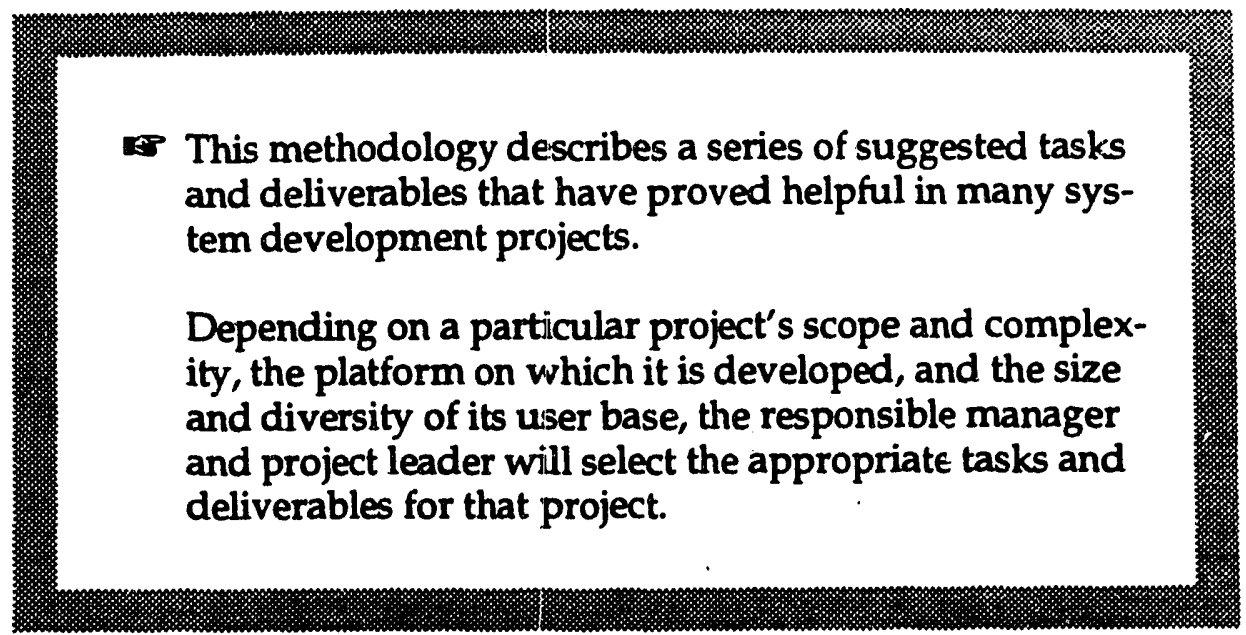

\section{Objective}

To install the completed system and effect a smooth transfer of responsibility for the system to the customer.

\section{Description}

The Project Quality Plan, prepared during the Project Initiation Phase and revised throughout the project life cycle, specifies required tasks and activities for the Implementation Phase.

During the Implementation Phase, ownership of the system is transferred to the customer. The major goals of this phase are to ensure that the system is in proper order for that transfer to take place, to effect the transfer itself, and to establish a mechanism for continuing support of the system. To that end, several tasks begun in previous phases (documentation, hardware installation, and training) are reviewed for completeness. The programs are moved to production status, and production files and databases are built. Finally, the system is reviewed with the group manager, and a support plan and a support ISE Service Order are created. 


\section{Tasks and Activities}

\section{Develop implementation plan}

Planning is very important to the implementation effort. Many of the tasks in this phase, such as file creation and data conversion, may not actually be performed by ISE personnel; the project leader is responsible for seeing that the tasks are performed on schedule and for coordinating the efforts of personnel across several organizations. Although implementation is a part of the overall project plan, a detailed implementation plan should be created at this time. The plan should list the specific tasks to be performed and the order in which they must be performed, deadlines, and the individuals responsible for each task. Much of the Implementation Phase is a scheduling effort.

\section{Review implementation plan}

The project leader and the team members review the tasks outlined in the implementation plan for accuracy, completeness, and consistency. Some of these tasks may include maps, tables, programs, etc. Once the plan is reviewed, the results are documented on an ISE Technical Review form. Then, the plan is filed in the project folder for future reference.

\section{Confirm customer organizational changes}

An assessment of required personnel changes was made by customer management during the Requirements Definition Phase. These changes should be completed and the affected personnel trained in their new duties prior to system turnover. The project leader should confirm with the customer liaison that the required personnel changes have taken place on schedule.

To ensure the succass of the system, ISE personnel must make the transition to the new system as smooth as possible. ISE personnel working closely with individuals within the customer organization(s) should encourage the customer personally and provide technical guidance. The attitude of those close to the system is often the deciding factor in a system's success or failure. On larger projects, ISE team members may be further removed from the end customer, but the team should take advantage of all customer contacts as an opportunity to present the system in a positive light.

\section{Confirm completion of documentation}

The system manual and the user's guide should be reviewed for completeness and accuracy. Special attention should be given to ensure that any changes made as a result of testing have been included in the manuals and that the documentation actually reflects the system being installed. The system manual will be the reference point for later maintenance and enhancements. The project leader should confirm with the ISE Technical Writing Team that the documents have been published and distributed. 


\section{Confirm installation of hardware}

Hardware installation and testing takes place during the Construction and Customer Acceptance Phase. However, it is important to confirm at this time that all necessary equipment is actually in place and completely operational, including any increased disk space or specialized equipment required to support the application. It is also necessary to confirm that facility or environmental preparations are complete.

\section{Transfer training}

Training of the customers or EUS Computer Education group personnel who will provide training for the system users occurs during the Construction and Customer Acceptance Phase. During the Implementation Phase, the project leader and/or the customer liaison confirms that training of the entire user base is progressing according to plans and that an appropriate number of employees in the customer organization or EUS are prepared to maintain the training effort in the future. The transfer of the training function to the customer or EUS frees ISE from the need to retrain customers as a result of employee turnover.

\section{Contact Help Desk}

The Help Desk personnel in EUS should be notified of the start-up date for any new system or major enhancement to an existing system. Early notification allows EUS personnel to adequately plan for the possible increase in support calls. If EUS is responsible for training the system's users, they will notify the Help Desk of the system start-up date.

\section{Create production files}

When appropriate, production files for the system can be created or modified by CTM. Information which defines the file characteristics, including space, usage, classiticatiun, protection level, and authorized personnel and their access levels must be provided to CTM.

\section{Implement conversion plan}

The conversion plan is documented as a part of the design document. Any necessary software is written and tested during the Construction and Customer Acceptance Phase. During the Implementation Phase, the plan is carried out under the coordination of the project leader. He or she coordinates the resources necessary to implement the plan. This task may include scheduling special conversion runs with CTM and scheduling personnel and hardware resources for the customer or CTM to complete massive data entry efforts.

Extreme care must be taken to verify data during conversion. Confirmation of file integrity should be given by ISE, the customer, and when appropriate CTM. The project should not continue until all organizations agree that the data is complete, accurate, and ready to use. 


\section{Install system}

Central Computer Facility programs must be installed in the production environment by CTM. The programs must be moved to the appropriate library and the New Program Information form or the Program Change Request form must be submitted to CTM. Prior to submission, these forms require approval and signature by an ISE group manager or authorized project leader. New programs must be accompanied by the Application Profile for online systems or the New Job Check-off Sheet for batch applications. These documents provide CTM the information needed to operate the jobs in the production environment. Forms can be found in dataset SYS1.USER.FORMS.

For VAX or personal computer systems, system installation is performed by one or more members of the project team.

All Central Computer Facility production turnover documentation and software change logs should reference the ISE Work Request number(s) which authorized the change. All changes to production systems must be traceable back to a Work Request.

\section{Retire old system}

When a new system is replacing an older system, the old programs and/or files can be retired once the new system is completely installed. The programs and files of high impact systems may require archiving to provide. a permanent record of the processing capabilities and a history of the system. The project leader consults with the customer and the ISE Quality Coordinator to determine archiving requirements. Contact the ISE clerical staff to have the status of the system changed from Production to Retired in the ISE Software Inventory.

\section{Count function points}

When the system is implemented, its function points should be counted again. This measurement should be used both to measure productivity and to identify changes to the original requirements. This count should also be used as the baseline count for any future enhancements or modifications. The ISE Methods Development Group can provide assistance in counting function points.

\section{Create support plan and support ISE Service Order}

Generally, while developing and testing a system, the project team identifies desired changes which are not implemented due to time or other constraints. These changes and a schedule for their implementation should be addressed in a support plan. A support ISE Service Order should be created to cover these efforts. The ISE Service Order is authorized on a fiscal year basis and specifies the estimated monthly support costs (consult the ISE clerks). 


\section{Conduct internal review}

An internal review of the Implementation Phase deliverables is required. The project leader and group manager should consider requesting participation by the following functional areas as appropriate for the project:

- customer liaison and other representative customers

- senior analyst(s) on the project

- CTM Database Administration (for systems that will run on the Central Computer Facility)

- ISE Data Administration

The group manager or another project leader in the same group will chair the review. Depending on the size and complexity of the project, other personnel may also be asked to serve on the review team. This review team will review the deliverables with the project team to ensure clarity and completeness. The review team will also point out potential problems or oversights, and offer various suggestions to improve the deliverables.

The team may make the following types of comments:

- mandatory changes-The review team will ask that the problems be corrected and the project team return for a follow-up review.

- recommendations-The review team will make recommendations for improving the system, but the final decision is left up to the project leader.

- suggestions-The review team will offer suggestions for the project team members to consider in future assignments.

The review team must approve the deliverables and record the results of the review on an ISE Technical Review form.

\section{Conduct customer review}

A review of the system is conducted for both the customer and ISE management. This review is primarily a marketing effort that emphasizes cost and timie savings, increased functionality, and fulfillment of the customer organizations' business goals. The presenter can draw heavily from the requirements definition document to demonstrate how the system has fulfilled the customer's goals. The support plan and support ISE Service Order, if any, should be presented for review and approval at this time.

\section{Update software inventory}

Contact the ISE clerical staff to change the status of the new system from Development to

Production in the ISE Software Inventory. 


\section{Write project closure letter}

The project closure letter is under the cover of the customer sign-off memo (for a sample memo, see the ISE Guide to Business and Technical Communication) and addressed to the customer and ISE management from the project leader. This letter should outline the major requirements met by the system and the benefits it provides. The letter should also indicate that the project is complete and that future changes or enhancements will be charged against the support ISE Service Order. If a support plan has been created, it should be referenced.

\section{Update project schedule}

The project leader should develop a detailed work schedule for the Evaluation and Review Phase. This schedule includes a list of milestones, all tasks and activities associated with each milestone, responsible personnel associated with each task and activity, and deadline dates for each entry.

\section{Update Project Quality Plan}

With the information gathered in this phase, the project leader should update the Project Quality Plan.

\section{Update project folder}

A copy of each deliverable must be filed in the project folder, and the title and location of each deliverable must be documented in the index.

\section{Deliverables}

- implementation plan

- production system

- support plan

- support ISE Service Order

- ISE Technical Review form (for Implementation Phase deliverables)

- project closure letter

- customer sign-off memo (for project closure letter)

- updated project schedule

- updated Project Quality Plan 
- updated project folder 


\section{Evaluating and Reviewing the System}

\section{Objective}

To evaluate the project's development process in order to gain knowledge which can be applied to future projects and to identify possible changes to the SDM; and to review the completed production system in order to identify benefits, problems, and improvement opportunities.

\section{Tasks and Activities}

conduct project evaluation

口 review SDM applicability

a review schedule adherence

a schedule post-implementation system review

a conduct post-implementation system review

口 interview customers

review requirements

review documentation

a review operating efficiency

review maintenance history

a identify problems or opportunities

a conduct customer review

complete project folder

\section{Deliverables}

a project evaluation report

Dost-implementation system review report

a completed project folder 


\section{Evaluating and Reviewing the System}

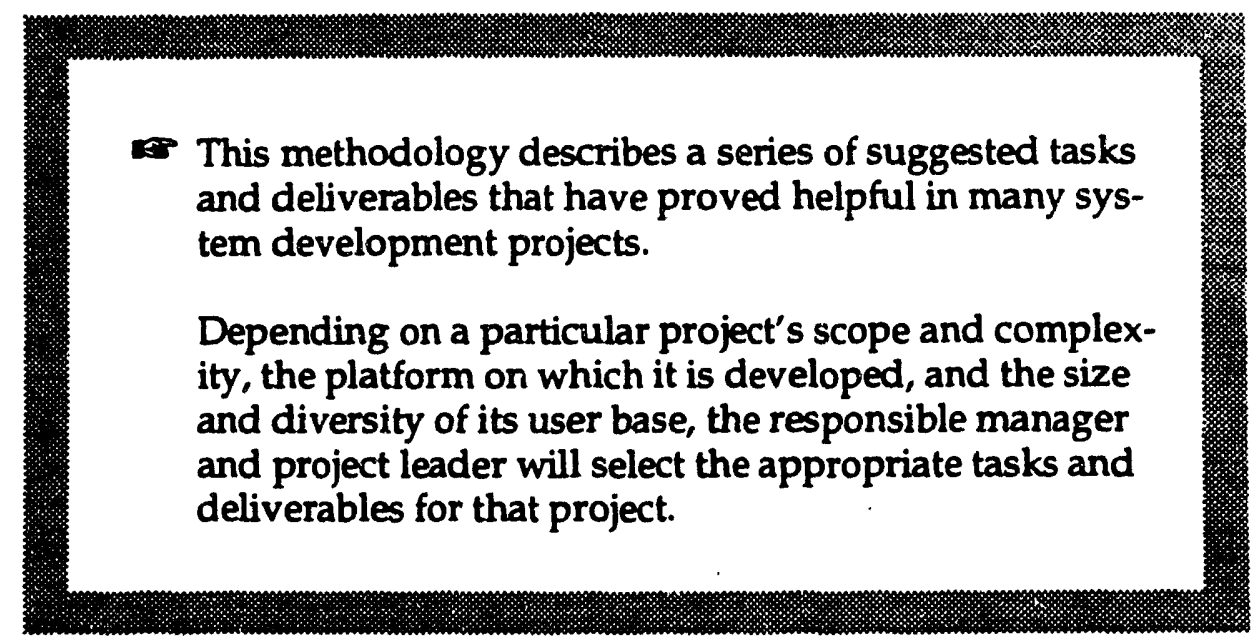

\section{Objective}

To evaluate the project's development process in order to gain knowledge which can be applied to future projects and identify possible changes to the SDM; to review the completed production system in order to identify benefits, problems, and improvement opportunities.

\section{Description}

The Project Quality Plan, prepared during the Project Initiation Phase and revised throughout the project life cycle, specifies required tasks and activities for the Evaluation and Review Phase.

The two functions of the Evaluation and Review Phase are separated by several months of time. The first function, the project evaluation, is designed to evaluate the completed project to determine how well the project followed the SDM, how the SDM might be improved, and how closely the system met its schedule estimates. The evaluation is intended as an opportunity to learn from experience and put that knowledge tc work in future projects. Two distinct results of the function are the improvement of estimating abilities and revision of the SDM to reflect more closely the actual processes involved in creating a quality system: 
The second function, the Post-implementation System Review, takes place some three to six months after system implementation (depending upon the system's cycle time). Its purpose is to review the system to see how closely it has adhered to its requirements and to identify and plan required changes and improvements.

\section{Tasks and Activities}

\section{Conduct project evaluation}

Immediately after project completion, the project team will meet to conduct the project evaluation.

\section{Review SDM applicability}

The SDM review is an opportunity to identify improvement opportunities for the SDM. The project team will discuss the usefulness of the methodology as customized in the Project Quality Plan. The team should be prepared to suggest alternatives to SDM sections or requirements which they feel do not contribute to the goal of a quality system. These suggestions will be documented in the project evaluation report and considered for changes to the SDM.

\section{Review schedule adherence}

The estimated project schedule should be compared to the actual schedule. In addition, an effort should be made to identify the causes of any discrepancies. This task allows more accurate future estimates to be made.

\section{Schedule post-implementation system review}

A Post-implementation System Review is required for all development projects and major enhancement projects. The review is scheduled as a part of the project evaluation step so that it is not forgotten in the press of other projects. The time lapse should be sufficient to allow each program (except yearly programs) to be run several times prior to evaluation.

\section{Conduct post-implementation system review}

The post-implementation review team should be led by the project leader and include the customer liaison, other customer personnel, and when appropriate the ADBA and CTM liaison. This review verifies that the system is meeting its requirements and identifies and plans needed changes or improvements. A list of suggested questions is included in Attachment 1, but this list should not be regarded as all-inclusive.

\section{Interview customers}

Customers of the system should be interviewed to determine their satisfaction with the system as well as with the development process. The emphasis should be on whether or 
not they regard the system as a useful tool to perform the organization's business. It is important to talk with customers in management and with those who actually use the system from day to day. Some users of the system may not be a part of the customer organization(s); these people should be interviewed as well.

\section{Review requirements}

The original system requirements definition document should be compared with the system as it was built. Does the system do what it was intended to do? If changes were made to the requirements, those changes should be reflected in the requirements definition document.

\section{Review documentation}

The review team should review all documentation associated with the system, especially the user's guide and system manual, for completeness and accuracy. If changes to the system have been made since implementation, the changes should be reflected in the documentation.

\section{Review operating efficiency}

Operating efficiency is a measure of how well the system meets its original technical requirements. CTM personnel are a good source of information concerning operating efficiency. Statistics such as response time and HELP line call logs should be examined. The CTM Database Administration group monitors new CCF applications for one month following production turnover.

\section{Review maintenance history}

The review team should examine ISE Work Request forms for the system to determine whether any programs have required excessive maintenance since implementation. Such programs are candidates for review and possible rewrite.

\section{Identify problems or opportunities}

The goal of the system review is to identify needed changes to the system or to the development process. These findings should be reported in the post-implementation system review report.

\section{Conduct customer review}

Findings of the post-implementation system review, both positive and negative, should be reviewed with both ISE and customer management. The goal is to identify strong and weak points of the system and provide a process to address problem areas. 


\section{Complete project folder}

When the project is complete, the final version of the Project Quality Plan is placed in the project folder with all documentation from the project. The project folder and all associated documentation is processed through the ISE Records Coordinator in accordance with the IRM Records Management procedure (for additional information, see IRM Procedure 1.04). A copy of the project folder should also be maintained by the group manager for future maintenance requests.

\section{Deliverables}

- project evaluation report

- post-implementation system review report

- completed project folder 


\section{Attachment 1: Post-implementation Review Questions}

1. What is the level of customer satisfaction with the system?

2. Have any problem areas or suggestions for significant changes been identified? If so, describe them.

3. Does the existing system meet the requirements of the original plan? If not:

- What requirements does it fail to meet?

- How can the situation be corrected?

- How have the requirements changed?

4. Did the original study properly define the scope of the system?

5. Was the scope properly followed during system development?

6. Were all of the benefits addressed in the original study realized? If not, explain.

7. Were any additional benefits realized?

8. Was the system developed according to schedule? Identify discrepancies and possible causes.

9. Was the customer training adequate and timely?

10. Is additional training necessary at this time?

11. In what category does each report fall: essential, useful, or unnecessary? (Unnecessary reports should be deleted.)

12. Are all reports legible and easily understood? If not, describe specific improvements needed.

13. Are all reports produced in a timely manner?

14. Are reports properly controlled (i. e., distribution/storage)?

15. In what category does each screen fall: essential, useful, or unnecesisary? (Unnecessary screens should be deleted.)

16. Are all screens legible and easily understood? If not, describe specific improvements needed.

17. Is system documentation complete, accurate, and up-to-date? If not, define specific problems. 
18. Is the user's guide understandable and helpful? If not, identify specific problems.

19. What is the status of suggested changes to the system?

20. What is the number of maintenance requests for the system?

21. What is the responsiveness of ISE staff to requests?

22. Are any problems delaying system maintenance? If so, what can be done to address them?

23. Have maintenance changes been reflected in the documentation?

24. Are any batch jobs or networks running longer than expected?

25. Is response time within acceptable limits? 
Maintaining the System 


\section{Maintaining the System}

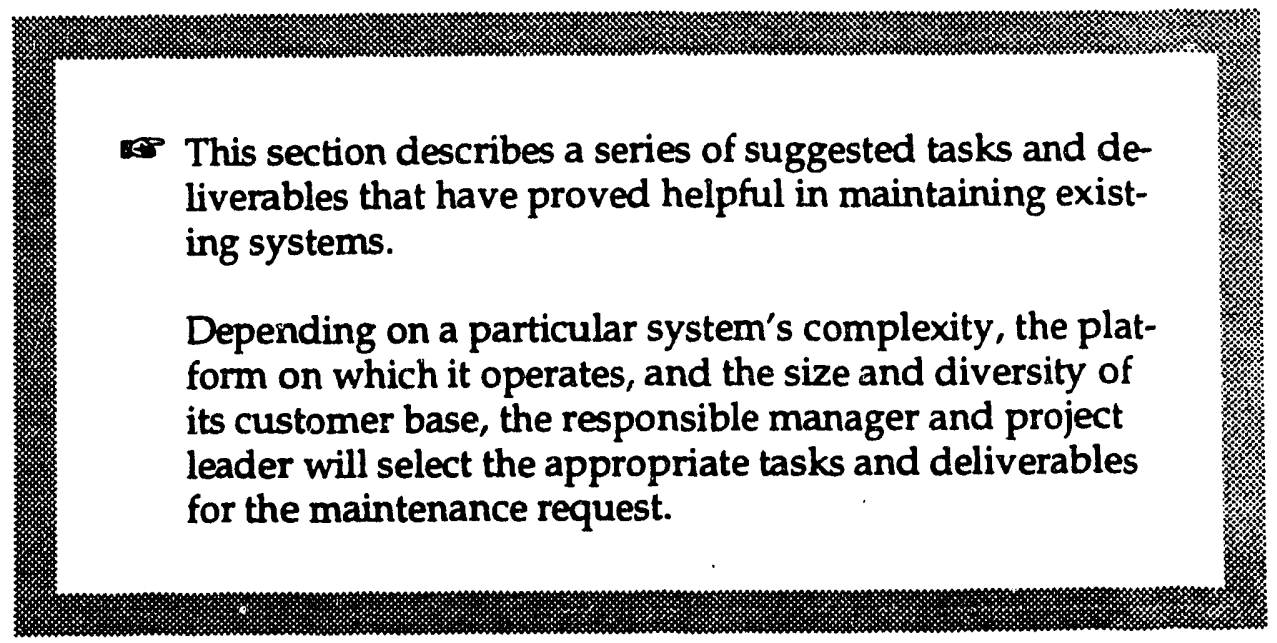

\section{Objective}

This section of the SDM is devoted to describing the ISE maintenance process. This process does not require the extensive documentation required for new development or major enhancements. However, quality is emphasized, while correct and expeditious response to maintenance requests is ensured.

\section{Description}

System maintenance is a series of tasks or activities performed to keep an existing system operating to meet the customer's requirements. System maintenance is subdivided into two major categories, emergency maintenance and scheduled maintenance.

\section{Emergency Maintenance}

Maintenance is classified as emergency when it must be performed under critical time constraints because any one of the following conditions exists:

- The problem adversely affects critical functions of other systems or applications. 
- The customer cannot perform normal functions.

- Production data is being corrupted.

- The system problem prevents regulatory requirements (DOE, EPA) from being met.

- Interfaces with other systems are interrupted, stopped, or contaminated.

\section{Scheduled Maintenance}

Any maintenance request that does not satisfy the requirements for emergency maintenance is considered scheduled maintenance. The four types of scheduled maintenance are defined below:

- Corrective-The program has defects (for example, the software does not perform according to its original specifications or customer requirements).

- Enhancement-The request for maintenance from the customer increases the functionality or changes the requirements.

- Ad hoc-The software resides (usually short term) in a nonproduction environment and has a limited customer base. Ad hoc requests report on production data but should never update production data. If the customer's request is ongoing or if the program has a wide customer base, the program should be placed in production.

- Adaptive-The software requires modifications to adapt to a new hardware/software environment.

\section{Tasks and Activities}

\section{Emergency Maintenance Process}

Described below is a series of suggested tasks and activities for emergency maintenance requests. The determination of which of these tasks and activities are to be performed for a particular emergency maintenance situation should be based on the analyst's knowledge of the system's maintenance history.

\section{Receive the request for work}

Establish the primary contact by documenting the reporter's name and telephone number, and the name and telephone number of a back-up employee. Gather as much information from the reporter as possible to determine the cause of the problem (for example, error codes, data, special runs, etc.). Determine the processor, security requirements, and data access procedures. This information is quite helpful to determine which support 
person has the proper access to correct the production problem. Ask the reporter to specifically define the criticality of the problem (that is, does the problem need to be fixed immediately, within a 24-hour period, by the end of the week, etc.).

\section{Define the problem}

This activity requires research and analysis, and follow-up on the information gathered from the reporter. Make sure that the input is resident in the system and the programs and hardware are functioning properly. Contact technical support and determine whether anything in the environment has been char:ged. Trace tlie history of the problem. First identify symptoms rather than causes; and from the symptoms identify possible causes. Review the data outpuit (for example, bad report, dump, analysis, etc). Make sure all components are functioning properly. Then, if possible, recreate the problem in the system with the reporter. If the probl m occurred during a production network run, determine whether or not to decrement the network to allow the other jobs to process. Document your findings.

\section{Measure the impact of the problem}

Determine whether the problem is an emergency based on the definition of emergency maintenance. If the problem is not an emergency, contact the reporter to let him/ her know that the problem will not be addressed immediately. (If the problem occurred during a production network run, let CTM or the appropriate system manager know whether or not to bypass the job(s) and continue running the network. Be certain that these instructions are clearly communicated.) If the problem is not an emergency, follow the Scheduled Maintenance process.

\section{Formulate a plan to correct the problem}

A plan should be formulated to correct the problem. Listed below (in no particular order) are some suggestions of tasks that can be included in the plan.

- Restore the file.

- Rerun the job.

- Correct the code and/or JCL.

- Correct and re-enter the data.

- Contact technical support for assistance.

- Ask the reporter to rekey the information online.

- Restart the network.

- Determine the solution's impact on the affected system as well as on other systems. 


\section{Acquire resources}

Identify and contact knowledgeable resources to assist in generating the solution to the problem. These resources may include the customer, technical support, I5E manager, senior programmer or analyst, ISE Data Administration, or CTM Database ididministration. Also, contact the reporter to inform him/her of the expected time required to solve the problem. This is not only good customer service, it informs the customer that you are addressing the problem.

\section{Disable the offender}

The offending function may need to be disabled. Inform the reporter and customers that the function must not be accessed for any reason. Consider sending out a message on the CCF console to alert users of the system. Listed below are some examples of disabling an offending function:

\begin{tabular}{|c|c|}
\hline 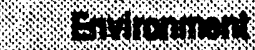 & witiplo \\
\hline NATURAL & $\begin{array}{l}\text { Uncatalog the program(s) and/or disable the } \\
\text { menu option }\end{array}$ \\
\hline CICS & Disable the CICS transaction \\
\hline VAX & Rename the program(s) \\
\hline Batch & Uncatalog and/or delete the comupt file \\
\hline
\end{tabular}

\section{Develop the test plan}

To validate the solution, make a list of necessary testing activities. These activities may include identifying the test data and the test cases. The expected results should also be identified. Consult with the customer to verify that the test plan is correct. Taking the time during an emergency to develop a good test plan helps ensure that the problem is corrected without causing other problems. Developing a test plan is of paramount importance when modifications are made to a program that updates a file or database. A test plan is very valuable when data fields are changed in one program and then the file or database is updated in a subsequent program or JCL utility.

\section{Solve the problem}

Until the new change control procedure is defined, make a copy of the original source code as a backup prior to making any source code changes. Copy the data and create test 
files, especially when changing a program that updates a file or database. Implement the plan to correct the problem by making the appropriate code or JCL changes.

At the conclusion of this step, be certain to refine the test plan to account for any new conditions introduced by the solution you have implemented.

\section{Test the solution}

Test the solution by executing the cases identified in the test plan. Include the user in testing when necessary. If the results do not match the predicted results, repeat preceding tasks or activities as appropriate.

\section{Move corrections to production}

Move the corrections tc production only if the solution has been tested and it solves the problem. Corrupted data in files or databases should be corrected and files/databases restored prior to restarting the production program.

\section{Perform follow-up}

As soon as possible after the emergency, complete the following tasks and activities:

- review code

- complete the appropriate documentation and file it in the project folder

- acquire approvals if necessary

- remove copies of source codes

- inform customer and other users if required

- initiate another work request if required to solve the root problem

Appropriate documentation for emergency maintenance may include but is not limited to the following:

- completion of the ISE Work Request form

- any informal documentation (notes, screen prints, sample erro: messages, flow diagrams, etc.) that includes pertinent information about the system

- identification of the changes that were made to correct the problem

- test plan as appropriate 
- identification of the affected programs, systems, applications, and personnel

- modifications if appropriate to the system manual, user's guide, production procedures, and desk procedures

- data dictionary changes

- software change control form and technical review form

\section{Scheduled Maintenance Process}

The scheduled maintenance procedure is similiar to the new development or major enhancement process described in Sections 2 through 8 of the ISE System Development Methodology Manual. The difference is in the level of documentation required (that is, no scope or requirements document may be required). If the system lacks adequate documentation, the ISE manager must determine the level of documentation needed as a result of the scheduled maintenance effort.

A PQP for each type of scheduiled maintenance with a list of suggested tasks and activities can be found in Attachments 1 through 4 on the following pages. The suggested activities are identified by phases for scheduled maintenance. These phases are the same . (Initiation, Requirements, etc.) as on the Project Quality Plan Checklist for development projects. Since the phases are the same, if more detailed information is needed, refer to the appropriate topic in the SDM.

Based on the definitions of the four types of scheduled maintenance, select the Corrective, Ad hoc, Adaptive, or Enhancement Scheduled Maintenance PQP. After consulting with the project leader or group manager, indicate on the PQP the activities that will be completed for this maintenance request.

Work outside the scope of the Project Quality Plans for corrective, enhancement, ad hoc, and adaptive maintenance on the following pages should be considered new development and should follow the Project Quality Plan found in Section 2 of this SDM. 


\section{Attachment 1: Scheduled Maintenance-Corrective Project Quality Plan Checklist}

\section{Scheduled Maintenance-Corrective Project Quality Plan Checklist}

ISE Work Request \#

Project

Page 1 of 4

This checklyst is used to designate the required tasks, activities, and deliverables for the above request.

Project Initiation Phase

Tasks and Activities

[ submit ISE Work Request

conduct initial analysis

a identify resources

口 prepare Corrective Project Quality Plan

口 identify ISE Service Order

口 set up and/or maintain project folder

口 review high impact software guidelines

Deliverables

ISE Work Request form

口 Project Quality Plan

Requirements Definition Phase

Tasks and Activities

a analyze current processes

a analyze desired processes

a analyze data

a analyze existing problems

a analyze current and projected volumes and frequencies 


\section{Scheduled Maintenance-Corrective Project Quality Plan Checklist}

ISE Work Request \#

Project

Page 2 of 4

a analyze desired interfaces

a assess impact on all organizations

write and verify ISE Work Request description of request

Deliverables

ISE Work Request description of request

\section{Design Phase}

\section{Tasks and Actioities}

a perform external design

a design online applications

口 design batch applications

design special processing logic

a perform internal design

口 redefine file structures/tables

a define/redefine specific interface requirements

a design audit trails

a create or modify program specifications

a develop customer trainin/z strategy

a develop test plan

\section{Deliverables}

Q informal write-up of tasks and activities

0 test plan 


\section{Scheduled Maintenance-Corrective Project Quality Plan Checklist}

ISE Work Request \#

Project

Page 3 of 4

Construction and Customer Acceptance Phase

Tasks and Activities

- generate physical files/tables and database structure

a develop in-house software

walk-through programs with peers

c create/identify test data

口 perform program testing

update user's guide

u update system manual

a train customers

\section{Deliderables}

u updated user's guide

a updated system manual

口 ISE Technical Review form

\section{Implementation Phase}

Tasks and Actioities

a develop implementation plan

口 - move to production

contact customers

Deliverables

a implementation plan 
Rev. 0, 2/17/92

ISE System Development Methodology Manual

WSRC-IM-91-4

Scheduled Maintenance-Corrective Project Quality Plan Checklist

ISE Work Request *

Project

Page 4 of 4

Evaluation and Review Phase

Tasks and Activities

- review operating efficiency

update project folder (including customer sign-off)

Deliverables

updated project folder with ISE Work Request and attachments

Maintaining the System

$9-10$ 


\section{Attachment 2: Scheduled Maintenance-Enhancement Project Quality Plan Checklist}

\section{Scheduled Maintenance-Enhancement Project Quality Plan Checklist}

\section{ISE Work Request \#}

Project

Page 1 of 4

This checklist is used to designate the required tasks, activities, and deliverables for the above request.

\section{Project Initiation Phase}

Tasks and Activities

a submit ISE Work Request

a conduct initial analysis

a conduct steering committee review

a identify resources

[ prepare Enhancement Project Quality Plan

a identify ISE Service Order

a set up and/or maintain project folder

a review high impact software guidelines

\section{Deliverables}

ISE Work Request form

口 Project Quality Plan

\section{Requirements Definition Phase}

\section{Tasks and Activities}

a analyze current processes

a analyze desired processes

analyze data

a analyze current and projected volumes and frequencies 


\section{Scheduled Maintenance-Enhancement Project Quality Plan Checklist}

ISE Work Request *

Project

Page 2 of 4

a analyze custodianship and security requirements

a analyze desired interfaces

a assess impact on all organizations

口 write and verify the ISE Work Request description of request

\section{Delioerables}

ISE Work Request description of request

\section{Feasibility Study Phase}

Tasks and Activities

a analyze benefits and costs

Deliverables

a benefits and costs statement

\section{Design Phase}

\section{Tasks and Activities}

ㅁ. perform external design

口 design online applications

a design batch applications

口. design special processing logic

- perform internal design

口 redefine file structures/tables

define/redefine backup and recovery and security mechanisms

- define/redefine specific interface requirements 


\section{Scheduled Maintenance-Enhancement Project Quality Plan Checklist}

ISE Work Request \#

Project

Page 3 of 4

口 design audit trails

a create program specifications

ㅁ develop customer training strategy

a develop test plan

\section{Deliverables}

a informal write-up of tasks and activities test plan

\section{Construction and Customer Acceptance Phase}

\section{Tasks and Activities}

- generate physical files/tables and database structure

a develop in-house software

walk-through programs with peers

c create/identify test data

口 perform program testing

u update user's guide

u update system manual

a train customers

\section{Deliverables}

updated user's guide

u updated system manual

a ISE Technical Review form 


\section{Scheduled Maintenance-Enhancement Project Quality Plan Checklist}

ISE Work Request \#

Project

Page 4 of 4

Implementation Phase

Tasks and Activities

口 develop implementation plan

a move to production

a contact customers

count function points

Deliverables

a implementation plan

Evaluation and Review Phase

Tasks and Actioities

review schedule adherence

0 review operating efficiency

u update project folder (including customer sign-off)

Deliverables

u updated project folder with ISE Work Request and attachments 


\section{Attachment 3: Scheduled Maintenance-Ad hoc Project Quality Plan Checklist}

\section{Scheduled Maintenance-Ad hoc Project Quality Plan Checklist}

ISE Work Request \#

Project

Page 1 of 3

This checklist is used to designate the required tasks, activities, and deliverables for the above request.

\section{Project Initiation Phase}

Tasks and Actioities

a submit ISE Work Request

口 conduct initial analysis

口 conduct steering committee review

a identify resources

口 prepare Ad hoc Project Quality Plan

$\square \quad$ identify ISE Service Order

a set up and/or maintain project folder

口 review high impact software guidelines

\section{Deliverables}

ISE Work Request form

口 Project Quality Plan

\section{Requirements Definition Phase}

\section{Tasks and Activities}

analyze current processes

analyze desired processes

a analyze data

w write and verify ISE Work Request description of request 


\section{Scheduled Maintenance-Ad hoc \\ Project Quality Plan Checklist}

ISE Work Request \#

Project

Page 2 of 3

Deliverables

ISE Work Request description of request

Design Phase

Tasks and Activities

p perform external design

Q design online applications

口 design batch applications

a design special processing logic

a. perform internal design

a design audit trails

a create program specifications

a develop customer training strategy

a develop test plan

\section{Deliverables}

informal write-up of tasks and activities

a test plan

\section{Construction and Customer Acceptance Phase}
- Tasks and Actioities
a develop in-house software
a create/identify test data
a perform program testing 


\section{Scheduled Maintenance-Ad hoc Project Quality Plan Checklist}

ISE Work Request \#

Project

Page 3 of 3

train customers

Implementation Phase

Tasks and Actioities

a develop implementation plan

a contact customers

Deliverables

口 implementation plan

Evaluation and Review Phase

Tasks and Activities

u update project folder (including customer sign-off)

Delioerables

u updated project folder with ISE Work Request and attachments 


\section{Attachment 4: Scheduled Maintenance-Adaptive Project Quality Plan Checklist}

\section{Scheduled Maintenance-Adaptive Project Quality Plan Checklist}

ISE Work Request \#

Project

Page 1 of 4

This checklist is used to designate the required tasks, activities, and deliverables for the above request.

\section{Project Initiation Phase}

Tasks and Activities

- submit ISE Work Request

ㅁ conduct initial analysis

a conduct steering committee review

a identify resources

a prepare Adaptive Project Quality Plan

口 identify ISE Service Order

- set up/maintain project folder

review high impact software guidelines

\section{Deliverables}

ISE Work Request form

口 Project Quality Plan

\section{Requirements Definition Phase}

- Tasks and Activities

a analyze current processes

a analyze desired processes

a analyze data

a analyze conversion requirements 


\section{Scheduled Maintenance-Adaptive Project Quality Plan Checklist}

ISE Work Request \#

Project

analyze current and projected volumes and frequencies

analyze desired interfaces

[ assess impact on all organizations

a analyze backup and recovery requirements

a write and verify the ISE Work Request description of request

\section{Deliverables}

口 ISE Work Request description of request

\section{Feasibility Study Phase}

\section{Tasks and Actioities}

a categorize requirements based on effort and cost considerations

r. review and reprioritize requirements with customer organization(s)

a consider external issues that will influence the maintenance project

a explore alternative system development solutions

analyze benefits and costs

口 prepare feasibility statement

\section{Deliverables}

feasibility statement

\section{Design Phase}

\section{Tasks and Activities}

a perform external design

a select hardware/software and facility requirements 


\section{Scheduled Maintenance-Adaptive Project Quality Plan Checklist}

ISE Work Request *

Project

Page 3 of 4

口 perform internal design

口 redefine file structures/tables

口 define/redefine backup and recovery and security mechanisms

a define/redefine specific conversion mechanisms

- define/redefine specific interface requirements

a design audit trails

a create program specifications

口 develop customer training strategy

口 develop test plan

Delioerables

test plan

[ informal write-up of tasks and deliverables

Construction and Customer Acceptance Phase

Tasiks and Activities

generate physical files/tables and database structure

[1 develop in-house software

install and test procured software and hardware

- prepare conversion software

a walk-through programs with peers

a create/identify test data

a perform program testing 


\section{Scheduled Maintenance-Adaptive Project Quality Plan Checklist}

ISE Work Request \#

Project

Page 4 of 4

u update user's guide

口 update system manual

a train customers

Deliverables

u updated user's guide

u updated system manual

口 ISE Technical Review form

Implementation Phase

Tasks and Activities

- develop implementation plan

a confirm installation of hardware

u update production files/tables

․ retire old system

a contact customers

Deliverables

a implementation plan

\section{Evaluation and Review Phase}

- Tasks and Actioities

a review operating efficiency

u update project folder 
Reviewing and Evaluating the SDM 


\section{Reviewing and Evaluating the SDM}

The ISE System Development Methodology Manual is a living document that provides ISE personnel with direction, organization, consistency, and improved communication when developing and maintaining computer systems. As such, it is constantly being reviewed and evaluated so that it may continue to provide quality guidance.

Any ISE employee may suggest changes to the SDM. These suggestions are reviewed and evaluated by the SDM Review Team, and those that are recommended for inclusion in the SDM are subject to approval by the ISE Level 3 Manager.

\section{Nomination Process}

A change to the SDM may be formally evaluated only after it has been submitted by an ISE employee. To suggest a change, the employee fills out an ISE Procedure/Manual Revision Request form (see Attachment 1) describing the change, and gives it to the ISE Procedures Coordinator. The Procedures Coordinator logs the request and forwards it to the SDM Review Team. (Copies of the ISE Procedure/Manual Revision Request form can be obtained from the ISE clerical staff.)

\section{Review Process}

The SDM Review Team is a standing committee in ISE. It consists of the SDM Custodian, appointed by the ISE Level 3 Manager, who serves as team leader; one representative of each group within ISE appointed by the corresponding group manager; one ISE Level 4 manager designated by the ISE Level 3 Manager; and one member of the ISE Technical Writing Team assigned to work with the SDM Review Team.

Each team member will serve a minimum of a one-year term, with one third of the members rotating off the team every six months. ISE employees interested in serving on the team should consult their managers.

When an ISE employee submits a Procedure/Manual Revision Request form suggesting a change to the SDM, the team conducts a review of the request to determine whether and when the change should be made. Review meetings will be conducted once a quarter, or more frequently if the volume or magnitude of suggested revisions requires. 
The SDM Custodian presents each revision request to the team for consideration. If necessary, the custodian will invite the person who submitted the revision request to attend the review to answer questions regarding his or her suggestion.

The review team will discuss each request and reach consensus as to whether the suggestion will be accepted. The SDM Custodian will notify the requester regarding the disposition of the suggested change.

\section{Approval Process}

Once the SDM Review Team has approved one or more conceptual changes to be made to the SDM, the Technical Writing Team representative on the team writes a revised draft of all sections affected by the approved change(s). The draft is circulated among the members of the team for review and approval. All members of the team must approve the draft before it can be published.

When approval has been obtained from all members of the SDM Review Team, the revised draft is submitted to the ISE Level 3 Manager for approval.

After the Level 3 Manager's approval has been obtained, the revisions are published. A cover memo highlighting the changes is attached to copies of the new revision of the SDM. Training on the changed portions of the SDM will also be developed and conducted if required. 


\section{Attachment 1: ISE Procedure/Manual Revision Request Form}

1111700

ISE Procedure/Manual Revision Request

To: G. F. Hayhoe, I8E Procedures Coordinator

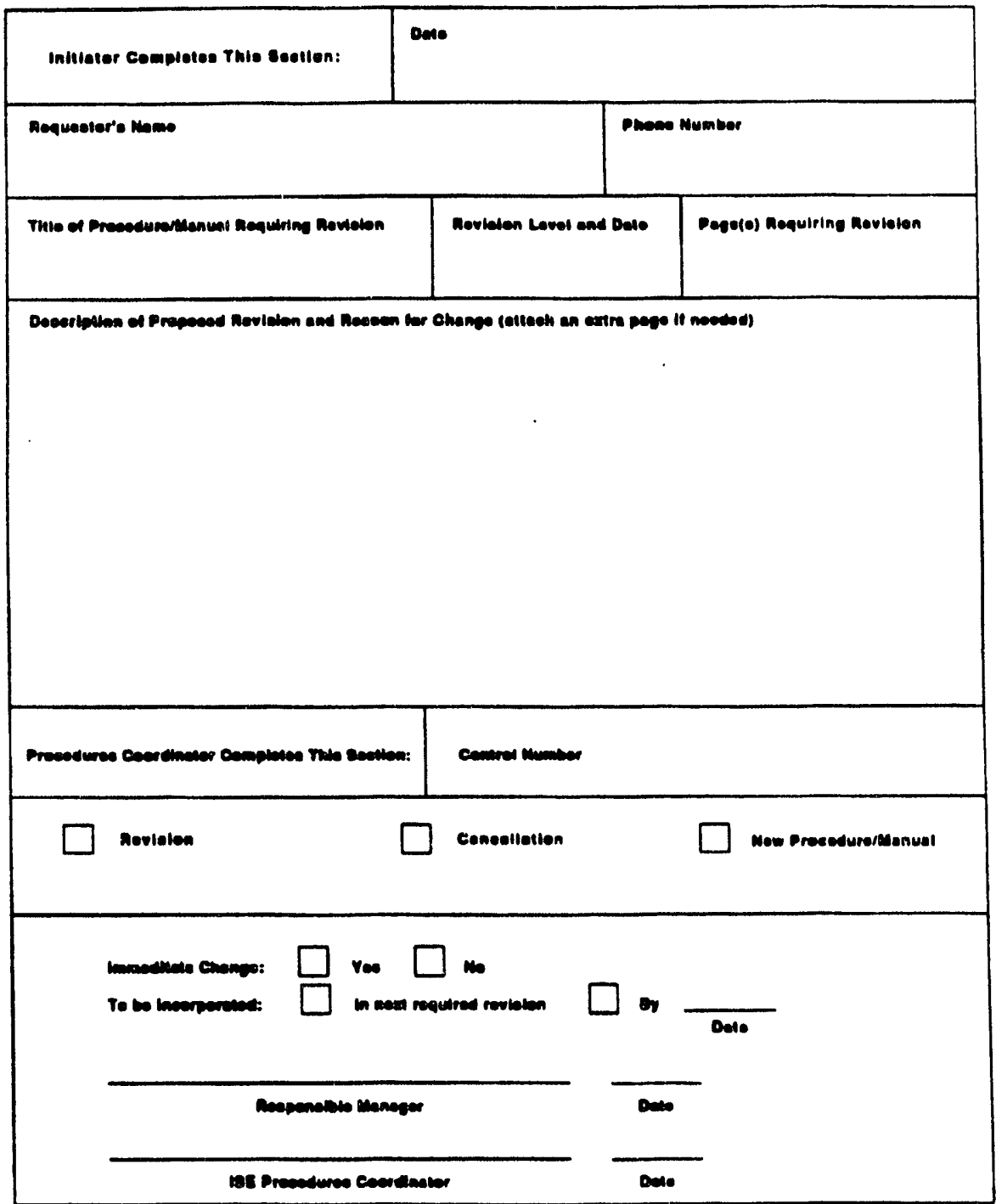


Glossary 


\section{Glossary}

Analyst

The ISE professional who evaluates the current system and designs the new system. This task includes design of the system, programs, inputs, outputs, and processing requirements.

The analyst:

- studies and documents the current business from a business perspective as well as a data processing perspective

- defines requirements for the new system (i. e., with customer liaison assistance)

- produces the system design

- assists the project leader in the development of a project schedule

- identifies and evaluates alternative solutions during the Feasibility Study Phase

- identifies the hardware configuration and processing requirements

- evaluates the ability of existing software packages to meet the system and business requirements

- participates in requirements and design reviews as required by the $S D M$

- ensures that appropriate user and system documentation is completed

- develops a comprehensive test plan

- develops user training with the help of the customer liaison 
Applications Database Administrator (ADBA)

Audit trail

Auditor

Business activity

Business area

Code review
The ISE professional who provides a central point of information for ISE personnel developing CCF applications. He or she serves as liaison between ISE and the CTM Database Administration group, providing information on system changes and problems, new products, new releases of system software, and other software or hardware questions requiring CTM assistance, especially those having to do with NATURAL and ADABAS.

The ADBA:

- assists in maintaining file design and coding standards

- assists in file design and code reviews for efficiency in data retrieval and storage

- monitors online response and batch resource usage, and reports these to project leaders

A series of designed provisions or capabilities which permit a person to follow and verify the system process.

A representative from the Internal Audit section, Internal Oversight Departiment, who may review all requirements definition and design documents.

The auditor:

- ensures that audit trails are provided by the new system

- ensures that checks and balances exist in the new system to identify processing errors

- ensures that proper data and system security has been considered and implemented

A procedure or series of steps to be followed in performing a single task.

A logically related series of activities which, taken together, fulfills a major business need involving the interaction of multiple functional units.

A scheduled review of program code with the author of the code and two or three peers in ISE. These peers should be selected on the basis of application and technical knowledge. The intent of the review is to share ideas, improve techniques, verify documentation, and ensure that guidelines are followed. 


\section{Computer Protection Program Manager (CPPM)}

\section{CTM liaison}

\section{CTM manager}

Customer liaison
The person in the Security section, Safeguards and Security Department, who is responsible for reviewing all requirements definition and design documents.

\section{The CPPM:}

- ensures that necessary backup and recovery procedures are in place

- ensures that data and system security requirements are met

The person from CTM assigned to the development team to ensure that CTM support for the system is available when needed and to coordinate and facilitate the development process from CTM's perspective.

The CTM liaison:

- assists in defining the customer's equipment and/or telecommunications needs

- ensures the timely installation of hardware and/or telecommunications equipment

- determines the performance of the proposed system by using modeling techniques

- determines the impact of the proposed system on the CCF

- plans CCF resources needed to accommodate the new system and ensures that CTM is able to maintain them

The CTM section manager who works with other management involved in the project in solving major issues relative to CTM. The CTM manager should be kept informed by the CTM liaison.

\section{The CTM manager:}

- provides personnel from CTM to assist with the project

- ensures the availability of hardware and other Central Computer Facility (CCF) resources as needed

Representative of the customer organization responsible for the coinpletion of the project from the customer perspective. The customer liaison is sometimes called the project liaison. He or she is the central point of contact 


\section{Customer manager}

between the customer and the ISE project team. In a project which spans several organizations, one customer liaison, who is a stakeholder in the project, must be selected to represent the interests of all organizations.

The customer liaison:

- makes most decisions concerning the system or project for the organization(s) being represented

- actively participates in defining the project, determining project scope, determining functionality, defining data, and defining the business

- accepts ultimate responsibility for the functional aspects of the system which is implemented

- administers the system after it is implemented and accepted

- coordinates, schedules, and arranges for personnel to deliver customer training

- helps develop the user's guide

Generally the manager of the requesting organization. However, if the project spans several organizations, the customer manager will be a person agreed upon by the various organizations' managers. He or she is not generally involved in the day-to-day decisions but makes the ultimate decision, especially when there is a point of disagreement. Normally, the customer manager is in contact with the responsible ISE group manager or project leader and attends the management review meetings.

The customer manager:

- initiates the ISE Work Request form

- provides necessary funding to support the system development or maintenance effort

- makes ultimate decisions concerning the organization he or she represents

- attends project review meetings

- assigns personinel from his or her organization to work on the project 


\section{Data flow diagram}

\section{Data model}

\section{End customer}

\section{Function points}

\section{Hardware \\ Information engineering approach}

\section{Integration testing}

Intemal review

ISE Data Administration
- provides ultimate approval of the implemented system

Graphical representation of the sources and destinations of data, the activities that transform the data, and the places where that data is stored.

A logical representation of a collection of data entities and the associations among those entities. The models represent the inherent properties of the data, independent of their physical environment.

A person who actually uses the current system or will use the new system.

The end customer:

- provides information on the current system

- provides input about the new system

- participates in system testing

- assists in developing and reviewing the user's guide

Function points are a means of quantifying the functionality provided by software, based primarily on logical design. A program is rated as having a certain number of function points based on the specific, countable functionality it provides to the user. Only user-requested, visible components are counted.

Physical equipment used in data processing, such as computers, terminal controllers, terminals, printers, etc.

A methodology which applies engineering discipline to developing integrated information systems. Each stage involves data and activities, with a strong emphasis on the importance of data.

Testing of a group of related programs and functions to test the interaction and dependency between programs in the system.

A review of tasks and deliverables by a group of ISE personnel and, in some cases, personnel outside ISE.

The ISE professionals responsible for coordinating information needs within and across systems and implementing information engineering through the use of data 
dictionaries, data modeling, data flow diagramming, and other data management tools and techniques.

ISE Data Administration:

- trains ISE personnel in the use of data management tools and techniques

- reviews dictionary input, data models, and data flow diagrams with the project team to ensure accuracy and consistency

- establishes and maintains the collection of definitions of Savannah River data items and user views in the master dictionary

- maintains and controls the master dictionary

- advises the project team conceming data availability and its logical structure

- maintains an overview of future needs and applications so that databases can evolve appropriately

- defines rules and functions to ensure data validity, consistency, and accuracy

- assists in determining the appropriate level of security protection for all data items and records

- ensures consistency among logical database designs based on information provided by the project team

ISE group manager

The ISE group manager responsible for the group developing or maintaining the system. He or she communicates with other management involved in the project throughout the project life cycle. The ISE group manager is concerned with determining priorities among projects and with providing adequate staff and other resources to complete each project.

The ISE group manager:

- works with the project leader to ensure that proper staffing is maintained for each project

- attends project review meetings

- reviews and approves the PQP 
ISE Quality Coordinator

ISE Seroice Order

Joint Application Design

(JAD)

Life-cycle approach

Logical design

Module

Physical design

Programmer
- enforces compliance with the SDM and the PQP

- meets periodically with the project leader to discuss progress

- ensures that the project team appropriately and adequately represents all affected organizations

The ISE Quality Coordinator:

- coordinates revisions to the SDM, including those resulting from project evaluations, site Quality Assurance requirements, and new techniques

- aids the project team in understanding and applying the SDM

- assists with the project evaluation after project completion

- assists with the post-implementation system review team

An authorization by the customer to charge that organization for work done by ISE.

A strategy for rapid analysis or design in which customers and data processing professionals participate in thorough, well-structured group sessions led by a facilitator.

A comprehensive process beginning with the definition of a problem and including all the subsequent development and implementation activities through final review and evaluation of the new system.

A business-oriented description of a system and its input, processing, and output requirements.

A unit within a system which addresses a particular function; a subsystem.

A technical, data processing description of hardware, software, and database (or file) organization requirements.

The ISE professional who constructs the software for the project based on the program specifications and tests the individual programs. 
Program flowchart

Project folder

Project leader
The programmer:

- programs and tests system programs

- assists in developing the test plan

- participates in design reviews as required by the SDM

- assists in completion of the user's guide and system manual

- assists in the development of the customer training program

A series of symbols and connections drawn to indicate the flow and requirements of processing for a particular program. The actual code can be constructed from this flowchart.

A file (paper or electronic) in which project deliverables are stored. Each group's project folders are stored in a central location. The first item in the project folder is an index specifying the order in which the contents are arranged. All deliverables selected $n$ the TOP should be stored in the project folder. Maintenance project folders contain ISE Work Requests with all accompanying documentation filed in ISE Work Request number sequence by system or application. Maintenance project folders also contain an index.

The ISE proiessional responsible for leading the project, seeing that requirements are met, planning and scheduling the project, specifying staffing requirements, and developing a Project Quality Plan for the project. The project leader is also responsible for ensuring that all deliverables are completed for each project phase and for scheduling the required reviews. On smaller systems and projects, there may not be an officially designated project leader. In this SDM., however, the term project leader is used to designate the person :esponsible for the project, even if there is oniy one person on the team.

The project leader:

- ensures that the project is defined with measurable and verifiable objectives

- develops the PQP

- ensures that the project scope is properly defined 
Project Quality Plan (PQP)

\section{Prototype}

Software

Steering committee

Structured walk-through
- conducts management reviews

- establishes and maintains the documentation in the project folder

- establishes controls and procedures for the development life cycle, such as status reports, intermediate milestones, review meetings, technical reviews, and change control procedures after completion of the project design

- ensures that the system and project appropriately and adequately interact with other systems and projects where data sharing and system integration are needed

- ensures that the SDM and the Project Quality Plan are followed

- notifies other organizations (customer, CTM, etc.) of the project's progress and schedules meetings to coordinate their efforts as required

- ensures that the documentation required in each life-cycle phase is completed and distributed to the appropriate personnel and expedites the approval process for all documents required in each phase

A plan that specifies the tasks and deliverables required for a particular project. The PQP is developed by the project leader and ISE group manager during Project Initiation and revised throughout the life cycle to provide direction on the project and encourage development of a quality product.

A simulation or model used to determine the completeness and feasibility of the requirements and/or design of a system.

\section{Computer programs.}

Group consisting of ISE and/or customer organization personnel responsible for evaluating and approving or disapproving ISE Work Requests and ensuring implementation of the approved Work Requests.

A method in which a review team works with the programmer or analyst to review tasks, activities, and deliverables to ensure compliance with the Project Quality Plan and the System Development Methodology. 
System

System flowchart

System test

Top-down design

Unit test
A series of interrelated elements that perform some activity, function, or operation.

A series of symbols and connections illustrating the flow of data through a system as well as that system's relationship to other systems and applications.

Testing of a module or group of programs to verify its functionality as a whole and to ensure it meets customer requirements.

A design strategy in which analysis proceeds from the general to the specific or the broad to the detailed.

Testing of an individual program to verify edits, calculations, and other logic within that program. 
Subject Index 


\section{Subject Index}

A

abnormal termination acceptance test access authorization acquisition and maintenance costs ad hoc maintenance ADABAS adaptive maintenance alternatives analyst

Applications Database Administrator (ADBA) audit trail

auditor

Authorized Derivative Classifier
$5-6,5-11$

6-5

6-7

4-4

2-2, 9-2, 9-6, 9-15 - 9-17

5-7, G-2

9-2, 9-6, 9-18 - 9-21

4-2, 4-8, 9-19

G-1

5-5, 5-7, 6-2, 6-6, 8-2, G-2

2-17, 5-7, 5-11, 9-8, 9-13, 9-16, 9-20,

G-2

G-2

4-5

B

backup and recovery

batch processing

benefits and costs

business activity

business area

business environment business functions business procedures business requirements
2-15, 2-17, 3-7, 3-10, 5-6, 5-11, 6-9, 9-12, 9-19, 9-20 2-17, 3-4, 5-3, 5-4, 5-6, 5-11, 6-7, 6-8, 8-6, 9-4, 9-8, 9-12, 9-16

2-7, 2-12, 2-16, 4-1 - 4-2, 4-6, 9-12, 9-19

G-2

2-6 - 2-7, 2-14, 3-1 - 3-3, 3-7 - 3-9,

G-2

4-3

$4-4$

4-3

G-1 
C

CASE tools

Central Computer Facility (CCF)

change control

change control log

CICS

client-server applications

code review

coding

Computer and Telecommunications

Management (CTM) section

Computer Education group

computer environment

Computer Program Protection Manager sign-off memo

Computer Protection Program Manager (CPPM)

Construction and Customer Acceptance Phase

conversion of existing system

corrective maintenance

CTM Database Administration group

CTM liaison

CTM manager

current system

custodianship

customer

customer liaison

customer manager

customer organization

customer review

customer satisfaction

customer sign-off memo
5-3, 5-10

1-2, 2-4, 2-8, 3-11, 5-4, 5-9, 6-10,

7-4 - 7-5, 8-3, 9-4, G-2, G-3

5-2

6-9

9-4

4-3

G-2

6-2

$1-2,2-4,2-12,4-8,5-2,5-4,5-6,6-7$, 7-3 - 7-4, 8-3, 9-3, G-2 - G-3, G-9

$6-10,7-3$

3-8, 4-4

2-15, 2-18, 3-12,

2-4, 2-12, 3-8, 3-11 - 3-12,

5-10 - 5-12, G-3

2-12, 2-19, 5-2, 5-7, 5-10 - 5-12, 6-1,

$7-3,9-13,9-16,9-20$

2-14, 2-17, 2-19 - 2-20, 3-11, 5-1, 5-6,

$5-11,7-3,9-18,9-20$

9-2, 9-6, 9-9 - 9-10

2-8, 3-11, 4-8, 5-4 - 5-5, 5-7, 5-9, 6-10, 7-5, 8-3, 9-4, G-2

2-4, 5-4, 5-6 - 5-7, 8-2, G-3

G-3

3-2, 3-9, G-5

2-15, 9-12

2-1 - 2-6, 2-8 - 2-9, 2-12, 2-16, 2-20,

2-22, 3-1 - 3-9, 3-11 - 3-12, 4-2,

4-5 - 4-6, 4-8, 5-1 - 5-2, 5-4, 5-8 - 5-9,

$5-11,6-1,6-5-6-7,6-10,7-1-7-3$,

8-2 - 8-3, 9-2, 9-4 - 9-5, 9-9, 9-14,

9-17, 9-21, G-3 - G-4, G-7, G-9

2-4 - 2-6, 2-8, 3-11, 4-1 - 4-2, 4-7 - 4-8,

$5-4,5-9,6-6,6-10,7-2,7-5,8-2, \mathrm{G}-1$, G-3 - G-4

2-6, 3-7 - 3-8, 4-6 - 4-7, 4-9, 5-8, 7-2,

$8-3, \mathrm{G}-4$

$4-2,7-5,8-3,9-19$, G-3, G-9

2-13, 2-15 - 2-19, 2-21 - 2-22, 3-12,

$4-9,5-5,5-11,6-10,7-5,8-3$

8-5

2-10, 2-14 - 2-16, 2-18, 2-20 - 2-21

9-10 
customer training

customer training strategy
2-19

2-18

\section{$D$}

data

data conversion

data custodian

data definition

data dictionary

data element

data entry

data flow diagram

data flows

data models

data-driven approach

database

database design

Department of Energy (DOE), U.S.

design document

Design Phase

desired system

development life cycle

disaster plan

documentation

DOE Order 1330.1C

DOE Order 1360.8

DOE-wide impact

E

effort

emergency maintenance

end customer

End User Services (EUS) section

enhancement

enhancement maintenance

enhancement requests

Environmental Protection Agency (EPA)

error messages

Evaluation and Review Phase

existing system
2-14

$6-2 ., 6-9,7-2$

3-6, 5-6

5-110

9-6, G-6

3-4-3-5

7-3

3-4 - 3-6, G-5 - G-6

2-6

3-5, G-5 - G-6

1-1

5-7, G-7

G-6

$1-1,2-6,4-3-4-4,9-2$

2-18, 5-1, 5-10 - 5-12, 6-1, G-2

2-12, 2-17, 3-3 - 3-4, 3-7 - 3-8,

$5-1-5-2,5-4-5-7,5-9,6-1-6-2$,

$6-4-6-5,6-8,9-8,9-12,9-16,9-19$

3-10

Ci-9

2-15, 3-7, 3-10

C -1

4-5

4-5

2.-6
$2-16,4-1-4-2,9-19$

$1-2,9-1-9-2$

$\mathrm{G}-5$

$1-2,2-4,2-12,5-2,5-8,6-10,7-3$

$3-3,3-8,4-4,4-6$

9-2, 9-6, 9-11 - 9-14

2-2

9-2

6-9

2-12, 2-22, 7-6, 8-1, 9-10, 9-14, 9-17,

9-21

2-16 - 2-17, 3-4 - 3-5, 4-4, 5-3, 5-6, 
existing system, continued

external design

external software purchases

$\boldsymbol{F}$

facility requirements

feasibility statement

feasibility study document

Feasibility Study Phase

file design

file structures/tables

flowchart

Forms Control group

function points

\section{$\boldsymbol{H}$}

hardware

hardware failure

Help Desk

high impact software

high impact software guidelines

HIPO charts

I

Implementation Phase

implementation plan

Information Engineering approach

Information System Engineering (ISE) section

initial analysis

Initiation Phase

input
5-10, 6-7 - 6-8, 9-1, 9-8, 9-12, 9-16, 2-17, 5-1 - 5-2, 5-4, 9-8, 9-12, 9-16, 9-19

$2-14,2-19,3-2,4-4$

5-2

9-19

2-16, 3-1, 3-8, 4-7, 4-9

2-5, 2-8, 2-12, 2-16, 3-12, 4-1 - 4-2,

$4-7,4-9,5-1-5-2,9-12,9-19$, G-1

G-2

2-17, 2-19, 4-4, 5-5, 6-2, 6-7, 9-8 - 9-9,

9-12 - 9-13, 9-20 - 9-21

$5-11$

5-3

$2-15,2-18,2-21,3-8,5-8,7-4,9-14$

G-5

G-5

3-7

$2-20,7-3$

$2-5$

$2-13,9-7,9-11,9-15,9-18$

5-7

2-12, 2-20, 6-11, 7-1 - 7-3, 7-5, 9-9,

$9-14,9-17,9-21$

2-20 - 2-21, 7-2, 7-6, 9-9, 9-14, 9-17,

9-21

1-1, G-5

$1-1-1-2,2-2-2-4,2-6,2-12,3-2,4-1-4-3$, $4-6,4-9,5-3,5-8,6-8,7-2-7-3,8-6$, 10-1, G-1 - G-2, G-4 - G-7, G-9

$2-2,9-7,9-11,9-15,9-18$

2-6, 2-8

$2-7,3-4,3-10,5-2$ 
input error

integration test

interface requirements

interfaces

Internal Audit section

internal design

Internal Oversight Department

internal review

interviewing

IRM long-range plan

IRM Procedures Manual

IRM Records Management procedure

ISE clerical staff

ISE Data Administration

ISE Department Computer Security Officer

ISE Guide to Business and Technical

Communication

ISE Level 3 manager

ISE Level 4 manager

ISE Methods Development group

ISE Procedure/Manual Revision Request form

ISE Procedures Coordinator

ISE Quality Coordinator

ISE Records Coordinator

ISE Service Order

ISE Standard Tool Set

ISE System Development Methodology Manual

ISE Technical Review

ISE Technical Writing Team

ISE Work Request

issues to be resolved
6-9

6-4, G-5

$2-17,5-6,9-8,9-12$

2-15, 3-4, 3-6, 3-10, 4-2 - 4-3, 5-7,

$6-9,9-2,9-8,9-12,9-19-9-20$

2-12, 3-9, 5-10 - 5-11, G-2

2-17 - 2-18, 5-1 - 5-2, 5-5, 5-8 - 5-9,

9-8, 9-12, 9-20

3-9, 5-10 - 5-11, G-2

$2-8,2-13,2-15-2-19,2-21,3-11,4-8$,

$5-4,5-9,6-10,7-5$, G-5

3-3

$4-3,4-5-4-6$

$2-9$

2-5, 8-4

$2-5-2-6,7-4-7-5,10-1$

2-4, 2-8, 3-5, 3-11, 4-8, 5-4 - 5-5, 5-9, $6-10,7-5,9-4$, G-5 - G-6

4-5

2-9, 3-12, 4-9, 5-5, 5-12, 6-11, 7-6

2-5, 10-1 - 10-2

1-1, 2-1 - 2-4, 2-6, 2-8, 3-1, 3-8, 3-11,

$4-1,4-7,4-9,5-1-5-2,5-9-5-10,6-1$,

$6-3,6-6,6-8,6-10,7-1,7-5,8-1,9-1$,

9-4, 9-6, 10-1, G-4, G-6

3-8, 5-8

$10-1,10-3$

10-1

$2-4-2-5,5-8,7-4, \mathrm{G}-7$

2-5, 8-4

$2-5,2-9,2-13$ - 2-14, 2-21, 7-1,

7-4 - 7-6, 9-7, G-7

5-3

8-1 - 8-2, 9-6, 10-1, G-7 - G-9

2-9 - 2-10, 2-14 - 2-16, 2-18,

2-20 - 2-21, 2-24, 3-11 - 3-12,

4-9 - 4-10, 5-5, 5-9, 5-12, 6-4,

6-10 - 6-11, 7-2, 7-5 - 7-6, 9-9, 9-13,

9-21

2-4, 6-6, 6-8, 7-2, 8-3, 10-1 - 10-2

2-2 - 2-3, 2-9, 2-11, 2-13, 6-9, 7-4, 9-5,

9-7 - 9-9, 9-10, 9-11 - 9-19, 9-21,

G-4, G-8 - G-9

2-7 
J

JCL

Joint Application Design

$L$

life-cycle approach

literature search

logical design
5-4, 9-3 - 9-5

3-3, G-7

1-1, G-7

2-16

G-7

\section{$\boldsymbol{M}$}

mainframe

maintenance

maintenance history

maintenance requests

management summary

manual files

midrange computer

minicomputer

modifications

module

MRP 3.41

multiple platform approaches

$N$

NATURAL

networks

New Job Check-off Sheet

New Program Information form

9-4, G-2

$4-3,8-6,9-3$

$7-4$

$7-4$

4-4, 5-2, 5-4

$1-2,2-4-2-5,3-3,8-6,9-1,9-19$, G-8

2-22, 8-3

8-6

3-9

5-6

4-4

4-4

3-8, 4-4

G-7

4-5

4-4

\section{O}

online processing

operating efficiency

2-17, 3-4, 5-3, 5-6, 5-10, 6-7 - 6-8, 9-8, 9-12, 9-16 2-22, 8-3, 9-10, 9-14, 9-21 
operating environment

output
4-2, 4-6, 5-10

$2-7,3-4,3-10,5-2$

\section{$\boldsymbol{P}$}

$\mathrm{PC} /$ host combination

performance

performance requirements

physical design

policies

post-implementation system review

post-implementation system review report

priorities

problem reports

problems

procedures

Procurement and Materials Management Department production data production environment production system

Program Change Request form program flowchart program maintenance suggestions program specifications

program testing programmer programming languages project closure letter project evaluation project evaluation report project folder

project folder index

Project Initiation Phase

project leader

project life cycle

Project Participation Matrix

Project Quality Plan (PQP) Checklist

\author{
4-4, 5-2, 7-4 \\ 4-4, G-3 \\ 2-14, 3-6, 3-10 \\ G-7 \\ 2-14 \\ 2-22, 8-2, G-7 \\ 2-22, 8-4, \\ 4-1 \\ 2-2 \\ 2-14 \\ 3-3 \\ 4-3
}

2-20, 5-6, 5-8, 7-1, 7-3, 9-2

$6-5,7-4$

$6-5,7-6$

$7-4$

$5-7, \mathrm{G}-8$

6-9

2-17, 5-7, 5-11, 6-3, 6-9, 9-8, 9-13,

$9-16,9-20$

2-19, 6-4

G-7

5-3

2-21, 7-6

2-22, 8-1 - 8-2

2-22, 8-4

2-2, 2-4 - 2-5, 2-9, 2-13 - 2-22, 3-12, 4-5, 4-10, 5-12, 6-11, 7-2, 7-6 - 7-7,

$8-4,9-7,9-10-9-11,9-14-9-15$,

9-17 - 9-18, 9-21, G-8 - G-9

2-9, 2-14, 3-12

2-1, 2-3, 2-12 - 2-13, 3-1, 3-4, 4-1, 5-1,

$6-1,7-1,8-1,9-7,9-15,9-18$

$1-1,2-1,2-3-2-5,2-8,2-19,3-1$,

3-11 - 3-12, 4-1, 4-8 - 4-10, 5-1 - 5-2,

$5-9,6-1,6-3-6-6,6-8,6-11,7-1-7-2$,

7-4 - 7-6, 8-1 - 8-2, 9-1, 9-6,

G-1 - G-2, G-6 - G-8

6-1, 6-8, 7-1, 8-1

$2-3,2-9,2-12-2-13$

$1-1-1-2,2-4,2-8-2-9,2-13-2-22,3-1,3-12,4-1$, $4-9-4-10,5-1-5-2,5-12,6-1-6-2$, 
Project Quality Plan Checklist, continued

project schedule

project scope document

project team

prototype

pseudocode

$Q$

Quality Assurance

\section{$\boldsymbol{R}$}

recovery

report delivery time

report format

reports

Request for Authorization form

Request for Information

requirements

requirements definition document

Requirements Definition Phase

response time

review team

$S$

Safeguards and Security Department Savannah River environment

Savannah River Site

schedule

scheduled maintenance

Scientific Computing Resource Center scope document

screens

SDM Custodian
G-7

6-6, 6-11, 7-1, 7-6, 8-1 - 8-2, 8-4, 9-6 - 9-21, G-6 - G-9

2-8, 2-10, 2-13 - 2-21, 3-12, 4-6, 4-10, 5-12, 6-2, 6-11, 7-6, 8-2

2-7, 2-9 - 2-10, 2-13 - 2-14, 3-2

$3-2,4-2,4-9,5-2,5-10$, G-4, G-6

3-3, 5-3, G-9

5-7, 6-3

3-7

3-6

5-4

5-2, 8-5

6-7

4-3

2-15, 4-1 - 4-3, G-1

2-15, 3-1 - 3-2, 3-8, 3-11 - 3-12,

6-1, 7-5, 8-3, G-2

2-9, 2-12, 2-14, 3-1, 4-4, 4-8 - 4-9,

$5-1,5-3,5-5,5-8,6-8,7-2,9-7,9-11$, 9-15, 9-18

3-6, 8-6

$3-11,5-4$ - 5-5, 5-9, 6-10, 7-5
$4-5,4-9$, G-3

5-3

2-4, 5-7

4-3, 5-2, G-4

$1-2,9-2-9-3,9-6$

5-8

2-6

5-2, 8-5

10-1 - 10-2 
SDM Review Team security

security requirements

Security section

sign-off sheet

software

Software Acquisition and Development Checklist software inventory

software purchases

special processing logic

SRS Computing Architecture

SRS publications

SRS Quality Assurance Manual

SRS Quality Assurance procedure 20-1

staff levels

steering committee

Stores

structured walk-through

subsystem

support plan

SYS1.USER.FORMS

system

system design

system development requests

system flowchart

system manager

system manual

system name

system test

system test plan
10-1 - 10-2

2-17, 3-2, 4-4, 5-6, 9-12, 9-20, G-6

2-15, 3-6, 3-10, 4-5, 9-12

G-3

2-6, 2-9, 3-9, 3-12, 4-7, 4-9 - 4-10, 5-5,

$5-10,5-12,6-11,7-6$

G-9

2-6, 2-23

$2-9,2-13,2-21,7-5$

2-16

$2-17,5-4,9-8,9-12,9-16$

4-5 - 4-6

4-3

$2-5$

4-5

3-8, 4-1

2-3, 2-13, 9-11, 9-15, 9-18, G-9

$5-3$

2-19, G-9

G-7

$2-21,7-1,7-4,7-6$

$7-4$

G-9

G-1

2-2

G-10

4-2, 4-6- 4-7

2-19 - 2-20, 6-8, 6-11, 8-3, 9-9, 9-13,

9-21, G-8

2-7

2-20, G-5, G-10

2-19

$T$

table-driven logic

5-5

task completion times

3-6

Technical Information Services $\quad 5-3$

Technical Library

4-3

Technology Research and Evaluation

4-3

test

5-1, 5-8, 6-2, 9-5

test data

$2-19,5-8,6-4-6-5,9-9,9-13,9-16$

$9-20$

test environment

6-5

test plan

2-18, 5-8, 5-11, 6-11, 9-4 - 9-5, 9-8,

top-down design

9-13, 9-16, 9-20, G-1, G-8

G-10 
Total Quality

trade magazines

training

transmittal document unit test

user's guide

V

VAX

VM

W

Westinghouse corporate reports

Westinghouse Electric Corporation

Westinghouse Savannah River Company (WSRC)

work history

work loads

Work Request folder

work request number
$1-1,2-4$

3-2

2-20, 3-7, 4-2, 4-7, 5-8, 6-10, 7-1, 7-3, 8-5, 9-8 - 9-9, 9-13, 9-16 - 9-17, 9-20 - 9-21, 10-2, G-1, G-4

2-6, 3-8, 3-12, 4-7, 5-5, 5-10, 5-12

6-4, G-10

2-19 - 2-20, 6-6, 6-10 - 6-11, 7-2, 8-3, 8-6, 9-9, 9-13, 9-21, G-4 - G-5, G-8

$5-10,7-4,9-4$

5-2

4-3

1-1

$1-1,4-3,4-5$

2-2

4-1

2-2 - 2-3

$2-2$ 

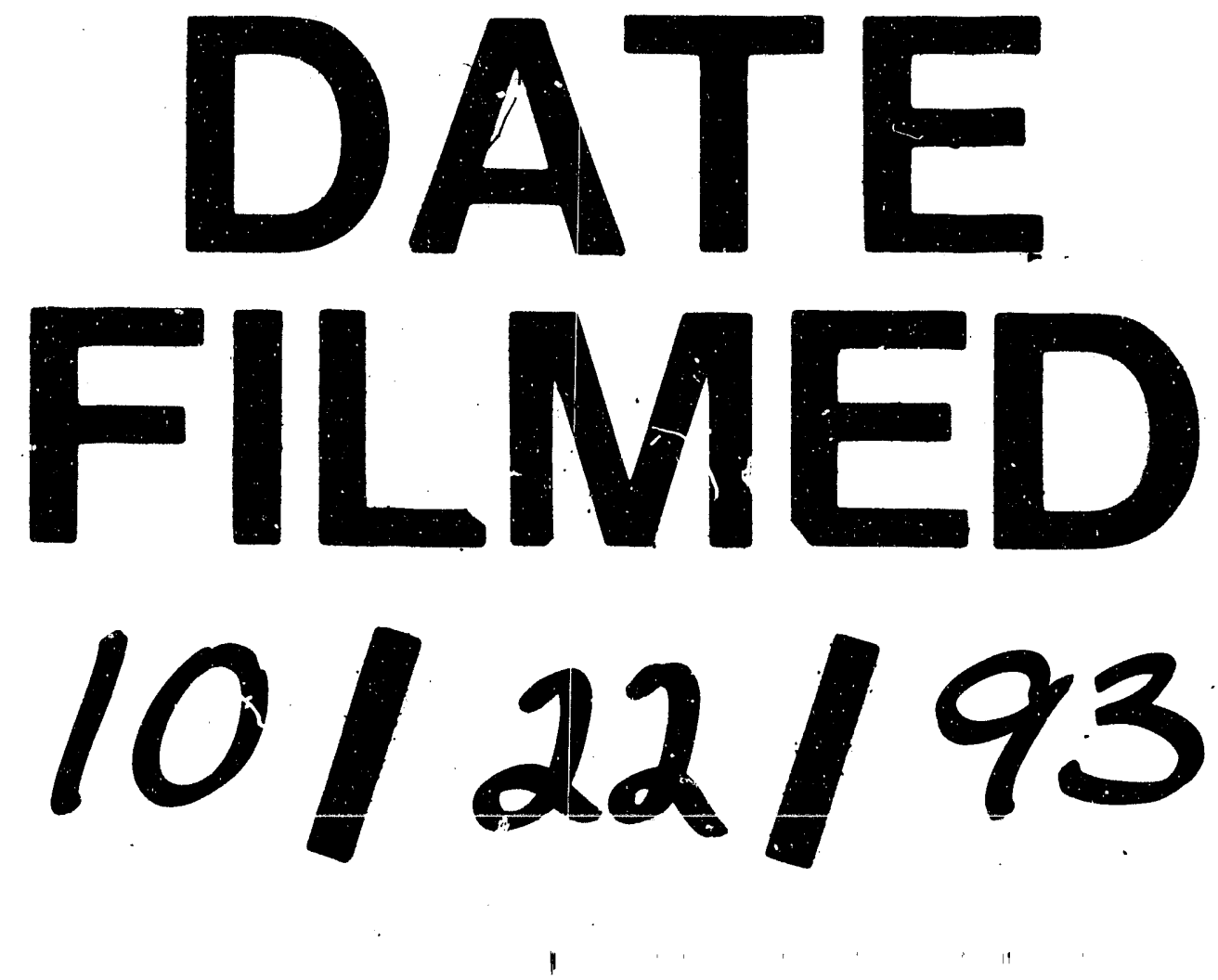

r 
